Análise filogenética e distribuição geográfica do subgênero Nyssorhynchus de Anopheles (Diptera, Culicidae).

\title{
JAQUELINE MARTINS
}

Tese apresentada à Faculdade de Saúde Pública da Universidade de São Paulo para obtenção do grau de Doutor.

Área de Concentração: Epidemiologia

Orientadora: Prof.” Dr. " Maria ANice M.

SALLUM

São Paulo

2004

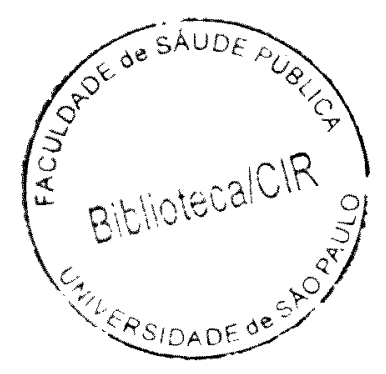




$$
1514412004 \text { doc }
$$

Autorizo, exclusivamente para fins acadêmicos e cientificos, a reprodução total parcial dessa tese, por processos fotocopiadores.

Assinatura:

Data: 
"Sabedoria é a arte de provar e degustar a alegria, quando ela vem. Mas só dominam essa arte aqueles que têm a graça da simplicidade."

Rubem Alves 
Dedicatória

À Ana Fávia, Marina e Luiza. 
Agradecimentos

Agradeço a todos que me ajudaram e acompanharam durante a realização deste trabalho:

à Profa. Maria Anice Mureb Sallum, pela orientação;

ao Prof. Oswaldo Paulo Forattini, por ter me recebido prontamente no NUPTEN;

ao Dr. Richard C. Wilkerson e ao Dr. Pollie Rueda, por terem me recebido no Walter Reed Army Institute of Research \Smithsonian Institution;

ao James F. Pecor, técnico especialista do "National Museum of Natural History", pela prestatividade, me proporcionando acesso ao material da coleção do Smithsonian Institution;

ao Departamento de Epidemiologia da Faculdade de Saúde Pública, onde o trabalho foi desenvolvido;

às secretarias Rosana, Roberta, Renilda, Márcia e Aparecida e aos técnicos do laboratónio Aristides, Justiniano e Rosa;

à Dra. Eliana Collucci, pela ajuda, comentários e sugestões para discussão dos caracteres e pelas discussões teóricas e leitura do trabalho;

à Dra. Maria Virgínia, pela ajuda com o uso do programa Hennig86 e TreeGardner e edição da tese;

ao Dr. Fernando Ferreira, pela ajuda quanto ao uso do progama ArcView;

aos membros da banca, Dr. Cláudio José Barros de Carvalho, Dr. Dalton de Souza Amorim, Dr. Délsio Natal, Dr. Sérgio Antônio Vanin e Dr. Ronaldo Toma pela leitura da versão preliminar da tese e pelas sugestões, críticas e comentários;

ao Dr. Cláudio Tadeu Daniel Ribeiro, às tutoras de projetos Dra. Denise Valle e Dra. Karima Brahimi e aos monitores do Seminário Laveran / Deane sobre malária do ano de 2001, pelas sugestões e comentários para desenvolvimento do projeto de doutorado; 
ao Dr. Sebastião, curador da coleção entomológica da FIOCRUZ, e à Denise Mota, pesquisadora do Laboratório de Hematozoários da FIOCRUZ;

à FAPESP, pelo apoio financeiro através de bolsa de doutorado Processo 00/05284-7 e do Projeto Temático nº 99/10517-1.

Meus agradecimentos pessoais e especiais:

à minha família: Iranides e Carlos, meus pais, Regina, Rosilene, Rogério e Robson, meus irmãos, pelo apoio e compreensão das ausências durante esses anos; e aos meus amigos Angel, Bell; Eliana, Helene, Imaculada, Isabel, Jõao Paulo, Keilla, Mary, Maria Virgínia, Ronaldo e Zoraida, entre outros, que me ajudaram com apoio, amizade e respeito. 


\section{RESUMO}

O gênero Anopheles ocorre em toda região biogeográfica e possui 437 espécies reconhecidas, tradicionalmente arranjadas em seis subgêneros Stethomyia, Lophopodomyia, Kerteszia, Nyssorhynchus, Anopheles e Cellia. O subgênero Nyssorhynchus apresenta 31 espécies conhecidas, divididas em três seções denominadas Albimanus, Argyritarsis e Myzorhynchella. Algumas espécies deste subgênero são importantes vetores de agentes causadores da malária humana na Região Neotropical. Devido a sua importância epidemiológica, o subgênero Nyssorhynchus tem sido bastante estudado, mas apesar disso, ainda existe carência de trabalhos que resultem em caracteres voltados para a sistemática, que possam ser utilizados para a elucidação das relações filogenéticas e para a identificação das espécies. Dessa forma, os objetivos deste trabalho são: estimar as relações filogenéticas entre espécies do subgênero Nyssorhynchus, fazer estudo morfológico das espécies para definição de caracteres de importância filogenética; e caracterizar a distribuição geográfica das espécies. $O$ estudo morfológio de adultos, larvas e pupas foi relizado utilizando-se material dos acervos da Coleção Entomológica de Referência da Faculdade de Saúde Pública/USP (FSP-USP) e do "National Museum of Natural History" (NMNH). Para a distribuição geográfica, foram consideradas todas as espécies atualmente reconhecidas para o subgênero. $O$ estudo foi feito através da compilação de dados obtidos da literatura, a partir dos quais foram construídos mapas de distribuição geográfica para as espécies. Para a análise filogenética, foram levantados 69 caracteres de adultos, macho e fêmea, larva, pupa e ovos para 22 espécies do subgênero Nyssorhynchus e três grupos externos específicos. As relações filogenéticas foram estimadas a partir da metodologia filogenética. Foram realizadas análises de busca heurística, com e sem pesagem de caracteres. Para suporte dos clados, foi realizada análise de boostrap. A análise filogenética da matriz realizada com algorítimos de busca heurística sem pesagem dos caracteres resultou em 328 cladogramas igualmente parcimoniosos, com 196 passos $(\mathrm{CI}=0,490 ; \mathrm{RI}=0,684 ; \mathrm{RC}=$ $0,335 ; \mathrm{HI}=0,510)$. $\mathrm{Na}$ análise com pesagem sucessiva foram obtidos 3 cladogramas igualmente parcimoniosos, estando incluídos entre os 328 obtidos na análise com caracteres sem pesos diferenciados, a partir dos quais foi construído um cladograma de 
consenso estrito. Foi construído um cladograma de consenso de maioria (50\%) a partir dos cladogramas obtidos na análise de bootstrap. Os resultados das análises filogenéticas realizadas neste estudo corroboram as hipóteses de monofiletismo de Nyssorhynchus e de polifiletismo das Seções Albimanus e Myzorhynchella, além de indicar que a Seção Argyritarsis é parafilética. Quanto à distribuição geográfica, Nyssorhynchus possui distribuição essencialmente Neotropical, com An. albimanus ocorrendo, também, na região sul dos Estados Unidos. Algumas espécies apresentam um complexo padrão de distribuição, com ampla ocorrência, enquanto outras parecem estar restritas a determinadas áreas da Região Neotropical.

Descritores: Anopheles, Nyssorhynchus, filogenia, distribuição. 


\section{SUMMARY}

The genus Anopheles Meigen is nearly worldwide in distribution. It includes 437 species divided into six subgenera: Stethomyia, Lophopodomyia, Kerteszia Nyssorhynchus, Anopheles and Cellia, The subgenus Nyssorhynchus includes 31 species distributed into 3 sections: Albimanus, Argyritarsis and Myssorhynchella. Some Nyssorhynchus species are important vectors of human malaria in the Neotropical Region. Due to its epidemiological importance, Nyssorhynchus has been extensively studied, although there are few works that provide characters intended for systematic, which may be useful to elucidate phylogenetic relationships, as well as species identification. The goals of this study are: to estimate phylogenetic relationships among members of Nyssorhynchus, to analyze morphological characters of the species in order to define important phylogenetic characters and to compile the distribution range for each member of Nyssorhynchus. The morphological study of adults, fourth-instar larva and pupa was carried out by examining material from the Entomological Collection of Faculdade de Saúde Pública/USP (FSP-USP) and National Museum of Natural History (NMNH). The geographical distribution study was performed for all species of Nyssorhynchus. For this, the distribution range of the species was compiled, and geographical distribution maps were designed for each member of Nyssorhynchus. Sixty-nine characters of adults, male and female, fourt-instar larvae, pupa and eggs for the 22 species of Nyssorhynchus, and 3 specific outgroup were used for phylogenetic study. Morphological data set was analyzed using phylogenetic methodology. Tree searches were conduced using the heuristic search criteria. The analyses were carried out using unweighted characters and successive weighting. Confidence in the topologies was estimated by bootstrap analyses. The numerical analyze of unweighted data set using heuristic search option resulted in a set of 328 equally parsimonious trees with a length of 196 steps $(C I=0.490 ; R I=0.684$; $\mathrm{RC}=0.335 ; \mathrm{HI}=0.510$ ). The numerical analysis using successive approximations weighting found 3 equally parsimonious trees, which were included in the results of the unweighted analyze. A strict consensus topology was obtained from 3 equally parsimonious trees from the successive weigh analysis. A fifty percent majority rule consensus was obtained of the bootstrap analyses. The results obtained corroborate the 
hypotheses of monophyly of the Nyssorhynchus subgenus and the poliphyly of Albimanus and Myzorhynchella Sections and suggest the paraphyly of Argyritarsis Section. The geographic range of Nyssorhynchus is mainly Neotropical, except for An. albimanus, which occur in the south region of United States. Many species are the pattern complex of distribution geographical occurring in many areas of Neotropical Region. Others species show be restricted in some areas.

Descriptors: Anopheles, Nyssorhynchus, phylogeny, distribution. 


\section{ÍNDICE}

1 INTRODUÇÃO 1

1.1 Considerações gerais sobre a família Culicidae 1

1.2 O Gênero Anopheles 1

1.3 Subgênero Nyssorhynchus 2

1.3.1 Considerações gerais $\quad 2$

1.3.2 Os complexos de espécies de Nyssorhynchus

1.3.3 Importância Epidemiológica de Nyssorhynchus 7

$\begin{array}{ll}1.3 .4 \text { Justificativa } & 8\end{array}$

2 OBJETIVOS 12

2.1 Objetivos gerais $\quad 12$

$\begin{array}{ll}2.2 \text { Objetivos especificos } & 12\end{array}$

3. MATERIAL E MÉTODOS 13

3.1 Material Biológico $\quad 13$

3.2 Estudo da morfologia externa do subgênero Nyssorhynchus 13

3.3 Análise Filogenética $\quad 16$

3.3.1 Grupo-Interno 16

3.3.2 Grupo-externo 16

$\begin{array}{ll}\text { 3.3.3 Codificação dos caracteres e construção da matriz } & 17\end{array}$

3.3.4 Análise filogenética para obtenção da matriz final $\quad 17$

$\begin{array}{ll}3.3 .5 \text { Construção do cladograma } & 18\end{array}$

3.4 Distribuição geográfica 19

3.4.1 Levantamento das localidades $\quad 19$

3.4.2 Levantamento das coordenadas geográficas $\quad 20$

3.4.3 Geração dos dados $\quad 20$

4. RESULTADOS E DISCUSSÃO 22 
4.1 Análise filogenética $\quad 22$

4.1.1 Lista comentada dos caracteres utilizados na análise 22

4.1.2 Topologias obtidas nas análises filogenéticas $\quad 49$

4.1.3 Comentários sobre as topologias obtidas 53

4.3. Distribuição geográfica

4.3.1 Distribuições geográficas obtidas para as espécies de Nyssorhynchus 59

4.3.2 Comentários sobre a distribuição geográfica das espécies de 92 Nyssorhynchus

5. CONCLUSÕES 99

5.1 Análise filogenética $\quad 99$

$\begin{array}{lr}5.2 \text { Distribuição geográfica } & 99\end{array}$

$\begin{array}{ll}\text { 6- REFERÊNCIAS } & 100\end{array}$

$\begin{array}{ll}\text { Anexo } & 110\end{array}$

$\begin{array}{ll}\text { Glossário } & 119\end{array}$ 


\section{INTRODUÇÃO}

\subsection{Considerações Gerais Sobre a Família Culicidae}

A familia Culicidae apresenta distribuição mundial e possui cerca de 3200 (HARBACH e KITCHING 1998) espécies conhecidas, arranjadas em 39 gêneros e 135 subgêneros (REINERT 2001). A família Culicidae é considerada monofilética, tendo como sinapomorfias a presença da pré-mandibula interna na larva (WOOD e BORKENT 1989), a presença de escamas eretas na cabeça, as peças bucais (labro, lacínia e hipofaringe) longas e desenvolvidas em uma probóscide e a presença de cerdas pré-alares nos adultos (HARBACH e KITCHING 1998).

A familia Culicidae, tradicionalmente é dividida em 3 subfamílias, Anophelinae, Culicinae e Toxorhynchitinae. Entretanto, HARBACH e KITCHING (1998) não reconhecem o status de subfamília do gênero Toxorhynchites, considerando-o como tribo da subfamília Culicinae. Dessa forma, aualmente, a família Culicidae é composta pelas subfamilias Anophelinae e Culicinae. A subfamilia Anophelinae é monofilética, tendo como sinapomorfias a presença da cerda 13-P, cerda abdominal 1 palmada, cerdas abdominais 6,7-I,II plumosas, aparelho espiracular posicionado em lobo, com uma estreita banda posterior esclerotizada, nas larvas de $4^{\circ}$ estágio; cerdas abdominais 9-IVVII sobre ou muito próxima ao ângulo do tergito, cerda abdominal 9-VIII inserida medianamente entre a superficie dorsal e ventral e cerda abdominal 14-VIII aproximada, nas pupas. A ausência de microcerdas na base do pedicelo da antena, ausência de vestimenta da álula e presença de veia espúria basal no setor radial da asa são sinapomorfias dos adultos. A subfamilia Anophelinae é dividida em três gêneros, Bironella Theobald, Anopheles e Chagasia Cruz (HARBACH e KITCHING 1998).

Alguns gêneros como Anopheles Meigen, Culex Linnaeus e Aedes Meigen apresentam importância epidemiológica por abrigarem espécies vetoras de agentes infecciosos que podem causar malária, arboviroses, e filarioses (FORATTINI 2002).

\subsection{O Gênero Anopheles}


O gênero Anopheles tem distribuição mundial (SALLUM et. al 2000) e possui 437 espécies reconhecidas (KRZYWINSKI et. al 2001a), sendo que 54 ocorrem no Brasil (ROSA-FREITAS et. al 1998).

O gênero Anopheles inclui os subgêneros Stethomyia Theobald, Lophopodomyia Antunes, Kerteszia Theobald, Nyssorhynchus Blanchard, Anopheles Meigen e Cellia Theobald, mas existe controvérsia quanto ao seu monofiletismo (FOLEY et. al 1998; SALLUM et. al 2000, 2002a; KRZYWINSKI et. al 2001a, 2001b). SALLUM et. al (2000) propuseram uma classificação para a subfamilia Anophelinae, baseada em caracteres morfológicos, na qual o gênero Bironella Theobald foi sinonimizado com o gênero Anopheles e os subgêneros Stethomyia e Lophopodomyia com o subgênero Anopheles. Nesse sentido, o gênero Anopheles ficou dividido em 4 subgêneros Kerteszia, Nyssorhynchus, Anopheles e Cellia. KRZYWINSKI et. al (2001a, 2001b), em estudos filogenéticos moleculares, discordaram dessa proposta, defendendo o uso da classificação tradicional da subfamília Anophelinae. Em contraste, Sallum et al (2002a), usando seqüências de fragmentos de 4 genes, confirmaram que o genero Anopheles é parafilético, pois exclui Bironella.

Algumas espécies de Anopheles são importantes vetores de agentes infecciosos. Membros dos subgêneros Nyssorhynchus e Kerteszia são os principais transmissores dos parasitas da malária humana na Região Neotropical (FORATTINI 2002). No Brasil, treze espécies de Anopheles já foram encontradas naturalmente infectadas com Plasmodium, agente causador da malária humana (PÓVOA et. al 2000).

\subsection{Subgênero Nyssorhynchus}

\subsubsection{Considerações gerais}

Theobald (1902) descreveu o gênero Laverania que foi renomeado por Blanchard (1902) como Nyssorhynchus, citados em GUIMARÃES (1997, p.20). O monofiletismo do subgênero é amplamente aceito (PEYTON et. al 1992; CONN 1998; SALLUM et. al 2000, 2002a; KRZYWINSKI et. al 2001a, 2001b). Segundo PEYTON et. al (1992), Nyssorhynchus é grupo monofilético bem definido, merecendo status subgenérico ou genérico. Dessa maneira, o subgênero Nyssorhynchus pode ser 
caracterizado por quatro sinapomorfias: ausência da cerda $10-\mathrm{VI}$ na pupa, forte esclerotinização do processo do esternito $\mathrm{X}$, conexão ventromedial do gonocoxito desenvolvido em processo truncado e claspete ventral grande e fundido, formando lobo ventromediano no adulto (SALLUM et. al 2000).

O subgênero Nyssorhynchus apresenta-se dividido em três seções denominadas Albimanus, Argyritarsis e Myzorhynchella (FARAN 1980; LINTHICUM 1988; PEYTON et. al 1992, HARBACH 1994). Apesar das revisões das Seções Albimanus (FARAN 1980) e Argyritarsis (LINTHICUM 1988), a sistemática do subgênero Nyssorhynchus permanece problemática, apresentando descrições de variedades $\mathrm{e}$ subespécies, constantes mudanças de status e sinonímias, o que torna dificil a compreensão e o acompanhamento das alterações na nomenclatura. O histórico taxonômico do subgênero pode ser encontrado nos catálogos de KNIGTH e STONE (1977) e GUIMARÃES (1997) e nas revisões de FARAN (1980) e LINTHICUM (1988).

O subgênero Nyssorhynchus inclui 31 espécies conhecidas, restritas à região Neotropical, exceto por An. albimanus que se estende até o sul da região Neártica. Algumas espécies de Nyssorhynchus apresentam ampla distribuição, estendendo-se desde a América Central até o sul do Brasil. As espécies atualmente reconhecidas no subgênero Nyssorhynchus e seus sinônimos-juniores estão apresentados no Quadro 1.

As formas imaturas desenvolvem-se em grande variedade de coleções aquáticas, naturais ou artificiais. Dessa maneira, as larvas podem desenvolver-se na água acumulada em pegadas de animais, sulcos produzidos por veículos, córregos, buracos em rochas, remansos de rios e em pântanos de água doce ou salobra. A atividade hematofágica ocorre durante o crepúsculo e no decorrer da noite (FORATTINI 2002). 
Quadro 1: Espécies atualmente reconhecidas no do subgênero Nyssorhynchus, divididas por seções segundo HARBACH (1994), apresentando a localidade-tipo e sinônimos-juniores.

\begin{tabular}{|c|c|c|c|}
\hline Seção & Espécie & Localidade-tipo & Sinônimo-júnior \\
\hline \multirow{10}{*}{ 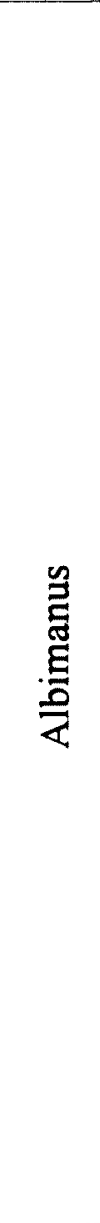 } & An. albimamus Wiedmann, 1821 & República Dominicana, Santo Domingo & $\begin{array}{l}\text { An. cubensis Agromonte, } 1900 \\
\text { An. albipes Theobald, } 1901 \\
\text { An. tarsimaculatus Goeldi, } 1905 \\
\text { An. gorgasi Dyar \&Knab, } 1907 \\
\text { An. bisignatus Hoffman, } 1938 \\
\text { An. trisignatus Hoffman, } 1938\end{array}$ \\
\hline & An. anomalophyllus Komp, 1936 & Panamá, próximo a Almirante & \\
\hline & An. aquasalis Curry, 1932 & Panamá, Zona do Canal do Panamá & $\begin{array}{l}\text { An. emilianus Komp, } 1941 \\
\text { An. guarujaensis Ramos, } 1942 \\
\text { An. guarauno Anduze, } 1948 \\
\text { An. delta Anduze, } 1948 \\
\text { An. deliaorinoquensis Cova-Garcia, Pulido } \\
\text { \& Amarista, } 1977\end{array}$ \\
\hline & $\begin{array}{l}\text { An. benarrochi Gabaldón, Cova-García \& Lopez, } \\
1941\end{array}$ & Venezuela, Trujillo, La Ceiba & \\
\hline & An. dunhami Causey, 1945 & Brasil, Amazonas, Tefé & \\
\hline & An. evansae Brèthes, 1926 & Argentina, Tucumán, Tucumán & $\begin{array}{l}\text { An. noroestensis Galvão \& Lane, } 1937 \text { a } \\
\text { An. metcalfi Galvão \& Lane, } 1937 \text { a } \\
\text { An. ayrozai Unti, } 1940 \text { a } \\
\text { An. clarki Komp, } 1942\end{array}$ \\
\hline & An. galvaoi Causey, Deane \& Deane, 1943 & Brasil, Acre, Rio Branco & \\
\hline & An. halophyllus Nascimento e Lourenço, 2002 & Brasil, Mato Grosso do Sul, Salobra & \\
\hline & An. ininii Sénevet \& Abonnenc, 1938 & Guiana Francesa, Mines de Saint-Elie & \\
\hline & & & Cont. \\
\hline
\end{tabular}




\begin{tabular}{|c|c|c|c|}
\hline Seção & Espécie & Localidade-tipo & Sinônimo-júnior \\
\hline \multirow{9}{*}{ 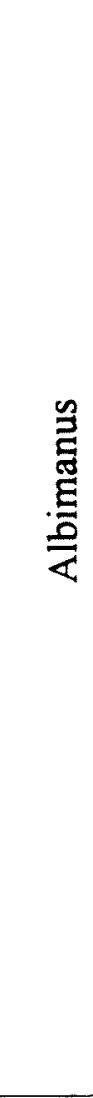 } & An. konderi Galvão \& Damasceno, 1942a & Brasil, Amazonas, Coarí & \\
\hline & An. muneztovari Gabaldón, 1940 & Venezuela, Cojedes, San Carlos & An. goeldii Rozeboom \& Galbadón, 1941 \\
\hline & An. oswaldoi Peryassú, 1922 & Brasil, Espírito Santo, Vale do Rio Doce & An. aquacaelestis Curry, 1932 \\
\hline & $\begin{array}{l}\text { An. rangeli Gabaldón Cova-García \& Lopez, } \\
1940\end{array}$ & Venezuela, Carabobo, Puerto Cabello & \\
\hline & An. rondoni Neiva \& Pinto, 1922 & Brasil, Mato Grosso, Ladário, Rio Paraguai & \\
\hline & An. sanctielii Sénevet \& Abonnenc, 1938 & Guiana Francesa, Mines de Saint-Elie & \\
\hline & An. strodei Root, 1926 & $\begin{array}{l}\text { Brasil, Minas Gerais,Água Limpa, próximo a } \\
\text { Juiz de Fora }\end{array}$ & $\begin{array}{l}\text { An. ramosi Unti, 1940b } \\
\text { An. albertoi Unti, } 1941 \\
\text { An. arthuri Unti, 1941 } \\
\text { An. artigasi Unti, } 1941 \\
\text { An. lloydi Unti, } 1941\end{array}$ \\
\hline & An. trianmulatus Neiva \& Pinto, 1922b & $\begin{array}{l}\text { Brasil, Mato Grosso, Fazenda São João, Rio } \\
\text { Cuiabá }\end{array}$ & $\begin{array}{l}\text { An. cuyabensis Neiva \& Pinto, } 1923 \\
\text { An. bachmanni Petrocchi, } 1925 \\
\text { An. davisi Paterson \& Shannon, } 1927 \\
\text { An. peresi Shannon \& Del Ponte, } 1927 \\
\text { An. chagasi Galvão, } 1941 \text { a }\end{array}$ \\
\hline & An. trinkae Faran, 1979 & Equador, Pastaza, $1,5 \mathrm{~km} \mathrm{~S}$ de Puyo & \\
\hline \multirow{3}{*}{ 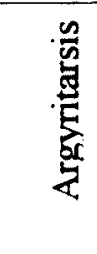 } & An. albitarsis Lynch Arribálzaga, 1878 & Argentina, Buenos Aires, Baradero & $\begin{array}{l}\text { An. limai Galvão \& Lane, 1937a } \\
\text { An. imperfectus Corrêa \& Ramos, } 1943 \\
\text { An. domesticus Galvão \& Damasceno, } 1944\end{array}$ \\
\hline & An. argyritarsis Robineau-Desvoidy, 1827 & Brasil, Rio de Janeiro, Rio de Janeiro & An. rooti Brèthes, 1926 \\
\hline & & & Cont. \\
\hline
\end{tabular}




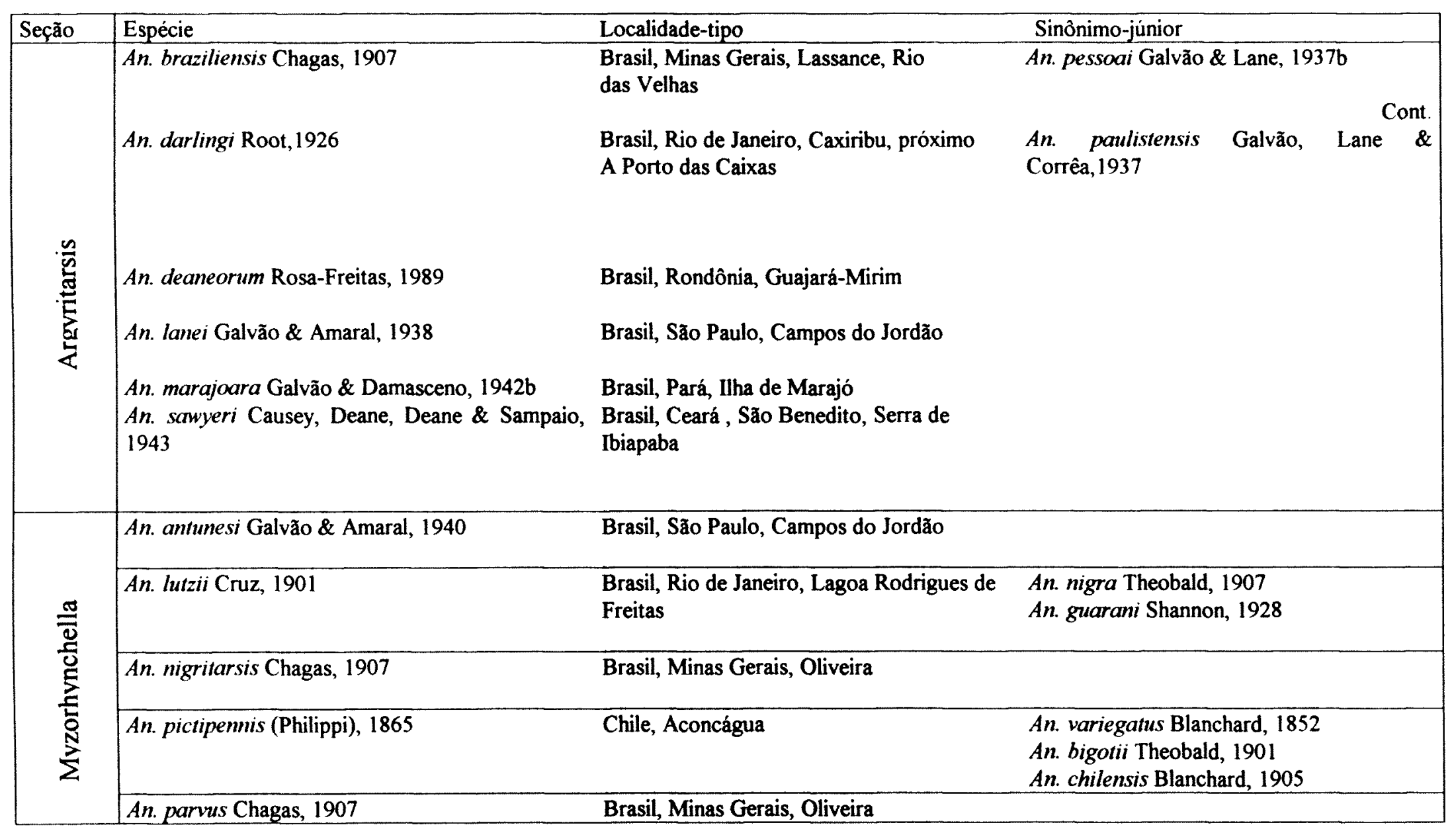


1.3.2 Os complexos de espécies de Nyssorhynchus

Vários táxons neotropicais do gênero Anopheles podem representar complexos de espécies crípticas. Nesse sentido, estudos comportamentais, morfológicos, isoenzimáticos, citogenéticos e de biologia molecular, envolvendo espécies de Nyssorhynchus, têm procurado esclarecer a sistemática de algumas espécies. Anopheles darlingi foi considerado monotípico; o complexo oswaldoi é formado por duas espécies, An. oswaldoi e An. konderi; Anopheles nuneztovari é, possivelmente, complexo de três espécies crípticas; An. aquasalis é considerado altamente polimórfico, mas possivelmente representa complexo; e An. triannulatus compreende pelo menos duas espécies ROSA-FREITAS et. al (1998). Recentemente, SILVA DO NASCIMENTO e LOURENÇO-DE-OLIVEIRA (2002) descreveram An. halophyllus, como uma espécie do Complexo Triannulatus.

O Complexo Albitarsis é formado por 4 espécies (An. marajoara, An. deaneorum, An. albitarsis e uma espécie não descrita, denominada An. albitarsis B) (WILKERSON et. al 1995a,b; ROSA-FREITAS et. al 1998).

A existência de complexos de espécies crípticas e a descrição de numerosas variedades e subespécies que atualmente estão em sinonímia são responsáveis pela existência dos problemas taxonômicos e de identificação apresentados para espécies de Nyssorhynchus e dos Culicidae em geral. A questão dos problemas taxonômicos de culicídeos já foi comentada por BATES (1949) que fez críticas à nomenclatura e à classificação dos mosquitos ao longo dos anos. Esse autor considerou que o conservadorismo dos pesquisadores gerou acúmulo de nomes que muitas vezes não representam unidades taxonômicas naturais.

\subsubsection{Importância Epidemiológica de Nyssorhynchus}


Algumas espécies deste subgênero são importantes vetores de agentes que podem causar malária humana na Região Neotropical. Anopheles darlingi é vetor principal no norte e nordeste do Brasil, bem como em várias áreas da América do Sul (LINTHICUM 1988); An. albimanus, na América Central; An. nuneztovari, no oeste da Venezuela, norte da Colômbia, Suriname e Bacia Amazônica (FARAN 1980); An. aquasalis na Venezuela, Trinidad e Tobago, Guianas e norte do Brasil (FORATTINI 2002). Além dessas espécies, Anopheles deaneorum, An. oswaldoi e An. marajoara têm sido incriminadas como vetores locais de malária (PÓVOA et. al 2000). Anopheles trinkae é considerado vetor principal na região oriental do Peru. Anopheles strodei e An. rangeli podem desempenhar papel auxiliar na transmissão. Anopheles triannulatus e An. nuneztovari são consideradas vetores potenciais de Plasmodium (FORATTINI 2002).

\subsubsection{Justificativa}

Desde que se demonstrou o papel de algumas espécies de Culicidae como vetores de agentes infecciosos, foram desenvolvidos numerosos estudos taxonômicos baseados em morfologia externa. Ao longo dos séculos $\mathrm{XIX}$ e $\mathrm{XX}$ foram descritos gêneros e espécies que foram agrupados em categorias informais que não são regidas pelo Código Internacional de Nomenclatura Zoológica.

Quanto ao subgênero Nyssorhynchus, a separação de algumas espécies do grupo é problemática devido à existência de complexos de espécies ou espécies cripticas (WHITE 1979). Muitas espécies são difíceis de ser identificadas por caracteres da fềmea adulta. Dessa forma, para o reconhecimento das espécies é feito o uso de caracteres da terminália masculina e moleculares e vários outros caracteres, inclusive da morfologia 
de ovos (SALLUM et. al 2002b). Muitos estudos estão sendo feitos com o emprego de dados moleculares, procurando estimar as relações evolutivas entre grupos de espécies ou identificar espécies cripticas de Nyssorhynchus (KREUTZER et. al 1976; ROSAFRETTAS et. al 1990; ROSA-FREITAS et. al 1992; NARANG et. al 1993; CONN et. al 1993; FRITZ et. al 1994; ROSA-FREITAS-SIBAJEV et. al 1995; WILKERSON et. al 1995a; WILKERSON et. al 1995b; CONN et. al 1998; LOUNIBOS et. al 1998; MALAFRONTE et. al 1999; MANGUIN et. al 1999).

Apesar do grande número de estudos morfológicos e moleculares para Nyssorhynchus e das revisōes para as seçòes Albimanus e Argyritarsis, ainda existe carência de trabalhos que resultem em caracteres voltados para a sistemática que possam ser utilizados para a elucidação das relações filogenéticas e para a identificação das espécies.

Segundo ANTHONY et. al (1999), as propostas de relaçð̃es filogenéticas para os Culicidae podem ser usadas no controle da malária e de outras doenças infecciosas cujos agentes são transmitidos por mosquitos. Além de considerar que o conhecimento dos relacionamentos entre espécies possibilitará a compreensão dos mecanismos de coevolução entre os vetores e os parasitas.

Alguns estudos filogenéticos foram conduzidos para vários niveis dentro da família Culicidae, tais como para os culicideos em geral (HARBACH e KITCHING (1998); para a subfamilia Anophelinae (SALLUM et. al 2000, 2002a; KRZYWINSKI et. al 2001a, 2001b); para as tribos Culicini (NAVARRO e LIRIA 2000) e Sabethini (JUDD 
1996), entre outros. Quanto ao gênero Anopheles destacam-se os estudos de COLLUCCI e SALLUM (2003) para o subgênero Kerteszia; de ANTHONY et. al (1999), PAPE (1992) e GREEN (1982), para o subgênero Cellia; de FOLEY et. al (1998) para espécies australianas; e de LINTHICUM (1988) e FARAN (1980), para Nyssorhynchus, propondo relações filogenéticas para as Seções Albimanus (Fig. 1A) e Argyritarsis (Fig. 1B), respectivamente.

Neste estudo, procurou-se diagnosticar caracteres morfológicos que pudessem contribuir para o conhecimento das relações filogenéticas entre as espécies de Nyssorhynchus. Nesse sentido, foram testadas as hipóteses de monofiletismo das Seções Albimanus, Argyritarsis e Myzorhynchella e levantadas as relações filogenéticas entre espécies do subgênero. Informações disponíveis na literatura para as espécies do subgênero Nyssorhynchus foram organizadas e utilizadas para estudar a distribuição geográfica das espécies. 

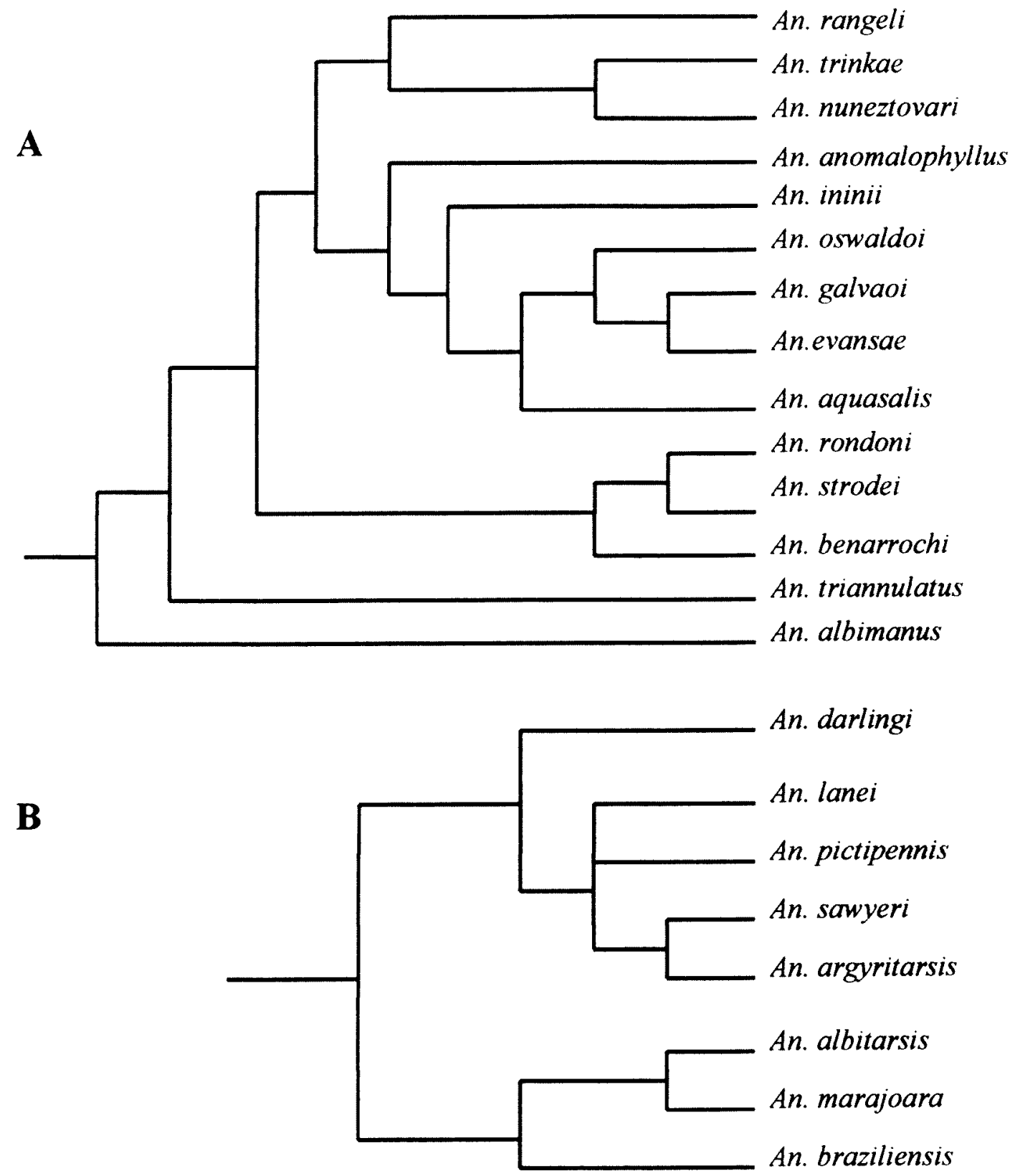

Fig. 1. Relações filogenéticas propostas para as seções de Nyssorhynchus: A. Cladograma proposto para a Seção Albimanus (FARAN 1980); B. Cladograma proposto para a Seção Argyritarsis (LINTHICUM 1988). 


\section{OBJETIVOS}

\subsection{Objetivos gerais}

- Estimar as relações filogenéticas entre espécies do subgênero Anopheles (Nyssorhynchus); $\mathrm{e}$

- caracterizar a distribuição geográfica das espécies.

\subsection{Objetivos específicos}

- Fazer estudo morfológico das espécies para definição de caracteres de importância filogenética.

- Compilar, atualizar e organizar dados disponíveis na literatura sobre distribuição das espécies. 


\section{MATERIAL E MÉTODOS}

\subsection{Material Biológico}

O estudo morfológio de adultos, larvas e pupas foi realizado utilizando-se material dos acervos da Coleção Entomológica de Referência da Faculdade de Saúde Pública/USP (FSP-USP) e do "National Museum of Natural History" (NMNH, EUA).

Em geral, os exemplares das coleções já estavam previamente identificados e as exúvias das larvas de quarto estágio, pupas e terminálias masculinas montados em lâminas permanentes. Quando necessário, algumas espécies foram identificadas utilizando as chaves de identificação de FARAN (1980), FARAN e LINTHICUM (1981), LINTHICUM (1988), FORATTINI (2002) e as descrições das espécies. Para espécies que não possuiam exemplares de algum estágio de desenvolvimento disponiveis para estudo foram utilizadas dados de literatura. A lista de material examinado encontra-se no Anexo I.

Os ovos foram estudados a partir de dados obtidos de ilustrações de microscopia eletrônica de varredura e descrições presentes na literatura.

\subsection{Estudo da morfologia externa do subgênero Nyssorhynchus}

O estudo foi feito com base em estruturas anatômicas da morfologia externa, utilizando caracteres dos adultos, macho e fêmea, larvas de $4^{\circ}$ estadio e pupas. (Fig. 2). Quando possivel, foram analisados pelo menos 10 exemplares de cada estágio. Quanto aos ovos, foram estudadas as estruturas do exocório, flutuadores e franja (Fig. 3). A terminologia utilizada segue o proposto por FORATTINI (1996). 
A

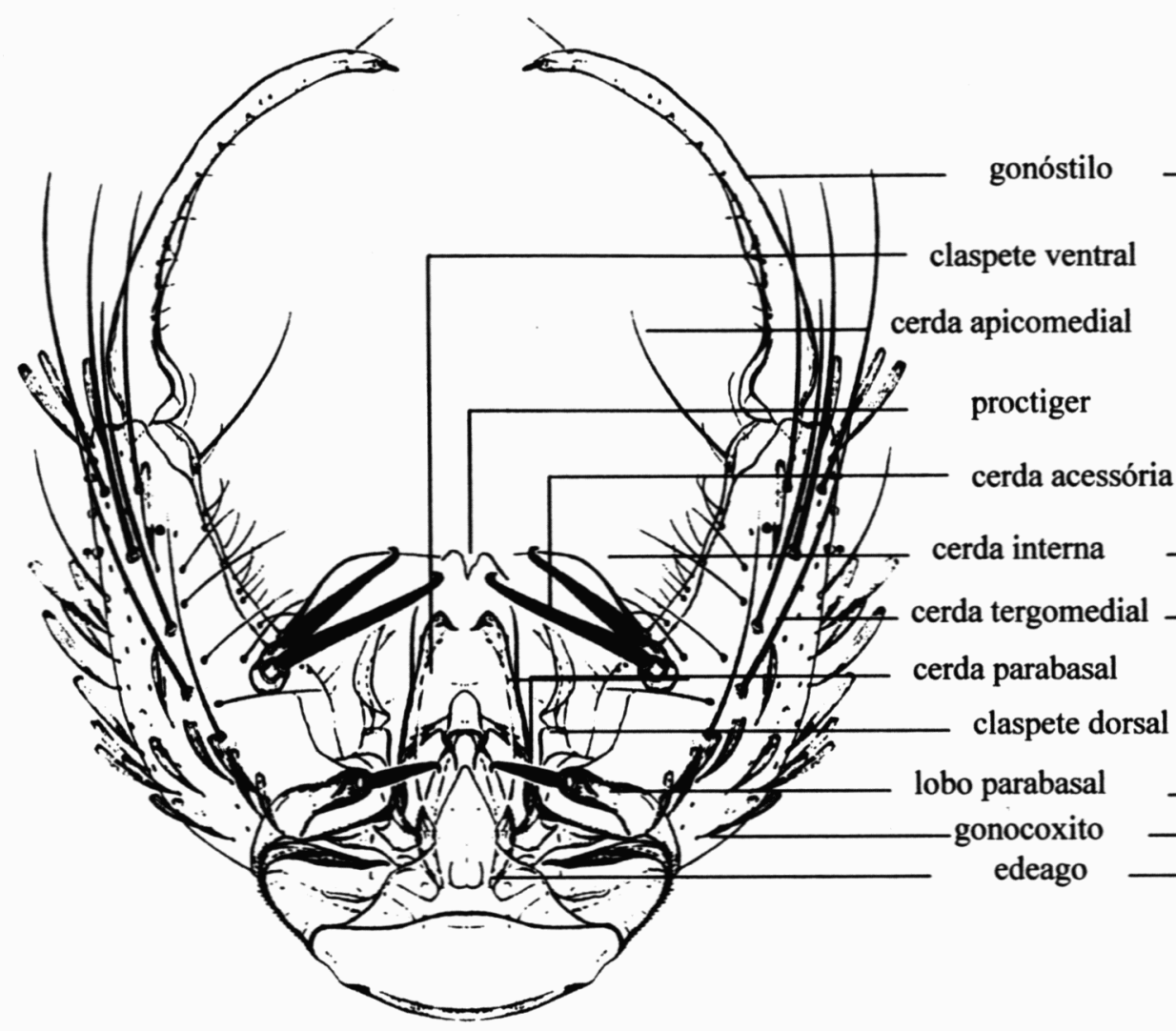

B

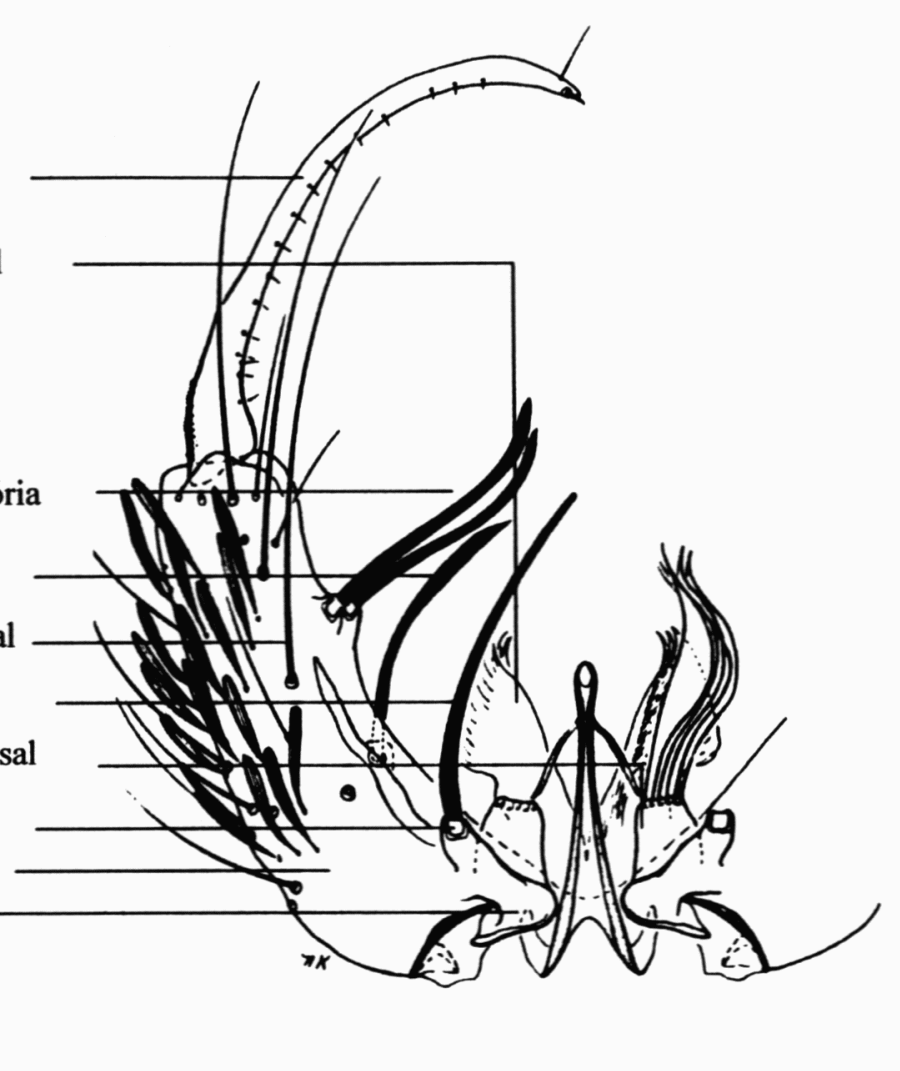

Fig. 2. Terminália masculina de Nyssorhynchus. A. An. (Nys.) darlingi, vista ventral (Fonte: LINTHICUM 1988); B. An. (Ker.) cruzii, vista ventral (Fonte: ZAVORTINK 1973). 


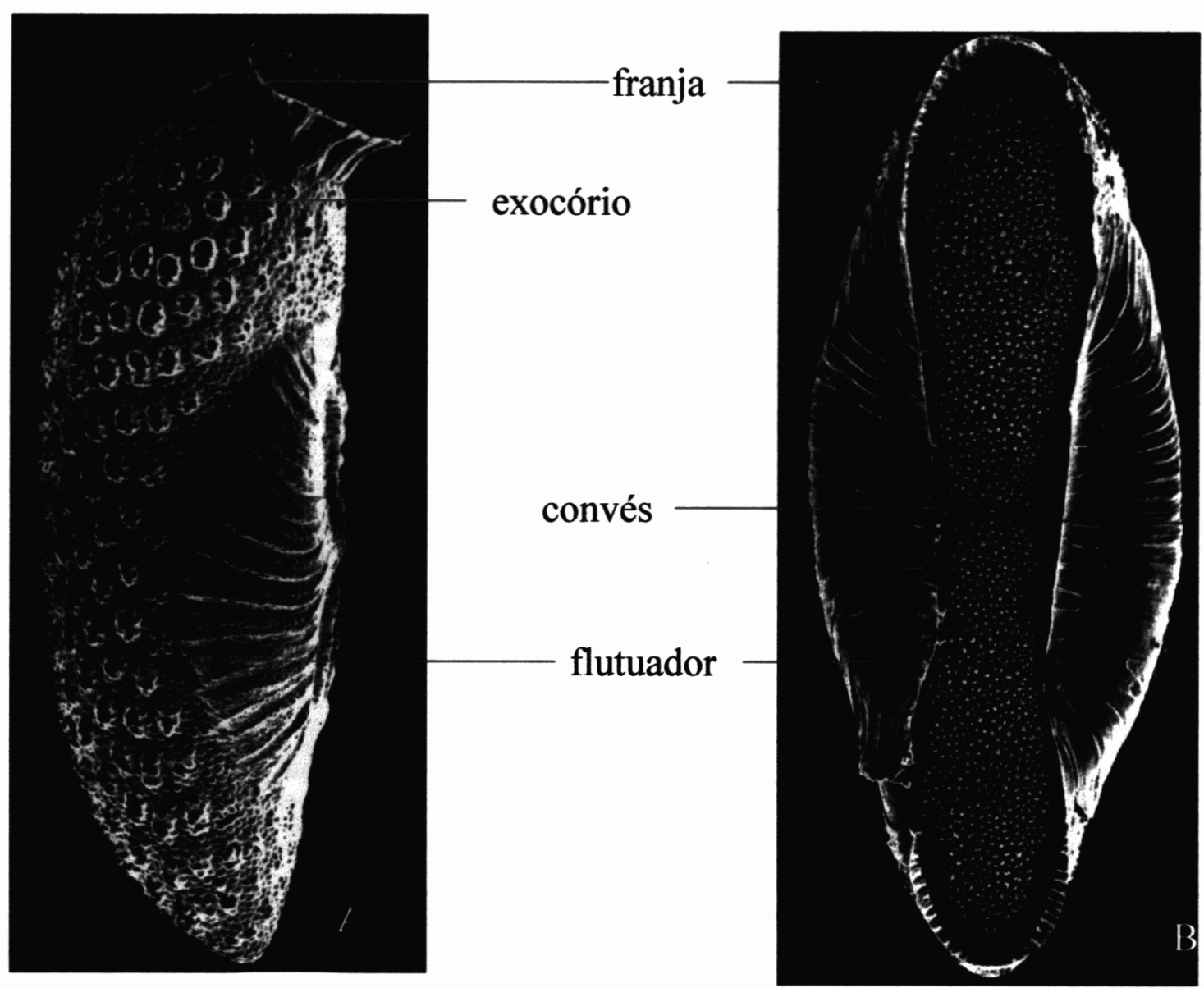

Fig. 3. Ovo: A: Ovo de An. (Nys.) darlingi, vista lateral (Fonte: LINLEY, 1992); B: Ovo de An. nuneztovari, vista dorsal (Fonte: LOUNIBOS et. al 1998). 


\subsection{Análise Filogenética}

A análise filogenética foi feita a partir da metodologia filogenética desenvolvida por HENNIG (1966), sintetizada em AMORIM (1997) e em KITCHING et. al (1998).

\subsubsection{Grupo-Interno}

Neste estudo, estão incluídas no grupo-interno as espécies $A n$. albimanus, $A n$. anomallophylus, An. aquasalis, An. benarrochi, An. evansae, An. galvaoi, An. ininii, An. nuneztovari, An. oswaldoi, An. rangeli, An. rondoni, An. strodei, An. trinkae e An. triannulatus, da Seção Albimanus; An. albitarsis, An. argyritasis, An. braziliensis, An. darlingi, An. lanei e An. sawyeri, da seção Argyritarsis, An. antunesi, An. lutzii e An. parvus, da Seção Myzorhynchella. Foram excluídas deste estudo An. pictipennis e An. nigritarsis (Seção Myzorhynchella), An. dunhami e $A n$. sanctielii (Seção Albimanus) devido a falta de material ou informações disponíveis, evitando o acúmulo de grande quantidade de "missing data" na matriz. Os complexos de espécies, An. oswaldoi e An. konderi; An. triannulatus e An. hallophylus; e An. albitarsis, An. deaneorum e An. marajoara, foram representados por An. oswaldoi, An. triannulatus e An. albitarsis, respectivamente.

\subsubsection{Grupo-externo}

A polarização dos caracteres foi realizada seguindo o método dos grupos externos (NIXON e CARPENTER 1993). Anopheles pseudopunctipennis Theobald, do subgênero Anopheles, e as espécies An. cruzii Dyar e Knab e An. neivai Howard do subgênero Kerteszia, grupo-irmão de Nyssorhynchus (SALLUM et. al 2000, 2002a), foram usadas como grupos-externos para enraizamento do cladograma e polarização dos caracteres. O conhecimento prévio do monofiletismo de Kerteszia e a sua relação filogenética com Nyssorhynchus foram essenciais para a escolha do grupo-externo. 
A polarização dos caracteres utilizando o método do grupo-irmão é defendida por vários autores, dentre eles DONOGHUE e CANTINO (1984), MADDISON et. al (1984), WILEY et. al (1991), NIXON e CARPENTER (1993).

\subsubsection{Codificação dos caracteres e construção da matriz}

Entende-se por caráter o conjunto de mudanças relacionadas dos estados de caráter numa série de transformação. Após o estudo morfológico e levantamento dos caracteres observados nas espécies, estes foram listados. Posteriormente, os estados de caráter receberam codificação numérica. "Missing data" foram representadas por interrogação (?), quando havia indisponibilidade do dado, e por (-) nos casos onde não foi possível estabelecer homologia, quando os estados dos caracteres não eram aplicáveis.

Após a codificação dos caracteres foi construída a matriz de dados, onde os estados dos caracteres foram tratados como não-ordenados. A matriz inicial foi construída utilizando o programa Tree Gardener 2.2 (RAMOS 1997). Posteriormente, caracteres que apresentavam dois ou mais estados para a mesma espécie foram codificados com todos os estados, sendo tratados como polimórfícos na matriz, para isso foi utilizado o programa computacional MacClade, versão 4.0 (MADDISON e MADDISON 2000).

\subsubsection{Análise filogenética para obtenção da matriz final}

Foram realizadas várias análises da matriz de dados, de maneira a avaliar as hipóteses de homologia e de codificação dos caracteres para obtenção da matriz usada na análise final, no entanto os caracteres polimórficos foram tratados como não comparáveis.

As análises preliminares foram realizadas com a utilização do programa Hennig86, através da interface para Windows, Tree Gardener 2.2 (RAMOS 1997). Os estados dos caracteres foram tratados como não-ordenados. Para verificar a consistência e congruência dos caracteres, foram utilizados os seguintes parâmetros de busca heurística: mhennig, bb, com e sem pesagem dos caracteres: 
mhennig- o qual executa os dados da matriz, ligando os terminais em diferentes seqüências, retendo os cladogramas mais parcimoniosos;

bb (extended branch swapping)- aplica a troca de ramos em todos os cladogramas iniciais, retendo os 100 cladogramas mais parcimoniosos encontrados a partir da análise inicial.

\subsubsection{Construção do cladograma}

Após a obtenção da matriz final, várias análises foram realizadas usando os programas computacionais PAUP, versão $4.0 \mathrm{~b} 10$ (SWOFFORD 2002) e MacClade, versão 4.0 (MADDISON e MADDISON 2000).

Os caracteres não-informativos foram excluídos das análises. Espécies que apresentavam diferentes estados para um mesmo caráter foram consideradas polimórficas.

Os caracteres receberam pesos utilizando-se a técnica de pesagem sucessiva ("successive approximations weigthing"), com base no valor do índice de consistência reescalonado, sendo cada procedimento de pesagem, realizado 5 vezes. $\mathrm{Na}$ pesagem sucessiva, uma topologia inicial é estimada a partir da totalidade de dados da matriz; posteriormente, os caracteres são avaliados quanto à congruência geral, sendo que os mais congruentes recebem peso maior que os demais e novas topologias podem ser geradas. $O$ procedimento é repetido sucessivamente, até que os resultados das análises se estabilizem (FARRIS 1969).

Os cladogramas foram gerados atavés da utilização dos seguintes algorítmos de busca heurística:

Branch swapping: algorítmo que executa uma série de rearranjos da topologia originada a partir de uma análise simples da matriz por busca heurística, visando encontrar o cladograma mais curto. Foi usada a opção Tree Bisection and Reconection (TBR), na qual, a partir de um cladograma principal, subcladogramas são cortados em cladogramas não enraizados, sendo posteriormente re-enraizados e reconectados a outro ramo do cladograma restante, gerando nova topologia. Dessa 
maneira, todas as possibilidade de bissecções, re-enraizamentos e reconexões são calculadas, procurando encontrar o conjunto ótimo de cladogramas.

Stepwise addition: algorítmo que adiciona progressivamente os taxa, procurando encontrar a melhor topologia. Inicialmente um cladograma de três taxa é escolhido, e, posteriormente, os outros são adicionados sucessivamente até que todos sejam incluidos. A escolha dos taxa iniciais e adição dos restantes na construção do cladograma foi feita de forma randômica. Foi utilizada a opção de 10.000 réplicas, de forma a garantir que todas as ilhas de cladogramas mais parcimoniosos fossem identificadas (KITCHING et. al 1998).

Para averiguar o suporte dos clados gerados pelas análises foram calculados os valores de Bootstrap (FELSENSTEIN 1985), através da utilização do PAUP, versão $4.0 \mathrm{~b} 10$ (SWOFFORD 2002). A análise de bootstrap foi conduzida usando 6000 pseudoréplicas e busca heurística, utilizando "branch swapping", com a opção TBR e e 10 réplicas com adição randômica por pseudoréplica.

A otimização dos caracteres foi feita usando o programa WinClada ver. 1.00.08 (NIXON 2002). Para discussão dos clados obtidos nas análises foram usados o s artificios Grupo e Grupo propostos por AMORIM (1982) e AMORIM (1994).

\subsection{Distribuição geográfica}

\subsubsection{Levantamento das localidades}

Para caracterizar a distribuição geográfica, foram consideradas todas as espécies atualmente reconhecidas para o subgênero apresentadas na Tabela 1 e a espécie não descrita do Complexo Albitarsis. Os dados de distribuição foram obtidos mediante compilação na literatura. $O$ levantamento bibliográfico foi realizado através das bases de dados Biological Abstracts, Cab Abstracts, MEDLINE e Zoological Records, usando como palavras-chave: Nyssorhynchus, malária, sistemática, filogenia, população, Seção Albimanus, Seção Argyritarsis, Seção Myzorhynchella, genética, molecular, evolução, morfologia. Foram ultizadas as localidades-tipo segundo as descrições originais, e outras localidades disponíveis na literatura. 


\subsubsection{Levantamento das coordenadas geográficas}

As coordenadas geográficas foram obtidas através de dados disponíveis nos trabalhos utilizados e de bancos de dados disponíveis em sítos da internet que fornecem informações sobre a latitude e longitude de localidades geográficas: "PRCIV195/IBGE" Sistema de apresentação de dados do Cadastro de Cidades e Vilas do Brasil; "Global Gazetteer" (http://www.calle.com/world/), Georeferencing for natural history colections (http:/biogeomancer.org/); "The Getty Thesaurus of Geographic Names browser" (http://www.getty.edu/research/tools/vocabulary/tgn/index.html). Além desses, quando preciso, foram utilizados outros sítios, tais como http:/www.traveljournals.net/countries/ e http:/www.lonelyplanet.com/destinations/, para encontrar as coordenadas.

As coordenadas fornecidas em graus, minutos e segundos foram convertidas para latitude e longitude modificadas, utilizando-se o programa de conversão de latitude e longitude disponível no sítio da Universidade Federal do Paraná (http://zoo.bio.ufpr.br/diptera/diptera-c/index.html). Localidades incompletas, onde constavam apenas o nome do país ou não havia possibilidade de se determinar as coordenadas sem a região administrativa (estado, departamento ou província), foram desconsideradas. Para localidades que atualmente apresentam nomes diferentes do apresentado no artigo original, os novos nomes foram pesquisados de forma a encontrar a coordenada pela denominação atual.

\subsubsection{Geração dos dados}

Os dados foram inseridos em uma planilha Excel (Microsoft), incluindo como colunas: gênero, espécie, país, estado/província/departamento, localidade, longitude e latitude (modificados). A latitude e longitude modificadas foram apresentadas em números inteiros com duas casas decimais, separadas por ponto. Os dados numéricos da planilha foram transformados em texto. Após a construção da planilha, esta foi salva em *xls. Posteriormente, a planilha foi selecionada, copiada e colada em uma 
dados numéricos da planilha foram transformados em texto. Após a construção da planilha, esta foi salva em *xls. Posteriormente, a planilha foi selecionada, copiada e colada em uma nova pasta do Excel, onde após ser selecionada, foi salva como DBF 3 (dBASE III) $\left({ }^{*} \mathrm{dbf}\right)$.

A partir da planilha construida no Excel com a extensão *dbf, foram gerados mapas de distribuição geográfica das espécies através do Programa ArcView GIS 3.2. Os dados das localidades foram plotadas em mapas, que após terem sido editados, foram salvos como arquivo de imagem. Os mapas serão apresentados nos resultados de acordo com a posição relativa da espécie no cladograma obtido na análise filogenética, bem como as espécies relacionadas pertencentes aos complexos. As espécies An. dunhami, An. nigritarsis, An. pictipennis e An. sanctielli serão apresentadas posteriormente, por não terem sido incluídas na análise filogenética. 


\section{4.- RESULTADOS E DISCUSSÃO}

\subsection{Análise filogenética}

Foram levantados 69 caracteres dos adultos, macho e fêmea, larva, pupa e ovos para 22 espécies do subgênero Nyssrohynchus e três grupos externos especificos. A matriz de caracteres está representada no Quadro 2 e os caracteres utilizados na análise estão listados a seguir.

\subsubsection{Lista comentada dos caracteres utilizados na análise}

Adultos

1. Tufo de escamas posterolaterais no tergito II: [0] ausente $\backslash$ [1] presente (3 passos, $\mathrm{CI}=0,33)$

Em Nyssorhynchus, as escamas estão presentes nos segmentos abdominais da maioria das espécies, em posição mediana e em tufos posterolaterais. A presença de tufo de escamas posterolaterais no terginto II é sinapomorfia para o Grupo-Darlingi ${ }^{+}$, sendo a ausência do tufo em An. braziliensis uma reversão. A presença desses tufos em An. lanei é homoplástica. Em An. pseudopuncitpennis, nas espécies de Kerteszia estudadas, e em An. parvus as escamas medianas e posterolaterais estão ausentes no tergito II.

2. Tufo de escamas posterolaterais do tegito VI: [0] ausente $\backslash$ [1] presente (2 passos, $\mathrm{Cl}=0,50)$

Os tufos de escamas caudolaterais do tergito VI estão presentes no GrupoArgyritarsis $^{\dagger}$. A ausência desses tufos de escamas é sinapomorfia para An. antunesi e An. lutzii. . Em An. pseudopuncitpennis, nas espécies de Kerteszia estudadas e em An. parvus as escamas medianas e posterolaterais estão ausentes no tergito VI.

3. Tarsômero 5 da perna posterior: $[0]$ inteiramente escuro $\backslash$ [1] com uma faixa basal escura e ápice claro $\backslash[2]$ inteiramente claro ( 4 passos, $\mathrm{CI}=0,50)$ 
Em Kerteszia, o tarsômero 5 da perna posterior possui uma faixa basal escura e o ápice coberto por escamas claras. A coloração do tarsômero inteiramente branca é uma sinapomorfia para Nyssorhynchus. A faixa basal escura no tarsômero 5 é uma sinapomorfia para o Grupo-Albimanus ${ }^{+}$, sofrendo uma reversão em An. braziliensis. Em An. psedopuncitpennis, a coloração do tarsômero 5 é inteiramente escura

Terminália masculina

4. Processo do esternito $X:$ [0] fracamente esclerotizado $\backslash$ [1] fortemente esclerotizado ( 1 passo, $\mathrm{CI}=1,0$ ).

5. Conexão ventromedial do gonocoxito: [0] desenvolvida em processo agudo \[1] desenvolvida em processo truncado $(1$ passo, $\mathrm{Cl}=1,0)$

Segundo SALLUM et. al (2000), o processo do esternito X bastante esclerotizado e a conexão ventromedial do gonocoxito desenvolvido em processo truncado são sinapomorfias de Nyssorhynchus.

6. Cerdas tergomediais: [0] não se estendendo até a metade basal do gonocoxito \} [1] estendendo-se até a metade basal do gonocoxito ( 1 passo, $\mathrm{CI}=1,0$ ).

As cerdas tergomedias são cerdas longas e fortes implantadas em alvéolos desenvolvidos, posicionadas em uma fileira submediana na superficie tergal do gonocoxito. Em Nyssorhynchus, apresentam-se em número de 4 a 6 enfileiradas, estendendo-se até a metade basal do gonocoxito (Fig. 2A), sendo uma sinapomorfia para o subgênero. Em Kerteszia, são encontradas 3 ou 4 cerdas tergomediais, que não se estendem até a metade basal do gonocoxito (Fig. 2B).

7. Cerda apicomedial: $[0]$ ausente $\backslash[1]$ presente ( 1 passo, $\mathrm{CI}=1,0)$.

A cerda apicomedial é uma cerda longa e diferenciada inserida no ápice do gonocoxito nos anofelíneos (FORATTINI 1996). Esta cerda está ausente em Kerteszia (Fig. 2A). A presença dessa cerda é uma sinapomorfia para Nyssorhynchus (Fig. 2B). 
8. Cerdas acessórias: [0] ausentes $\backslash$ [1] presentes, inseridas na metade apical do gonocoxito \[2] presentes, inseridas na metade basal do gonocoxito ( 2 passos, $\mathrm{CI}=1,0)$.

As cerdas acessórias são duas cerdas longas e fortes, com ápice em gancho, situadas dorsomedianamente no gonocoxito, em dois tubérculos proeminentes (Fig. 2 A-B). Em Nyssorhynchus, as cerdas acessórias estão posicionadas na metade basal do gonocoxito, sendo uma sinapomorfia para o subgênero. Em Kerteszia, as cerdas acessórias estão posicionadas na metade apical do gonocoxito e em $A n$. pseudopuncitpennis estão ausentes.

9. Cerda interna: [0] fracamente desenvolvida $\backslash$ [1] fortemente desenvolvida (1 passo, $\mathrm{CI}=1,0)$.

A cerda interna é uma cerda diferenciada, inserida subapicalmente na face mediana do gonocoxito de anofelíneos (FORATTINI 1996). Em Nyssorhynchus esta cerda apresenta-se delgada e com o ápice agudo. Em Kerteszia, a cerda interna é bastante desenvolvida e forte, sendo uma apomorfia para o subgênero.

10. Número de cerdas parabasais: [0] dois $\backslash[1]$ um ( 1 passo, $\mathrm{CI}=1,0)$.

As cerdas parabasais são cerdas individualizadas situadas na superfície dorsobasal do gonocoxito (FORATTINI 1996). FARAN (1980) considerou a presença de uma cerda parabasal uma apomorfia para Nyssorhynchus. No entanto em Kerteszia, uma cerda parabasal também esta presente. Apesar da relação entre Kerteszia e Nyssorhynchus não estar resolvida nessa análise, a presença de uma cerda parabalsal é considerada homóloga entre os dois subgêneros.

11. Cerda parabasal: [0] não inserida em tubérculo saliente $\backslash$ [1] inserida em um tubérculo saliente $(0,02-0,03 \mathrm{~mm}) \backslash[2]$ inserida em um tubérculo saliente, longo $(0,04-0,05 \mathrm{~mm})(2$ passos, $\mathrm{CI}=1,0)$.

Em An. pseudopuncitpennis, a cerda parabasal é inserida em uma base levemente saliente, não formando tubérculo. Em Kerteszia e Nyssorhynchus, a cerda 
parabasal encontra-se inserida em um tubérculo fortemente desenvolvido e alongado (Fig. 2 A-B). Nas espécies An. rangeli e An. benarrochi, os tubérculos apresentamse mais longos que nas demais espécies de Nyssorhynchus, sendo uma sinapomorfia paras as duas espécies.

12. Posição do tubérculo da parabasal em relação ao gonocoxito: [0] perpendicular \ [1] paralelo (1 passo, $\mathrm{Cl}=1,0)$.

Em Nyssorhynchus, o tubérculo apresenta-se em posição perpendicular ao gonocoxito, sendo uma sinapomorfia para o grupo (Fig. 2A). Nas espécies de Kerteszia, o tubérculo da cerda parabasal está posicionado paralelamente ao gonocoxito (Fig. 2B).

Segundo PEYTON et. al (1992), o desenvolvimento das cerdas interna, parabasal e acessórias existentes em Nyssorhynchus e Kerteszia não pode ser comparado a outros subgêneros de Anopheles, sendo muito similares nesses dois subgêneros. Devido à semelhança entre estas cerdas, em estudos mais antigos, os subgêneros Kerteszia e Nyssorhynchus eram considerados sinônimos.

13. Borda dorsomedial do gonocoxito: [0] pouco desenvolvida, formando apódema curto $\backslash[1]$ bastante desenvolvida, formando apódema longo ( 1 passo, $\mathrm{Cl}=1,0)$.

A borda dorsomedial do gonocoxito apresenta-se pouco desenvolvida em Kerteszia. A presença de apódema bastante desenvolvido e fortemente esclerotizado na borda dorsomedial do gonocoxito é uma sinapomorfia para espécies de Nyssorhynchus (SALLUM et. al 2000).

14. Claspete ventral: [0] desenvolvido em dois lobos laterais $\backslash[1]$ desenvolvido em lobo mediano único ( 1 passo, $\mathrm{CI}=1,0)$.

O claspete ventral em Kerteszia apresenta-se dividido em dois lobos separados, expandidos lateralmente e unidos na base (Fig. 4A). Em Nyssorhynchus, o claspete ventral está fundido em uma estrutura única e complexa (Fig. $4 \mathrm{~A}-\mathrm{V}$ ), sendo uma sinapomorfia para o subgênero (SALLUM et. al 2000). 
15. Claspete ventral: [0] alongado $\backslash[1]$ curto $(3$ passos, $\mathrm{CI}=0,33)$.

Claspete ventral curto (Fig. 4 B-E,F) é uma sinapomorfia para Nyssorhynchus, tendo o alongamento do claspete surgido duas vezes independentemente, uma no Grupo-Lutzii ${ }^{+}$(Fig. C-D)e outra no Grupo-Albimanus ${ }^{+}$ (Fig. 4 G-V).

16. Margem lateral do claspete ventral: [0] reta \[1] oblíqua \[2] arredondada (2 passos, $\mathrm{Cl}=1,0)$.

A margem lateral reta do claspete ventral é uma sinapomorfia para o clado Grupo-Lutzii ${ }^{+}$e Grupo-Lanei ${ }^{+}$(Fig. 4 C-D). No entando, ocorreu o arredondamento da margem lateral no Grupo-Lutzii ${ }^{+}$.

17. Margem lateral do claspete ventral: [0] constrita na região mediana \[1] não constrita na região mediana ( 2 passos, $\mathrm{CI}=0,5$ ).

A constrição mediana (Fig. $4 \mathrm{C}$ ) no claspete ventral é uma sinapomorfia para o clado Grupo-Lutzii ${ }^{+}$e Grupo-Lanei ${ }^{+}$, sendo que em An. lanei (Fig. 4 D) ocorre uma reversão.

18. Lobo apicolateral do claspete ventral: [0] ausente $\backslash$ [1] arredondado [2] triangular, paralelo ao eixo mediano $\backslash$ [3] triangular, perpendicular ao eixo mediano ( 8 passos, $\mathrm{CI}=0,37$ ).

A presença de um lobo apicolateral arredondado no claspete é uma sinapomorfia para o Grupo-Albimanus ${ }^{+}$. No Grupo-Strodei ${ }^{+}$o lobo apicolateral é triangular e perpendicular ao eixo do claspete (Fig. M-P). Em An. triannulatus, ocorre a presença de um lobo triangular grande e perpendicular ao eixo do claspete (Fig. $4 \mathrm{H}$ ), mas trata-se de um surgimento independente. Em An. parvus um pequeno lobo arredondando pode ser encontrado, mas trata-se de uma homoplasia. Para An. lanei e An. sawyeri a presença de um lobo apicolateral triangular e paralelo ao eixo mediano (Fig. C-D) do claspete ventral é uma sinapomorfia para as espécies, mas 
esse lobo não é homólogo aos demais. Em An. nuneztovari e An. evansae ocorre uma reversão, sendo que o lobo apicolateral está ausente (Fig. J, S).

19. Margem distal do claspete ventral: $[0]$ sinuosa $\backslash[1]$ reta (4 passos, $\mathrm{CI}=0,25$ ).

Esse caráter apresenta-se bastante homoplástico, surgindo três vezes uma em An. triannulatus (Fig. 4 H), em An. nuneztovari (Fig. 4 J) e no Grupo-Trinkae ${ }^{+}$(Fig. $\mathrm{N}-\mathrm{P})$ sendo que para este grupo representa uma sinapomorfia.

20. Lobo basal do claspete ventral: [0] globuloso, com grande expansão lateral \[1] globuloso, com pouca expansão lateral \[2] triangular \[3] estreito (4 passos, $\mathrm{CI}=0,75)$

O lobo basal do claspete pouco expandido lateralmente é uma sinapomorfia para o Grupo-Albimanus ${ }^{+}$, no entando no Grupo-Rondoni ${ }^{+}$ocorre uma grande expansão lateral do lobo basal (Fig. 4 L-N, P-V). Em An. benarrochi ocorre um estreitamento do lobo basal, perdendo o formato globuloso e a expansão lateral (Fig. 4 O). O estado de caráter lobo basal estreito é uma sinapomorfia para o clado formado pelos grupos Lutziii ${ }^{+}$e Lanei ${ }^{+}$(Fig. 4 C-D).

21. Porção apical do claspete ventral: [0] definida, claramente separada da porção basal $\backslash[1]$ indefinida ( 2 passos, $\mathrm{CI}=0,50$ )

O claspete ventral com a porção apical definida, separada da porção basal é encontrado em dois grupos de espécies de Nyssorhynchus, de forma independente. Essa condição é encontrada nos clados formados pelos grupos Lutzii ${ }^{+}$e Lanei ${ }^{+}$(Fig. 4 C-D) e no Grupo-Albimanus ${ }^{+}$(Fig. 4 C-D, G-V).

22. Porção basal do lobo basal do claspete ventral: [0] arredondada $\backslash$ [1] reta (Fig. 4 $\mathrm{B}, \mathrm{E}-\mathrm{F})(2$ passos, $\mathrm{CI}=0,50)$

O claspete ventral com a porção basal do lobo basal do claspete ventral arredondada é encontrado em dois grupos de espécies de Nyssorhynchus, de forma independente. Essa condição é encontrada nos clados formados pelos grupos Lutzii ${ }^{+}$ e Lanei ${ }^{+}$e no Grupo-Albimanus ${ }^{+}$(Fig. 4 C-D, G-V). 
23. Superficie ventral do claspete ventral: [0] com espículas na superficie médiolateral $\backslash$ [1] com espículas apenas na metade basal, não atingindo o ápice $\backslash$ [2] com espículas estendendo-se além da metade basal [3] com espículas presentes da base ao ápice $\backslash[4]$ glabra $(6$ passos, $\mathrm{CI}=0,67)$

As espículas no claspete ventral estão presentes em Kerteszia (Fig. 4 A), sendo mais longas e fortes que as de Nyssorhynchus. Em Nyssorhynchus, o claspete ventral pode ser coberto por espículas da base ao ápice, parcialmente coberto ou nú. Ausência de espículas no claspete ventral é uma sinapomorfia para Nyssorhychus (Fig. 4 B-I). No Grupo-Nuneztovari ${ }^{+}$as espículas estão presentes da base ao ápice (Fig. 4 J, N, P-T), exceto em An. rondoni (Fig. 4 L), An. strodei(Fig. 4 M), An. benarrochi (Fig. 4 O) e no Grupo-Ininii ${ }^{+}$que apresentam espiculas que se estendem além da metade basal do claspete, sem, no entanto, atingir o ápice (Fig. 4 U-V). Essa condição é uma sinapomorfia para o Grupo-Ininii ${ }^{+}$, mas representa uma homoplasia em relação a $A n$. strodei. Em An. parvus, as espículas estão presentes, mas representa uma homoplasia.

24. Espículas da margem basal do claspete ventral: [0] curtas $\backslash$ [1] longas (3 passos, $\mathrm{CI}=0,50)$

Espículas longas na base do claspete (Fig. L-N, P-V) é uma sinapomofia para o Grupo-Rondoni ${ }^{+}$, sendo secundária a condição espículas da margem basal do claspete ventral curtas as de espículas curtas em An. benarrochi (Fig. 4).

A descrição e nomenclatura das estruturas do claspete ventral que serão apresentadas a seguir foram primeiramente descritas por GABALDON (1940). A placa pré-apical é uma estrutura quitinosa, situada no vértice do claspete ventral unindo os dois lobos nesse ponto. A estrutura refringente está situada basalmente à placa pré-apical, tendo a forma de forquilha com pontas dirigidas para a base. A fenda mediana é uma área membranosa que interliga os lobos ventrais presente no claspete ventral das espécies de Nyssorhychus. 
25. Placa pré-apical do claspete ventral: [0] ausente \ [1] presente, pouco desenvolvida $\backslash[2]$ presente, bastante desenvolvida (4 passos, 0,50 ).

A presença da placa pré-apical é uma sinapomorfia para o Grupo-Darlingi ${ }^{+}$ (Fig. $4 \mathrm{~F}-\mathrm{V}$ ) $\mathrm{O}$ forte desenvolvimento dessa placa é uma sinapomorfia para o GrupoNuneztovari ${ }^{+}$. Anopheles benarrochi apresenta a placa pré-apical pouco desenvolvida, sendo uma reversão. Em An. argyritarsis (Fig. 4 B), a presença de uma região mais esclerotizada na região pré-apical do claspete ventral é homoplástica.

26. Posição da placa pré-apical em relação à borda apical do claspete ventral: [0] distal $\backslash[1]$ proximal $(1$ passo, $\mathrm{Cl}=1,0)$.

A posição da placa pré apical distal à borda apical do claspete ventral é uma sinapomorfia para o Grupo-Nuneztovari ${ }^{+}$(Fig. $4 \mathrm{~J}-\mathrm{V}$ ).

27. Estrutura refringente do claspete ventral: [0] ausente $\backslash[1]$ presente $(3$ passos, $\mathrm{CI}=$ $0,33)$.

A presença da estrutura refringente do claspete ventral é uma sinapomorfia para o Grupo-Braziliensis*. A presença dessa estrutura em An. albitarsis e An. argyritarsis é homoplástica.

28. Fenda mediana do claspete ventral: [0] estreita $[1]$ larga (1 passo, $\mathrm{CI}=1,0)$.

O alargamento da fenda mediana do claspete ventral é uma sinapomorfia para o Grupo-Braziliensis* (Fig. $4 \mathrm{H}-\mathrm{V}$ ).

29. Fenda mediana do claspete ventral: [0] curta $\backslash$ [1] moderadamente longa, não se estendendo da base ao ápice \[2] longa, se extendendo da base ao ápice (4 passos, 0,50$)$

Fenda mediana longa se estendendo da base ao ápice do claspete vental é uma sinapomorfia para An. lanei e An sawyeri (Fig. 4 C-D). A fenda mediana curta parece ter surgido independemente 3 vezes, representando uma sinapomorfia de $A n$. 
lutzii e An. antunesi, um surgimento independente em An. nuneztovari (Fig. $4 \mathrm{~J}$ ) e sinapomorfia para Grupo-Anomalophyllus ${ }^{+}$(Fig. 4 Q-V).

30. Sulco mediano: [0] raso $\backslash[1]$ profundo ( 1 passo, $\mathrm{CI}=1,0)$.

Sulco mediano profundo é uma sinapomorfia de An. lanei e An. sawyeri (Fig. 4 C-D).

31. Cerdas apicais do claspete dorsal: [0] organizadas em dois grupos apicais $\backslash$ [1] organizadas em um grupo apical ( 1 passo, $\mathrm{CI}=1,0$ ).

A organização das cerdas apicais do claspete dorsal em dois grupos é uma sinapomorfia de Kerteszia

32. Cerdas foliáceas apicais do claspete dorsal: [0] sinuosas na porção apical \[1] sinuosas na porção basal \[2] não sinuosas ( 2 passos, $\mathrm{CI}=1,0)$.

33. Número de cerdas foliáceas apicais do claspete dorsal: [0] superior a $3 \backslash$ [1] $3 \backslash$ [2] 2 (2 passos, $\mathrm{CI}=1,0)$.

A sinuosidade na porção basal das cerdas foliáceas do claspete dorsal é uma sinapomorfia de Nyssorhynchus. Em Kerteszia, essas cerdas são contorcidas e sinuosas na porção apical, sendo mais longas e largas, podendo variar de 3 a 6 elementos. Anopheles pseudopunctipennis apresenta três cerdas planas apicais. A presença de apenas duas cerdas foliáceas apicais do claspete dorsal é uma sinapomorfia para o clado formado pelos grupos Lanei ${ }^{+} \mathrm{e}$ Lutzii ${ }^{+}$. As demais espécies de Nyssorhynchus apresentam três cerdas foliáceas apicais.

34. Cerda espiniforme subapical do claspete dorsal: [0] ausente $\backslash[1]$ presente (1 passo, $\mathrm{CI}=1,0)$.

A presença de uma cerda espiniforme subapical, mais delgada e reta no claspete dorsal é uma sinapomorfia de An. antunesi e An. lutzii.

35. Forma da garra do gonóstilo: [0] espatulada \[1] lanceolada ( 1 passo, $\mathrm{CI}=1,0)$. 
A forma espatulada da garra do gonóstilo é uma sinapomorfia de An. lanei, An. sawyeri, An. lutzii e An. antunesi. Nas demais espécies de Nyssorhynchus a garra é lanceolada.

36. Edeago: [0] delgado $\backslash[1]$ largo (1 passo, $\mathrm{CI}=1,0$ ).

Em Kerteszia, o edeago apresenta-se mais delgado, afilando-se em direção apical, sendo formado por um tubo colunar fechado (Fig $5 \mathrm{~A}$ ). O edeago largo é uma sinapomorfia de Nyssrohynchus (Fig. 5 B-Y). Em An. pseudopunctipennis, o edeago é delgado

37. Projeção subtriangular ventromediana do edeago: [0] ausente $\backslash$ [1] presente (2 passos, $\mathrm{Cl}=0,50)$.

Em Nyssorhynchus, o edeago apresenta um par de esclerotinizações subtriangulares, em posição subapical que se estendem em direção ao eixo longitudinal mediano (Fig. 5 F-Y). Essa esclerotinização estende-se ventromedianamente formando um tubo incompleto e largo da base ao ápice. A projeção subtriangular ventromediana do edeago está presente na maioria das espécies de Nyssorhynchus, exceto em An. parvus (Fig. 5 B), sendo uma sinapomorfia para o Grupo-Argyritarsis ${ }^{+}$A ausência dessa projeção em An. lutzii e An. anıunesi (Fig. D-E) representa uma reversão, sendo uma sinapomorfia para as duas espécies.

38. Ápice do edeago: [0] simples $\backslash$ [1] com expansão dorsoapical (1 passo, $\mathrm{CI}=1,0)$.

A presença de expansão dorsoapical no ápice do edeago é uma sinapomorfia de Nyssorhynchus (Fig. 5).

39. Folíolos subapical no edeago: [0] ausente $\backslash[1] 1$ presente, curto \[2] presente, longo e liso $\backslash[3]$ presente, longo e serrilhado ( 8 passos, $\mathrm{CI}=0,37$ ).

Os folíolos edeagais são estruturas pares, apicais e foliáceas presentes e posicionadas lateralmente no edeago de algumas espécies de Kerteszia (Fig. 5 A) $e$ Nyssorhynchus, sendo provavelmente homólogas nos dois grupos, mas apresentando 
caráter bastante homoplástico. Entretanto, a presença de foliolos edeagais também é observada em outras espécies do gênero Anopheles.

Em Kerteszia, os folíolos apresentam-se longos e lisos. Em Nyssorhynchus os folíolos podem ser longos ou reduzidos, serrilhados ou lisos. A condição dos folíolos longos e lisos de An. parvus (Fig. 5 A) parece ser a plesiomórfica, por ser encontrada também em An. cruzii. Em An. neivai, os folíolos estão ausentes. A presença de folíolos serrilhados é uma sinapomorfia do Grupo-Argyritarsis ${ }^{+}$(Fig. 5 C-G), tendo ocorrido uma perda no Grupo-Albitarsis ${ }^{+}$(Fig. H, J-L). Em. An. nuneztovari e An. ininii (Fig. $5 \mathrm{M}, \mathrm{Y}$ ) existem pequenas expansões laterais curtas e lisas, não homólogas. Em An. anomalophyllus os folíolos edeagais longos e serrilhados estão presentes (Fig. $5 \mathrm{~S}$ ), representando uma reversão. Em Anopheles pseudopunctipennis, a presença de foliolos edeagais serrilhados é homoplástica.

Pupa

40. Fenda do meato da trompa: [0] ausente $\backslash[1]$ presente ( 1 passo, $\mathrm{CI}=1,0$ ).

A ausência de fenda no meato da trompa é uma sinapomorfia para Kerteszia.

41. Cerda 10-VI: $[0]$ presente $\backslash[1]$ ausente (1 passo, $\mathrm{CI}=1,0)$.

A ausência da cerda $10-$ VI é considerada uma sinapomorfia de Nyssorhynchus (SALLUM et. al 2000).

42. Espículas da margem externa da paleta natatória: [0] não alcançando a cerda1-P \ [1] terminando no nível da 1-P $\backslash[2]$ ultrapassando a cerda 1-P (4 passos, $\mathrm{CI}=0$, $50)$.

A presença de espículas na margem externa da paleta ultrapassando o nível da Cerda 1-P é uma sinapomorfia do Grupo-Darlingi ${ }^{+}$. Nas demais espécies de Nyssorhynchus as espiculas terminam no nivel da cerda 1-P. Em An. antunesi, as espículas não alcançam o nível da Cerda 1-P, sendo uma autapomorfia para a espécie. As espiculas terminando no nível da Cerda 1-P parece ser secundária, sendo encontrada em An. triannulatus e An. braziliensis. Em An. cruzil e An. neivai as 
espículas não alcançam a cerda 1-P e em An. pseudopunctipennis terminam no nível da 1-P.

Larva de $4^{\circ}$ estágio

43. Cerda 1-A: [0] curta $\backslash[1]$ longa (8 passos, $\mathrm{CI}=0,12$ )

A natureza desse caráter é extremamente homoplástica, estando a Cerda 1A longa presente na maioria das espécies de Nyssornhynchus. A condição longa da Cerda 1-A é uma sinapomorfia para o Grupo-Argyritarsis ${ }^{+}$. Cerda 1-A curta apresenta vários surgimentos, estando presente em An. darlingi e An. ininii. A condição curta é uma sinapomorfia entre as espécies An. evansae e An. galvaoi e para o Grupo-Trinkae ${ }^{+}$. O alongamento dessa cerda em An. benarrochi é uma reversão. Em An. parvus a cerda 1-A é curta e em An. (Ker.) neivai é longa.

44. Posição da cerda 2-C em relação à linha mediana longitudinal da cabeça: [0] proximal $\backslash[1]$ distal $(8$ passos, $\mathrm{Cl}=0,12$ )

Esse caráter é extremamente homoplástico, no entanto, a posição da cerda 2$\mathrm{C}$ distal da linha mediana da cabeça éuma sinapomorfia para o Grupo-Albitarsis ${ }^{+}$. A posição proximal dessa cerda é uma sinapomorfia para o Grupo-Rondoni ${ }^{+}$, sofrendo uma reversão no clado formado pelos grupos Evansae ${ }^{+}$e Oswaldoi ${ }^{+}$e noGrupoTrinkae ${ }^{+}$. Em An. evansae e An. ininii ocorre uma reversão.

A condição proximal também é encontrada em An. braziliensis, sendo uma homoplasia. Em An. pseudopuncipennis é proximal e em An. cruzii e An. neivai é distal, em relação à linha mediana longitudinal da cabeça.

45. Cerda 1-P: [0] aciculada $\backslash[1]$ palmada $\backslash[2]$ em leque (2 passos, $\mathrm{CI}=1,0)$.

Cerda 1-P em forma de leque é uma sinapomorfia para Nyssorhynchus. A cerda 1-P palmada é uma sinapomorfia do Grupo-Albimanus ${ }^{+}$. Em An. cruzii, An. neivai e An. pseudpopunctipennis, as cerdas 1-P são aciculadas. 
46. Cerda 4-M: [0] curta $\backslash[1]$ moderadamente longa $\backslash[2]$ muito longa (2 passos, $\mathrm{CI}=$ $1,0)$.

A cerda 4-M curta é uma sinapomorfia para o Grupo-Braziliensis ${ }^{+}$. Nas demais espécies de Nyssorhynchus e An. pseudopunctipennis apresentam a Cerda 4$\mathrm{M}$ longa. Em Kerteszia a Cerda 4-M é muito longa.

47. Haste da cerda 4-P: [0] delgada $\backslash[1]$ grossa (2 passos, $\mathrm{CI}=0,50$ ).

As espécies do grupo-externo e as espécies mais basais de Nyssorhynchus, An. parvus e An. argyritarsis, apresentam a haste da cerda 4-P delgada. Haste da cerda 4-P grossa parece ser uma sinapomorfia para as demais espécies de Nyssorhynchus, tendo sofrido uma reversão no Grupo-Albimanus ${ }^{+}$, sendo a condição delgada uma sinapomorfia para este grupo.

48. Cerda 3-T: [0] palmada $\backslash[1]$ em leque $\backslash[2]$ ramificada (4 passos, $\mathrm{CI}=0,50$ ).

Cerda 3-T em forma de leque é sinapomorfia para Nyssorhynchus. A cerda 3T palmada está presente no Grupo-Albitarsis ${ }^{+}$, sendo uma sinapomorfia para o grupo. As espécies An. triannulatus e An. strodei apresentam a cerda 3-T em forma de leque e isso representa uma reversão. Nos grupos externos utilizados, a cerda 3-T é ramificada.

49. Cerda 0-III: [0] pequena, pouco desenvolvida \ [1] grande, fortemente desenvolvida ( 1 passo, $\mathrm{Cl}=1,0)$.

O forte desenvolvimento da cerda 0-III é uma sinapomorfia do GrupoAlbitarsis $^{+}$.

50. Cerda 6-IV: [0] ramificada $\backslash[1]$ aciculada $\backslash[2] \operatorname{simples}(3$ passos, $\mathrm{CI}=0,67)$.

A presença de ramificação nas cerdas 6-IV-VI nas larvas de $A n$. antunesi, $A n$. parvus e An. lutzii são consideradas caracteristicas diagnósticas para espécies da "Seção Myzorhynchela", mas essa ramificação da cerda é homóloga apenas entre 
An. antunesi e An. lutzii. Nas demais espécies de Nyssorhynchus, essa cerda é simples. Em Kerleszia e An. pseudopunclipennis apresentam-se aciculadas.

51. Cerda $2-\mathrm{V}$ : [0] curta $(0,1-0,2 \mathrm{~mm}) \backslash[1]$ longa (acima de 0,3mm) $(6$ passos, $\mathrm{CI}=$ $0,17)$

Cerda 2-V longa é uma sinapomorfia do Grupo-Darlingi ${ }^{+}$. A presença de $2-\mathrm{V}$ curta em An. trinkae é secundária. No grupo-Oswaldoi ${ }^{+}$, a cerda $2-\mathrm{V}$ é curta podendo ser considerada uma reversão, que representa uma sinapomorfia para o grupo, com aumento no tamanho da cerda em An. aquasalis. Em An. parvus e Grupo-Lanei ${ }^{+}$a Cerda 2-V é longa, sendo uma homoplasia.

52. Extensão lateral da placa mediana do aparelho espiracular: [0] ausente \[1] presente ( 3 passos, $\mathrm{Cl}=0,33$ )

A presença da extensão lateral da placa mediana do aparelho espiracular é uma sinapomorfia do Grupo-Albitarsis ${ }^{+}$, apresentando uma reversão em $A n$. darlingi. A presença de extensão lateral da placa também ocorre no Gupo-Lanei ${ }^{+}$, não parecendo ser condição homóloga entre os dois grupos. Em An. pseudopunctipennis a extensão lateral também está presente, representando uma homoplasia.

53. Cerda 1-X: $[0]$ curta $(0,2-0,3 \mathrm{~mm}) \backslash[1]$ longa $(0,4-0,5 \mathrm{~mm}) \backslash[2]$ muito longa $(0,6-$ $0,7 \mathrm{~mm})(4$ passos, $\mathrm{CI}=0,50)$

As espécies basais de Nyssorhynchus apresentam a Cerda 1-X muito longa, sendo uma sinapomorfia para o subgênero. $O$ encurtamento dessa cerda ocorre no GrupoAlbitarsis ${ }^{+}$, representando uma sinapomorfia para esse clado. A Cerda 1-X curta de $A n$. benarrochi e An. oswaldoi pode ser considerada reversão. Em $A n$. neivai, An. cruzi e An. pseudopunctipennis essa cerda é curta.

Ovo

54. Superficie dorsal do ovo: [0] côncava $\backslash[1]$ plana (4 passos, $\mathrm{Cl}=0,25$ ) 
O entendimento da evolução desse caráter foi prejudicado pela falta de informação a respeito da morfologia dos ovos de An. argyrilarsis, An. lanei e An. sawyeri, entretanto, com a otimização dos caracteres a superficie dorsal plana parece ser uma sinapomorfia do Grupo-Argyritarsis ${ }^{+}$. Em An. evansae e An. galvaoi, a superficie é côncava e representa uma sinapomorfia para as duas espécies. A superficie dorsal côncava do ovo apresentada por An. nuneztovari e An. lutzii e Grupo-Evansae ${ }^{+}$é reversão.

55. Células coriônicas: [0] com margens definidas $\backslash$ [1] sem margens definidas (2 passos, $\mathrm{C} i=0,50$ )

A ausência de definição das margem nas células coriônicas é uma sinapomorfia de Nyssorhynchus, entretanto An. sawyeri apresenta as margens das células coriônicas definidas, sendo uma autapomorfia. A falta dessa informação para An. lanei prejudicou o entendimento do caráter, entretando, na otimização dos caracteres a definição das margens das células aparece como uma sinapomorfia paras o Grupo-Lanei ${ }^{+}$. Em Kerteszia, as margens das células coriônicas são definidas.

56. Estrutura coriônica: [0] formando montículos definidos $\backslash$ [1] formando "bolhas arrebentadas" । [2] uniforme, sem montículos ou "bolhas arrebentadas" (3 passos, $\mathrm{Cl}=0,67$ )

O revestimento do ovo é representado pelo cório, que apresenta-se em duas camadas, a mais externa, denominada exocório, e a mais interna, endocório. $\mathrm{O}$ exocório apresenta-se ornamentado com esculturas, que podem ser saliências, bosseladuras e tubérculos com formas variadas (FORATTINI 1996).

A formação de montículos definidos na estrutura coriônica dos ovos é uma sinapomorfia do Grupo-Darlingi ${ }^{+}$(Figl0. F-N, O-S). Entretanto, a estrutura coriônica uniforme presente em An. benarrochi (Fig. $10 \mathrm{~N}$ ) pode ser considerada uma reversão. A formação de estruturas semelhantes a "bolhas arrebentadas" (Fig. 10 D, E) é uma sinapomorfia do clado formado pelos grupos Lutzii $^{+}$e Lanei ${ }^{+}$. As espécies $A n$. 
parvus, An. argyritarsis e An. albitarsis e os grupos externos apresentam a estrutura corionnica uniforme (Fig. $10 \mathrm{~B}, \mathrm{E}$ ).

57. Flutuador: [0] curto, restrito à porcão mediana do ovo $\backslash$ [1] longo, se estendendo da região anterior do ovo até a posterior $(4$, passos, $\mathrm{CI}=0,25)$.

Os flutuadores são expansões exocoriais, presentes na superficie dorsal do ovo, dispostas bilateralmente. Flutuador longo é uma sinapomorfia do GrupoAlbimanus ${ }^{+}$, estando, também, presentes em An. lutzii e An. antunesi, sendo uma sinapomorfia para as duas espécies. O flutuador longo encontrado nos dois grupos de espécies é uma homoplasia.

58. Flutuadores: [0] laterais $\backslash[1]$ dorsais (4 passos, $\mathrm{CI}=0,25$ )

A posição lateral do flutuador no ovo é uma sinapomorfia do GrupoArgyritarsis ${ }^{+}$. Entretanto, em An. anomalophyllus o flutuador em posição dorsal é uma reversão. No clado formado pelos grupos Lutzii $^{+}$e Lanei ${ }^{+}$, o flutuador está presente em posição lateral.

59. Flutuadores: [0] alargados lateralmente $\backslash[1]$ estreitos ( 3 passos, $\mathrm{CI}=0,33$ )

Os flutuadores estreitos surgiram surgimento independentemente em $A n$. parvus e An. rondoni.

60. Franja da região anterior do ovo: [0] ausente $\backslash$ [1] presente, não formando corola no pólo anterior \[2] presente, formando corola dorsal no pólo anterior \[3] presente, formando corola isolada no pólo anterior ( 6 passos, $\mathrm{CI}=0,50$ )

A franja é uma borda saliente presente na superficie dorsal do ovo (FORATTINI 1996). A presença de franja formando corola dorsal no pólo anterior do ovo é uma sinapomorfia para o clado formado pelos grupos Strodei ${ }^{+} \mathrm{e}$ Anomalophyllus ${ }^{+}$, tendo sofrido uma perda no clado formado pelos grupos Evansae ${ }^{+}$ e Oswaldoi ${ }^{+}$'sendo assim, a perda da corola, é uma sinapomorfia para esteste grupo. A presença de franja fomando corola dorsal no pólo posterior em An. darlingi é homoplástica. Em An. parvus a franja está presente formando corola posicionada na 
região apical do pólo anterior do ovo, representando uma autapmorfia para a espécie. A ausência de franja é uma sinapomorfia de An. lutzii e An. antunesi. Nas demais espécies de Nyssorhynchus e em Kerteszia a franja está presente, não formando corola. Em An. pseudopuncitpennis a condição da corola isolada no pólo anterior do ovo é homoplástica .

61. Posição da franja em relação à margem anterior do flutuador: [0] contínua \[1] descontínua ( 4 passos, $\mathrm{Cl}=0,25)$

A continuidade da franja em relação à margem do flutuador é observada na maioria das espécies de Nyssorhynchus, exceto em An. parvus, An. darlingi, An. rangeli e An. benarrochi. A posição descontínua da franja em relação à margem anterior do flutuador é uma sinapomorfia para An. rangeli e An. benarrochi, para as demais representa homoplasia. Em An. pseudopuncitpennis, a franja é descontinua.

62. Paredes da franja: [0] mais altas medianamente do que lateralmente $\backslash$ [1] mais baixas medianamente do que lateralmente $\backslash[2]$ subiguais ( 6 passos, $\mathrm{CI}=0,33$ )

A condição paredes subiguais da franja é sinapomorfia para Nyssorhynchus. No Grupo-Rondoni ${ }^{+}$as paredes da franja apresentam-se mais altas medianamente do que lateralmente, sendo uma sinapomorfia para o grupo. Essa condição também é encontrada em An. albitarsis, não sendo homólogas. Em Grupo-Oswaldoi ${ }^{+}$, as paredes da franja apresentam-se mais baixas medianamente do que lateralmente, sendo uma sinapomorfia para o clado. Essa condição também é observada em $A n$. albimanus.

63. Plastrão na extremidade posterior: [0] cobrindo o pólo posterior $\backslash[1]$ não cobrindo o pólo posterior ( 5 passos, $\mathrm{CI}=0,20$ )

A condição do plastrão não cobrindo a extremidade posterior do pólo posterior do ovo é uma sinapomorgia para o Grupo-Argyritarsis ${ }^{+}$, ocorrendo também, se forma independente nas espécies de Kerteszia utilizadas como grupos externos. O plastrão cobrindo o pólo posterior aparece em $A n$. darlingi, no Grupo-Trinkae ${ }^{+}$e no 
clado formado pelos grupos Evansae ${ }^{+}$e Oswaldoi ${ }^{+}$e no Grupo-Trinkae ${ }^{+}$, de forma independente.

64. Colar da micrópila: [0] tocando a franja \[1] não tocando a franja (2 passos, $\mathrm{CI}=$ $0,50)$

O colar da micrópila tocando a franja é uma sinapomorfia para o GrupoAlbitarsis ${ }^{+}$. No Grupo-Braziliensis ${ }^{*}$ a franja está separada do colar da micrópila.

65. Flutuadores: [0] fundidos anteriormente $\backslash[1]$ não fundidos anteriormente (5 passos, $\mathrm{CI}=0,20)$

A condição flutuadores não fundidos anteriormente é uma sinapomorfia para o Grupo-Argyritarsis ${ }^{+}$. A condição fusão do flutuados na região anterior é bastante homoplástica, sendo encontrada de forma independente em An. darlingi, no GrupoLutzii $^{+}$e no Grupo-Strodei ${ }^{+}$. Nas espécies de Kerteszia utilizadas como grupos externos, os flutuadores não apresentam fusão anterior.

66. Flutuadores: [0] fundidos posteriormente \[1] não fundidos posteriormente (4 passos, $\mathrm{CI}=0,25$ )

A condição flutuadores não fundidos posteriormente é uma sinapomorfia para o Grupo-Argyritarsis ${ }^{+}$. A fusão do flutuados na região posterior é encontrada no clado formado pelos grupos Strodei ${ }^{+}$e Anomalophyllus ${ }^{+}$. Nas espécies de Kerteszia utilizadas como grupos externos, os flutuadores não apresentam fusão posterior.

67. Tubérculos lobados do no pólo anterior: [0] presentes $\backslash[1]$ ausentes ( 1 passo, $\mathrm{CI}=$ $1,0)$

68. Tubérculos do convés: [0] dispostos irregularmente $\backslash[1]$ dispostos uniformemente ( 2 passos, $\mathrm{CI}=0,50)$.

O convés representa a região da superficie dorsal demilitada pelos flutuadores e franja. Nele pode-se observar a presença de ornamentação representada por nódulos e tubérculos. Os tubérculos dispostos uniformemente no convés é uma 
sinapomorfia de Nyssorhynchus. O Grupo-Albitarsis ${ }^{+}$os tubérculos estão dispostos de forma irregular, sendo uma sinapomorfia para o clado.

69. Contorno dos tubérculos do convés: [0] irregular $\backslash[1]$ liso $(\mathrm{CI}=0,50)$.

O contorno irregular dos tubérculos é uma sinapomorfia para o GrupoArgyritarsis $^{+}$. No Grupo-Darlingi ${ }^{+}$o contorno do tubérculo é liso. 


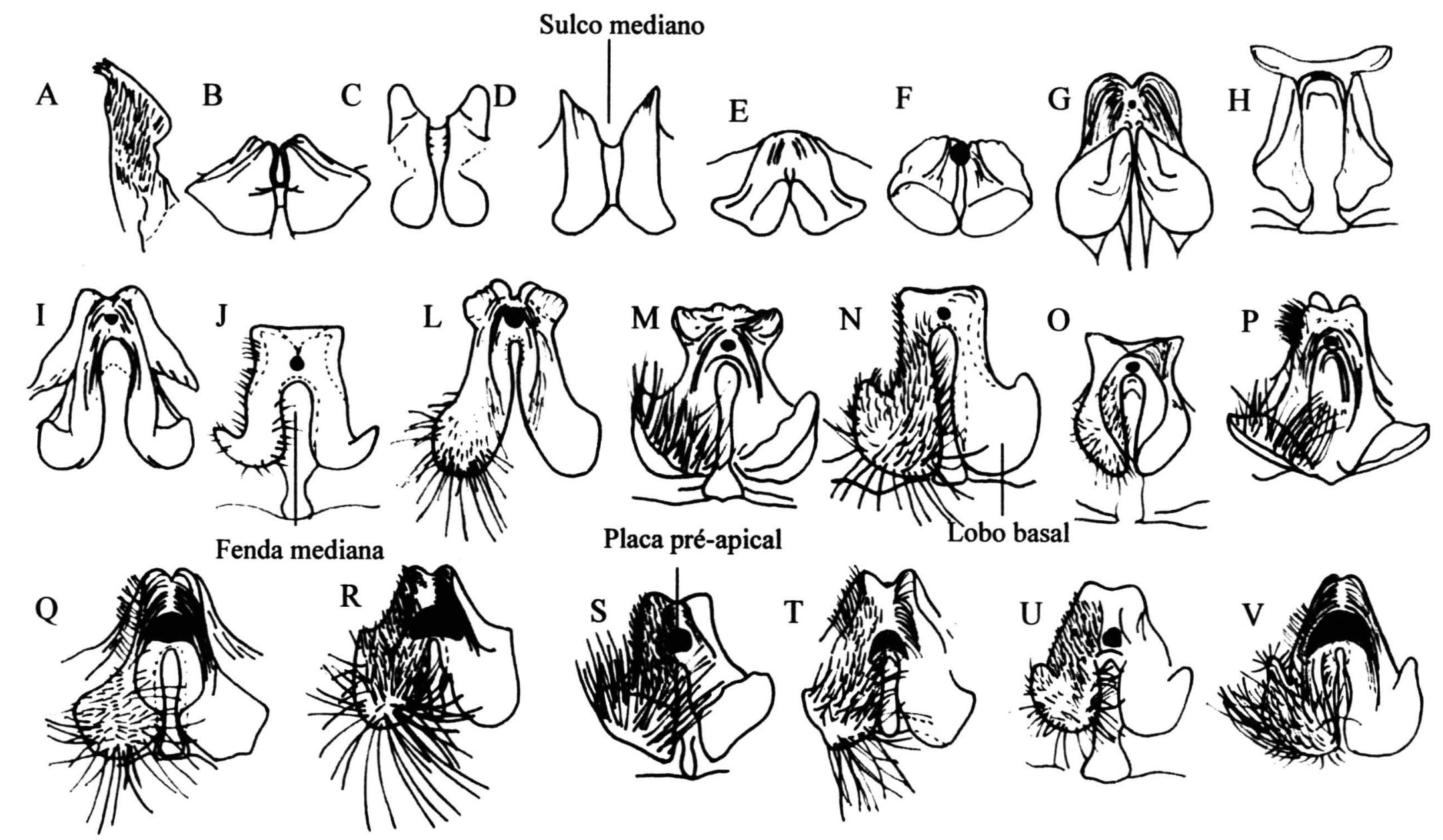

Fig 4. Terminália Masculina, claspete ventral: A-An.(Ker.) cruzii ; B-An. argyritarsis; C- An. sawyeri; D- An. lanei; E. An. albitarsis; F-An. darlingi; G- An. albimanus; H-An. triannulatus; I- An. braziliensis; J. An. nuneztovari; L- An. rondoni; M. An. strodei; N. An. trinkae; O. An. benarrochi; P. An. rangeli; Q. An. anomalophyllus; R. An.galvaoi; S. An. evansae; T. An. oswaldoi; U. An. aquasalis V. An. ininii (Fonte: Figs. A- ZAVORTINK 1973; B- F, I. LINTHICUM 1988; G-H, J-V. FARAN 1980). 

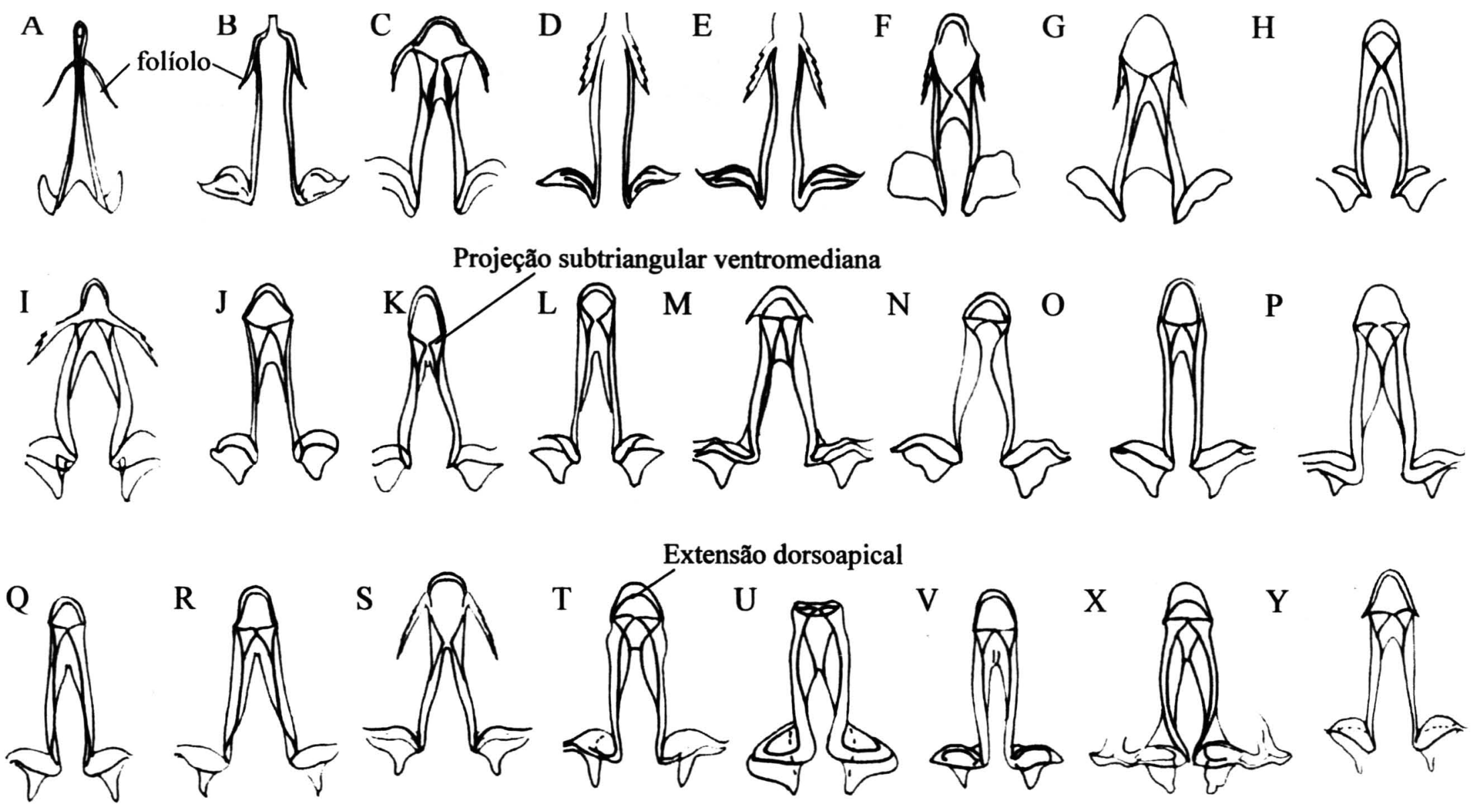

Fig 5. Terminália Masculina, edeago: A-An.(Ker.) cruzii, B-An. parvus; C- An. argyritarsis; D- An.antunesi; E- An. lutzii; F- An. sawyeri; G- An. lanei; H. An. albitarsis; I- An. darlingi; J- An. albimanus; K- An. triannulatus; L- An. braziliensis; M. An. nuneztovari; N- An. rondoni; O. An. strodei;P. An. trinkae; Q. An. benarrochi; R. An. rangeli; S. An. anomalophyllus; T. An.galvaoi; U. An. evansae; V. An. oswaldoi; X. An. aquasalis; Y. An. ininii (Fonte: Figs. A- ZAVORTINK 1973; B,D-E. FORATTINI 1962, C, F- I, L. LINTHICUM 1988; J-K, M-Y. FARAN 1980). 

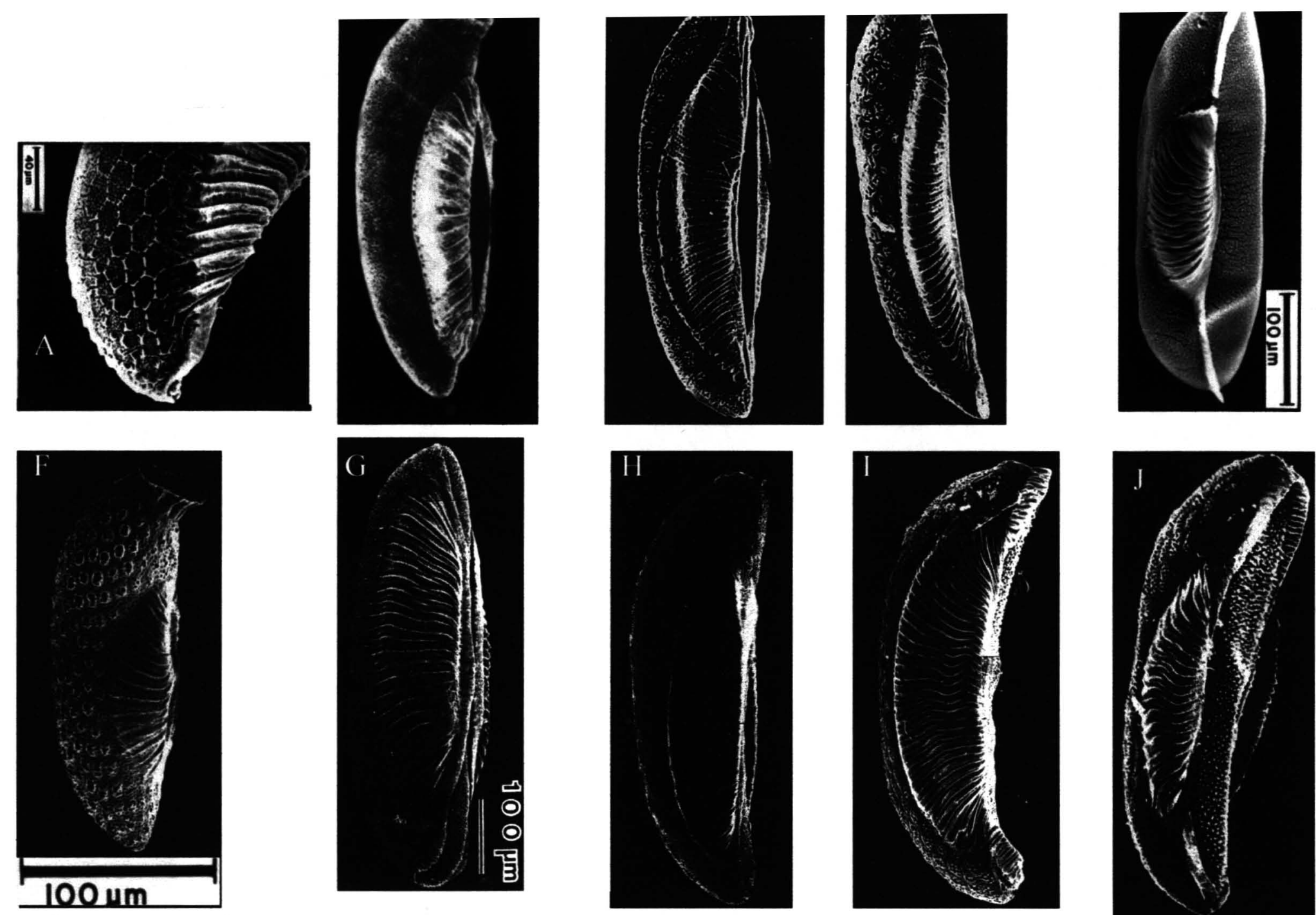

Fig. 6. Ovo, vista lateral: A-An. (Ker.) cruzii B-An. parvus; C-An.antunesi; D-An. lutzii; E-An. albitarsis; F- An. darlingi; G- An.albimanus; H- An. triannulatus; I- An. nuneztovari; J- An. rondoni (Fonte: Figs. A. FORATTINI e MARUCCI 1993; B, D, J. FORATTINI et. al 1998; C. FORATTINI et. al 1997; E. MARUCCI 1996; F. LINLEY 1992; G. RODRIGUEZ et. al 1992; H. LOUNIBOS et. al 1997; I. LOUNIBOS et. al 1998). 

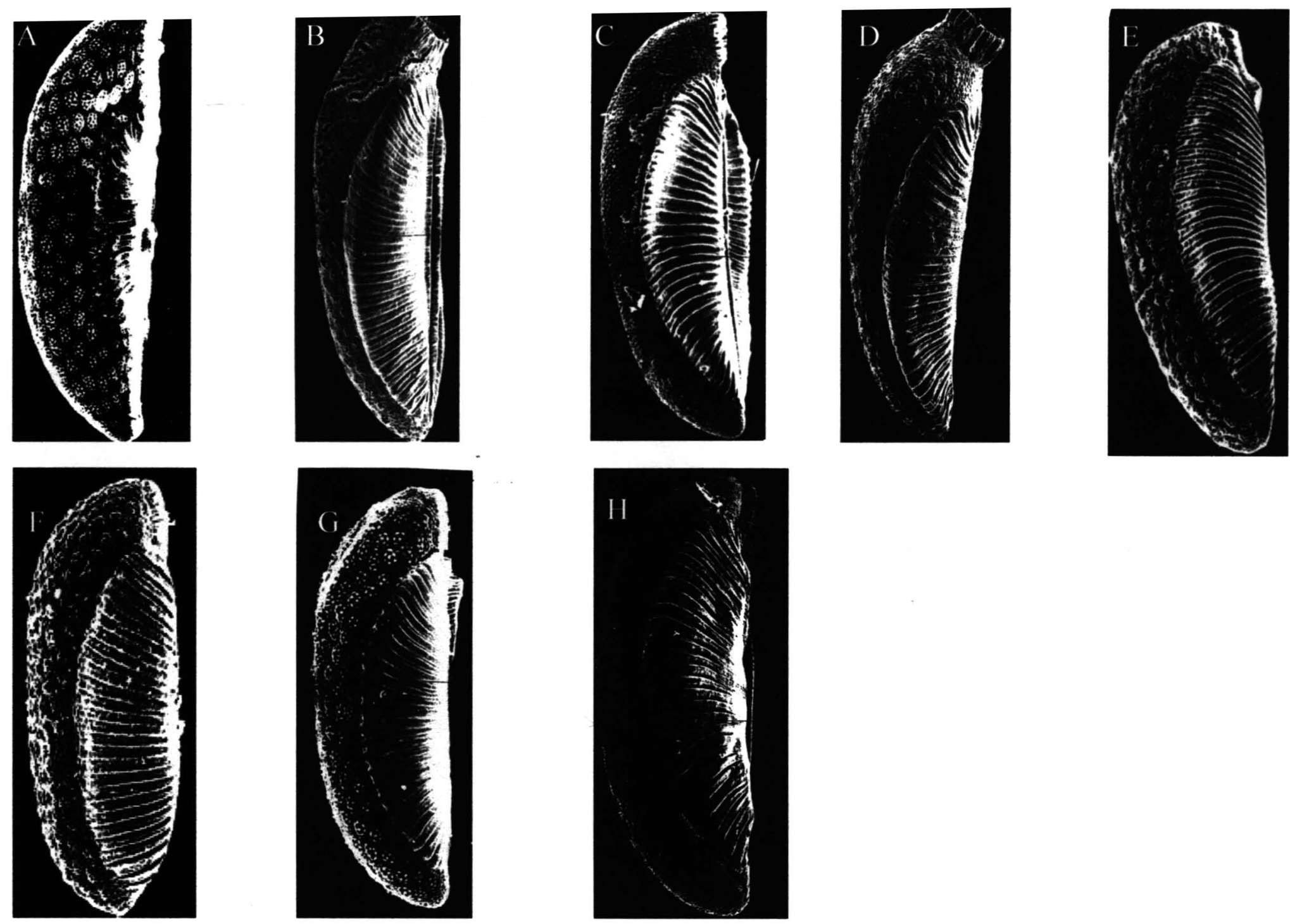

Fig. 7. Ovo, vista lateral: A- An. strodei. B- An. trinkae; C-An. benarrochi, D- An. rangeli; E- An. galvaoi; F- An. evansae; G. An. oswaldoi; H. An. aquasalis (Fonte: Figs. A, C, G. LOUNIBOS et. al 1997; B, D. LINLEY e LOUNIBOS 1993; E-F. SALLUM et. al 2002b; H. LINLEY et. Al 1993 ). 

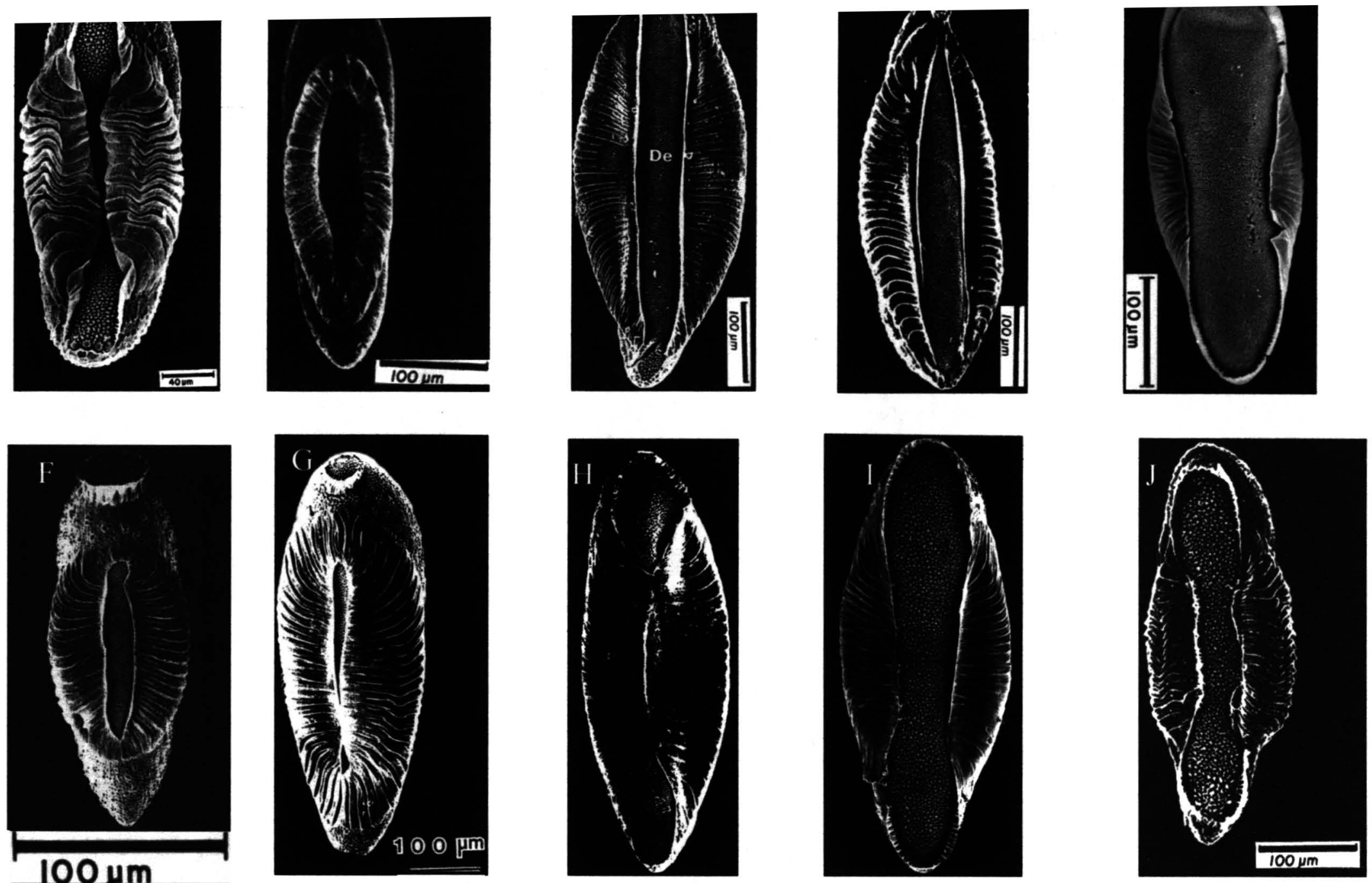

Fig. 8. Ovo, vista dorsal: A- An. (Ker.) cruzii; B-An. parvus; C-An. antunesi; D- An. lutzii; E-An. albitarsis; F- An. darlingi; G- An. albimanus; H- An. triannulatus; I- An. nuneztovari; J- An. rondoni (Fonte: Figs. A. FORATTINI e MARUCCI 1993; B, D, J. FORATTINI et. al 1998; C. FORATTINI et. al 1997; E. MARUCCI 1996; F. LINLEY 1992 ; G. RODRIGUEZ et. al 1992; H. LOUNIBOS et. al 1997; I. LOUNIBOS et. al 1998). 

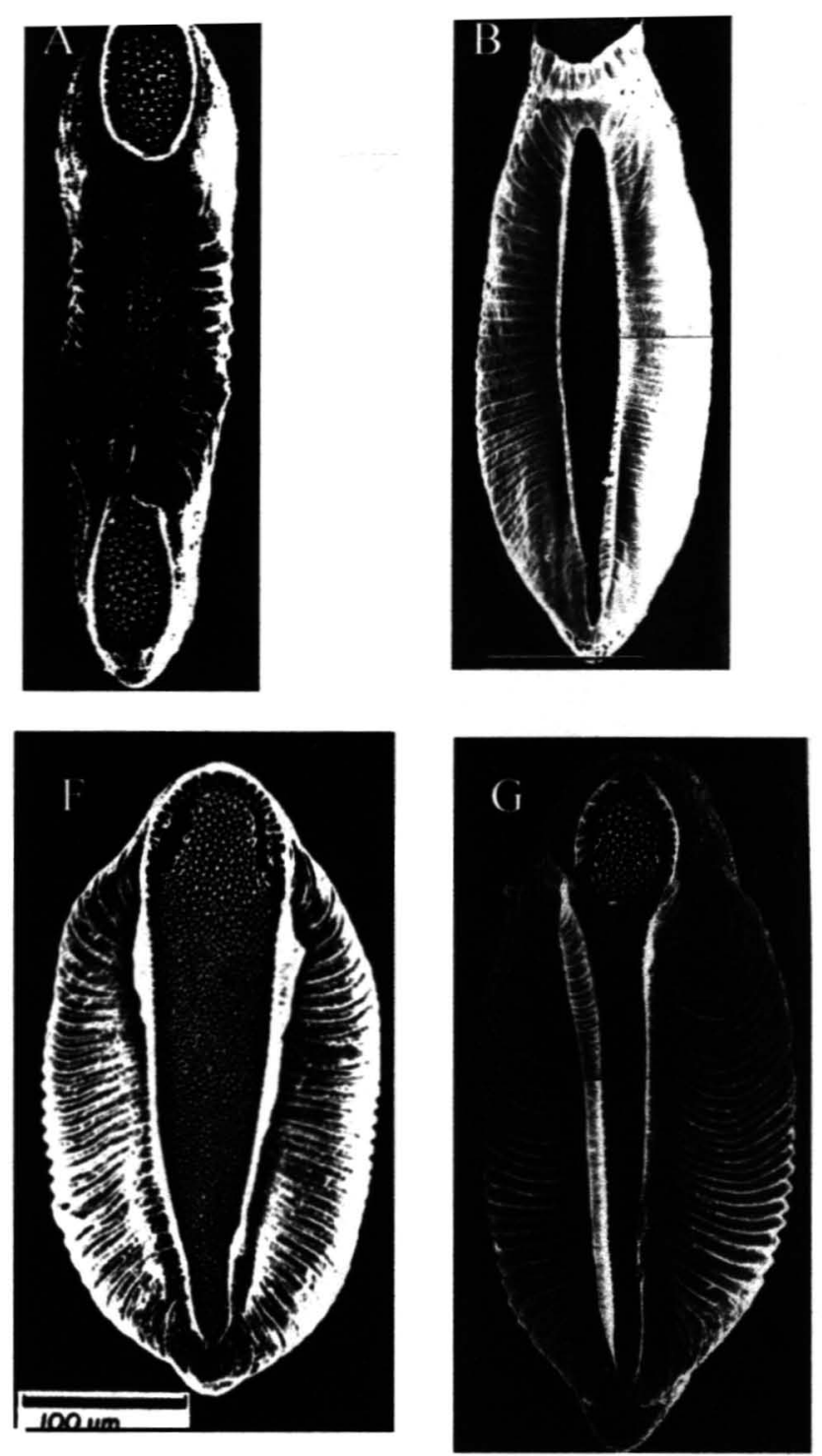
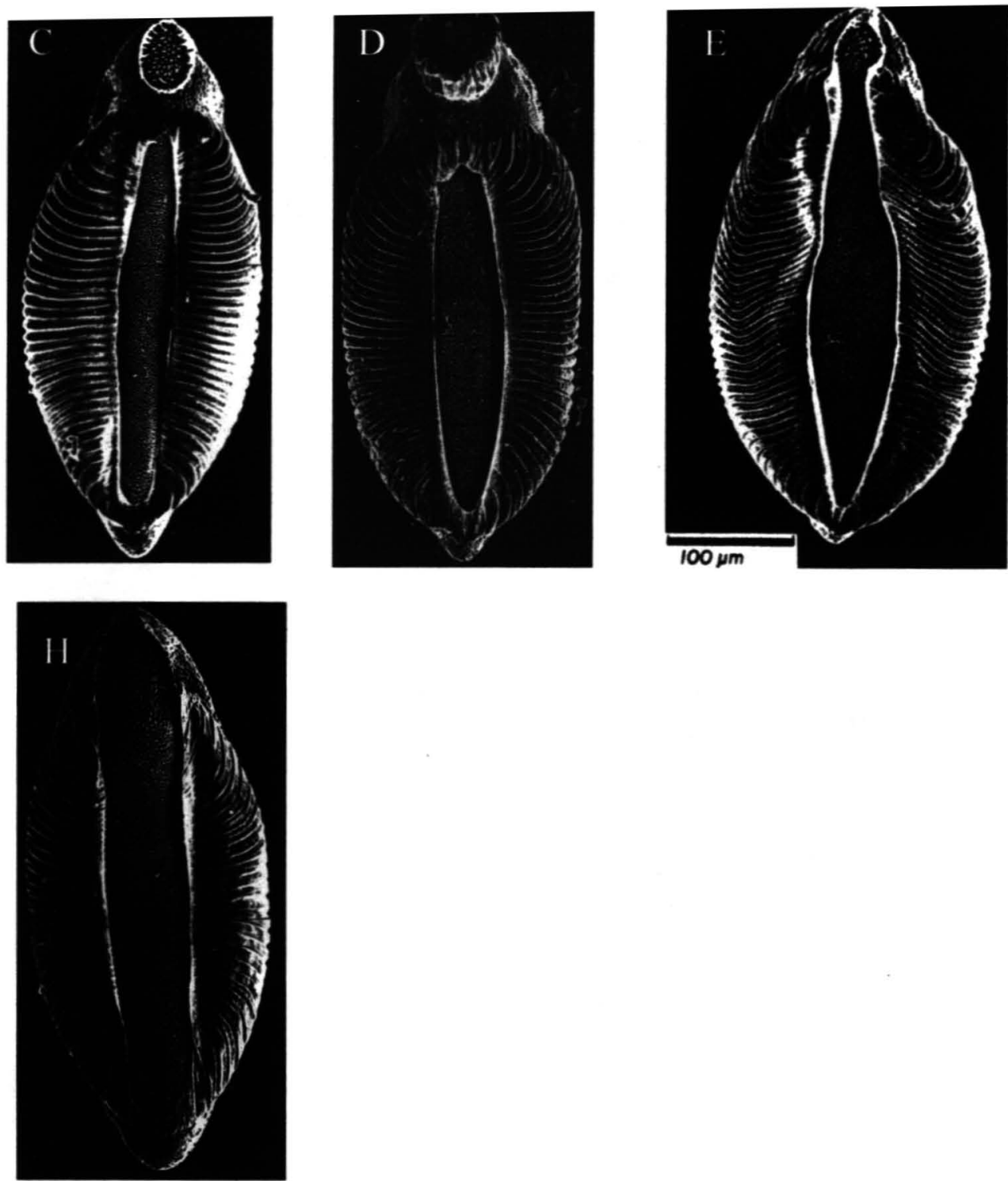

Fig. 9. Ovo, vista dorsal: A- An. strodei. B- An. trinkae; C- An. benarrochi D- An. rangeli; E- An. galvaoi; F- An. evansae; G. An. oswaldoi; H. An. aquasalis (Fonte: Figs. A, C, G. LOUNIBOS et. al 1997; B, D. LINLEY e LOUNIBOS 1993; E-F. SALLUM et. al 2002b; H. LYNLEY et. al 1993 ). 

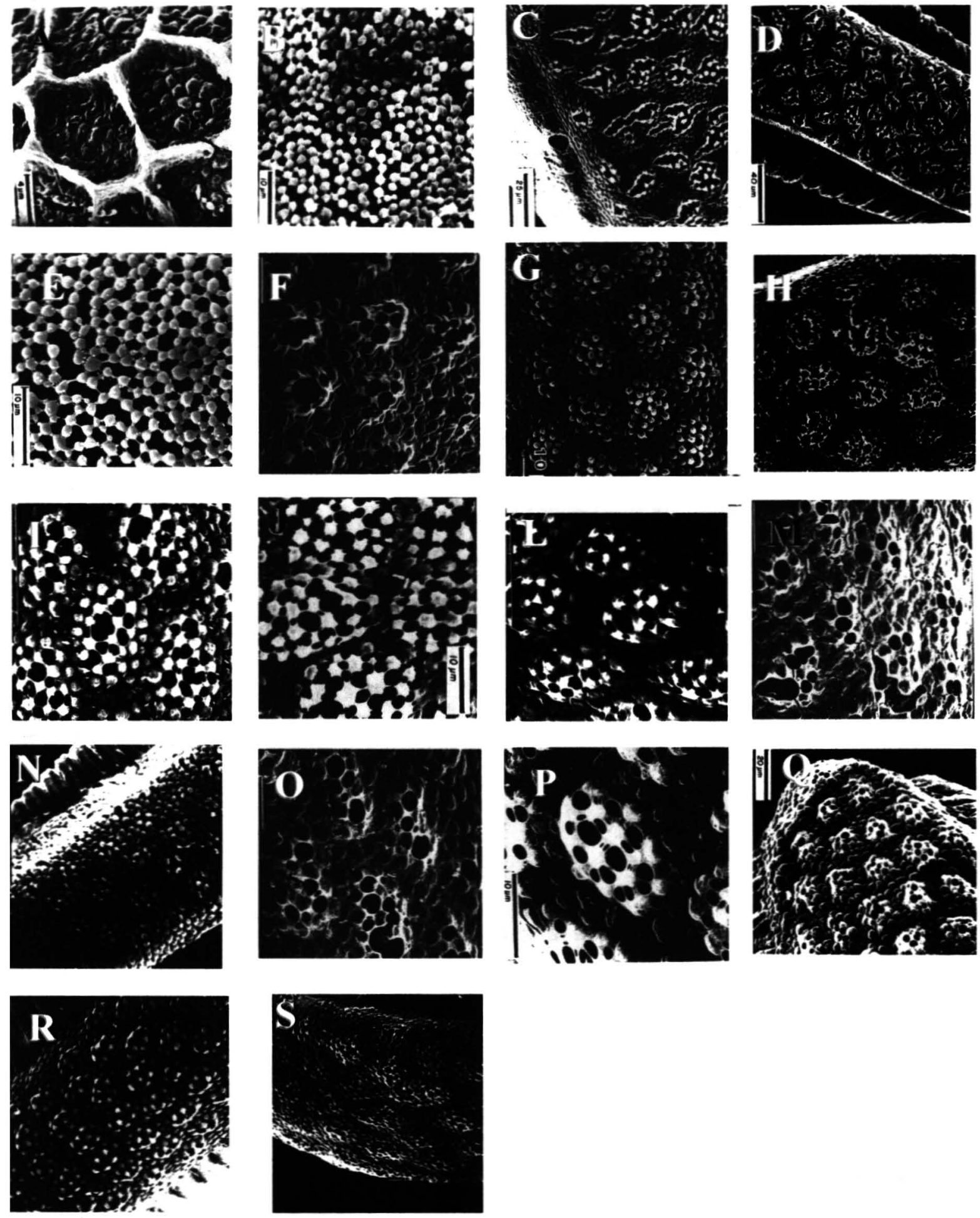

Fig. 10. Ovos, exocório: A- An. (Ker.) cruzii B-An. parvus; C-An.antunesi; D- An. lutzii; E-An. albitarsis; F- An. darlingi; G- An. albimanus; H- An. triannulatus; I- An. nuneztovari; J- An. rondoni; L- An. strodei. M- An. trinkae; N-An. benarrochi; O- An. rangeli; P-An. galvaoi; Q- An. evansae; R. An. oswaldoi; S. An. aquasalis (Fonte: Figs. A. FORATTINI e MARUCCI 1993; B, D, J. FORATTINI et. al 1998; C. FORATTINI et. al 1997; E. MARUCCI 1996; F. LINLEY 1992; G. RODRIGUEZ et. al 1992; H, L, N, R LOUNIBOS et. al 1997; I. LOUNIBOS et. al 1998) M, $\mathbf{O}$. LINLEY e LOUNIBOS, 1993; P-Q. SALLUM et. al 2002b). 
Quadro 2: Matriz de caracteres de Nyssorhynchus, contendo 26 taxa e 69 caracteres, onde (?) representa "missing data" e (-) dados não comparáveis.

\begin{tabular}{|c|c|c|c|c|c|c|c|}
\hline & 1 & 2 & 3 & 4 & 5 & 6 & \\
\hline & 0 & 0 & 0 & 0 & 0 & 0 & \\
\hline An pseudopunctipennis & 0000000000 & $0-00 ? \ldots \ldots$ & $-0 \ldots \ldots$ & 1210100031 & $11 ? 0010202$ & 0102021103 & $120 ? 00 ? m$ \\
\hline An. cruzii & 0010000111 & $10000 \ldots$ & $--0 \ldots \ldots$ & 0000100020 & 1001020201 & 0000020101 & 011111001 \\
\hline An. neivai & 0010000111 & $10000 \ldots$ & $-0 \ldots \ldots$ & 0000100000 & 1011020201 & o0027?7??? & ???? ?? ??? \\
\hline An. parvus & 0021111201 & 1111111102 & $11400-0010$ & 1110110121 & 0100210100 & $10 ? 0120113$ & 120100011 \\
\hline An. argyritarsis & 0121111201 & 1111111002 & $114-111010$ & 1110111131 & 0110210102 & $002 ? ? ? 0001$ & $0 ?|?| 1 ? ? ?$ \\
\hline An. antunesi & 0021111201 & 1111020003 & $004-0-0000$ & 1121010131 & 0010211100 & 0021111100 & $? 21101110$ \\
\hline An. lutzii & 0021111201 & 1111020003 & $004-0-0000$ & 1121010131 & $0 ? 1021 ? 700$ & 0070111110 & $? ? 1100 / 1110$ \\
\hline An. sawyeri & 0121111201 & 1111000203 & $004-0-0021$ & 1120011131 & 0110211102 & 102?07???1 & ??1??? ??? \\
\hline An. lanei & 1121111201 & 1111001203 & $004-0-0021$ & $1120 ? 11131$ & orm???m2 & ?????0101 & $0 ?|?| 1 ? ? ?$ \\
\hline An. albitarsis & 0121111201 & 1111111002 & $114-0-1010$ & 1110111101 & 0111211012 & 0111120001 & $? 01011100$ \\
\hline An. darlingi & 1121111201 & 1111111002 & $114-110010$ & 1110111131 & 0201211012 & 1011100002 & 120000101 \\
\hline An. albimanus & 0111111201 & 1111011101 & $004-110010$ & 1110111101 & 0211110012 & 11111010012 & $0 / 110 / 100 / 10 / 1101$ \\
\hline An. triannulatus & 1111111201 & 1111011311 & $004-111110$ & 1110111101 & 0111100112 & 1111101101 & $0 ? 1111101$ \\
\hline An. braziliensis & 1121111201 & 1111011101 & $004-111110$ & 1110111101 & $07 ? 0107012$ & ?11??????1 & ??1?????? \\
\hline An. nuneztovari & 1111111201 & 1111011011 & 0030201100 & 1110111111 & 0201100012 & 1110101001 & 021111101 \\
\hline An. rondoni & 1111111201 & 1111011100 & 0011201110 & 1110111101 & 0210100012 & 1111100011 & 001111101 \\
\hline An. strodei & 1111111201 & 1111011300 & 0021201110 & 1110111101 & 0210100112 & 1111101002 & $\begin{array}{llllll}0 & 01 & 100101\end{array}$ \\
\hline An. trinkae & 1111111201 & 1111011310 & 0031201110 & 1110111101 & 0201100012 & 0111101002 & 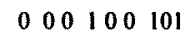 \\
\hline An. benarrochi & 1111111201 & 2111011313 & 0010101110 & 1110111101 & 0210100012 & 1101121002 & 120100101 \\
\hline An. rangeli & 1111111201 & 2111011100 & 0031201110 & 1110111101 & 0201100012 & 1111101002 & 120100101 \\
\hline An. anomalophyllus & 1111111201 & 1111011100 & 0031201100 & 1110111131 & 0210100012 & $111 ? ? ? 1102$ & $0 ? 11 ? 10 ? ? ?$ \\
\hline An. galvaoi & 1111111201 & 1111011100 & 0031201100 & 1110111101 & 0201100012 & 1110101001 & 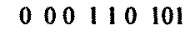 \\
\hline An. evansae & 1111111201 & 1111011000 & 0031201100 & 1110111101 & 0200100012 & 1110101001 & 000110101 \\
\hline An. oswaldoi & 1111111201 & 1111011100 & 0031201100 & 1110111101 & 0211100012 & $010110 ? 001$ & 010110101 \\
\hline An. aquasalis & 1111111201 & 1111011100 & 0021201100 & 1110111101 & 0211100012 & $111 ? 101001$ & $\begin{array}{llllllll}0 & 1 & 0 & 1 & 1 & 0 & 101\end{array}$ \\
\hline An. ininii & 1111111201 & 1111011100 & 0021201100 & 1110111111 & 0201100012 & $0117 ? ? ? ? ? ?$ & ?????? ??? \\
\hline
\end{tabular}




\subsubsection{Topologias obtidas nas análises filogenéticas}

Da totalidade de 69 caracteres morfológicos utlilzados na análise, 68 foram informativos. A análise filogenética da matriz obtida com algorítimos de busca heurística sem pesagem dos caracteres resultou em 328 cladogramas igualmente parcimoniosos, com 196 passos $(\mathrm{CI}=0,490 ; \mathrm{RI}=0,684 ; \mathrm{RC}=0,335 ; \mathrm{HI}=0.510)$. $\mathrm{Na}$ análise com pesagem sucessiva foram obtidos 3 cladogramas igualmente parcimoniosos, estando incluídos entre os 328 obtidos na análise com caracteres sem pesos diferenciados. A otimização dos caracteres realizada a partir de um dos cladogramas obtidos por pesagem sucessiva está representada na Figura 11. Os cladogramas de consenso estrito das três árvores da pesagem sucessiva e de consenso de maioria obtido na análise de bootstrap está apresentado na Figura 12 e 13, respectivamente. 


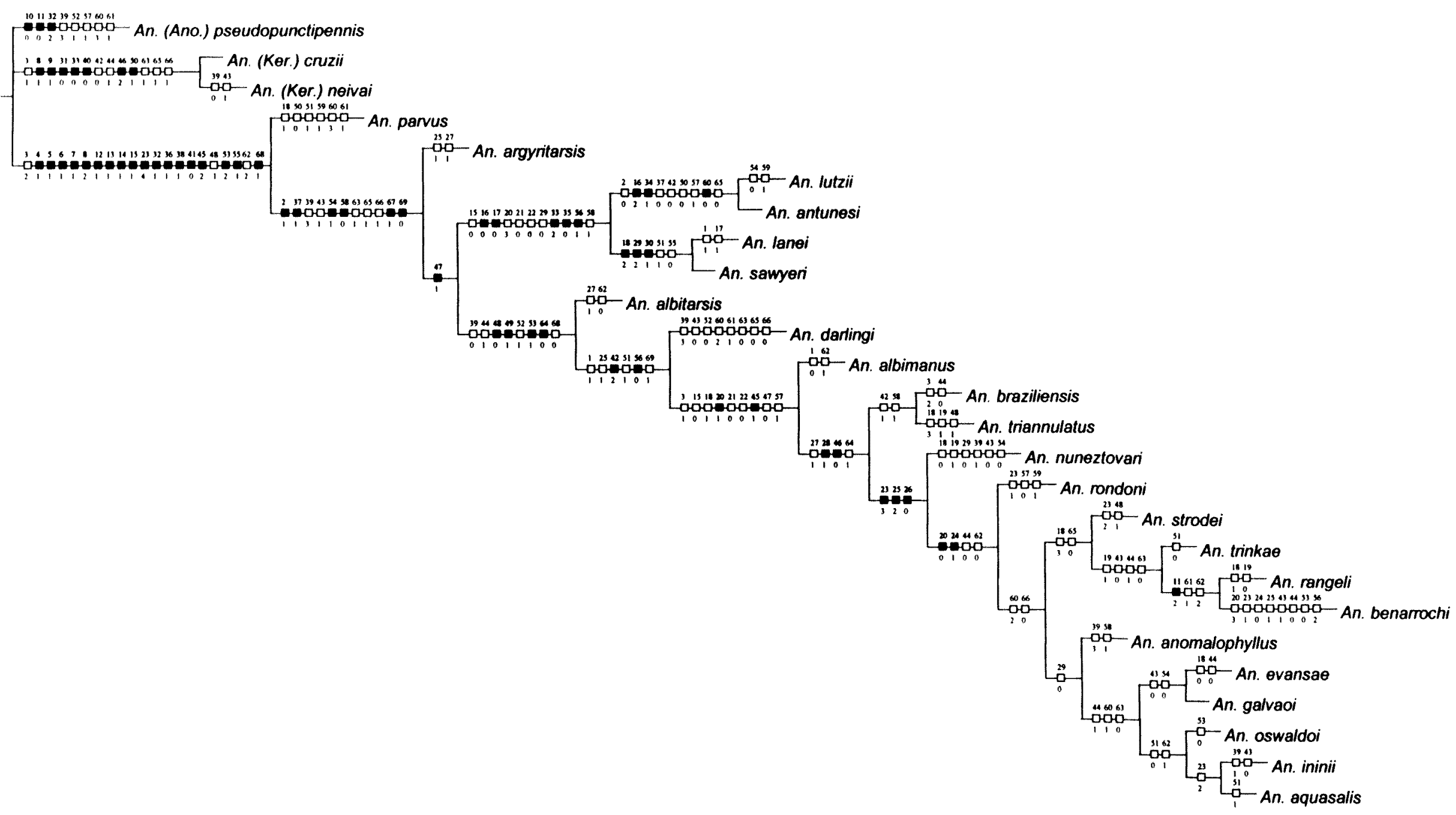

Fig. 11. Otimização dos caracteres em um dos cladogramas mais parcimiosos obtidos por pesagem sucessiva para Nyssorhynchus. Os números acima dos ramos indicam os caracteres e os números abaixo representam o estado do caráter. Os quadrados pretos representam caracteres sinapomórficos não homoplásticos e os brancos representam homoplasias. 


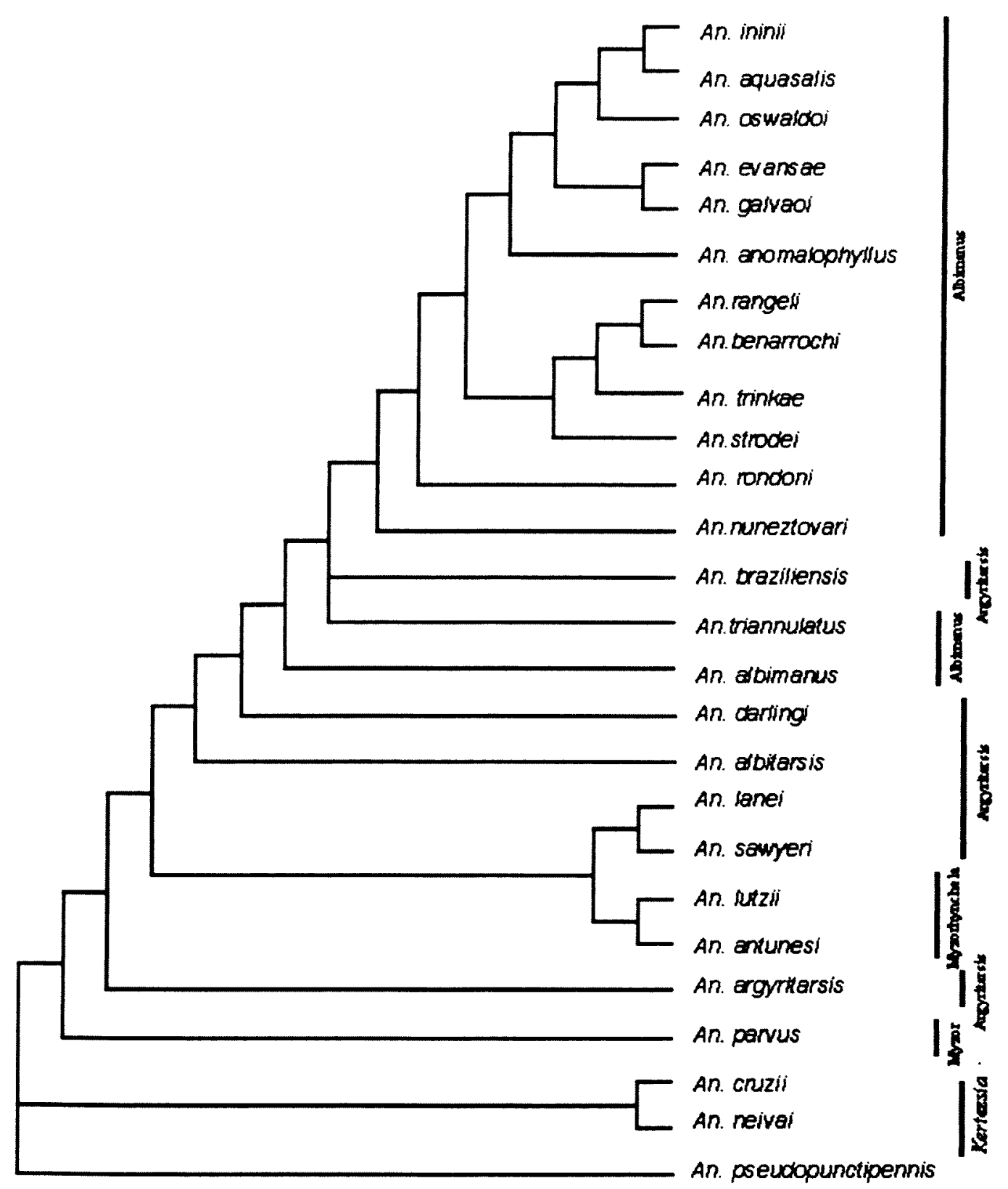

Fig. 12. Cladograma de consenso estrito para Nyssorhynchus gerado a partir dos 3 cladrogramas mais parcimoniosos obtidos por pesagem sucessiva (Comprimento= 196 passos, $\mathrm{CI}=0,490, \mathrm{RI}=0.682, \mathrm{RC}=0,334)$. 


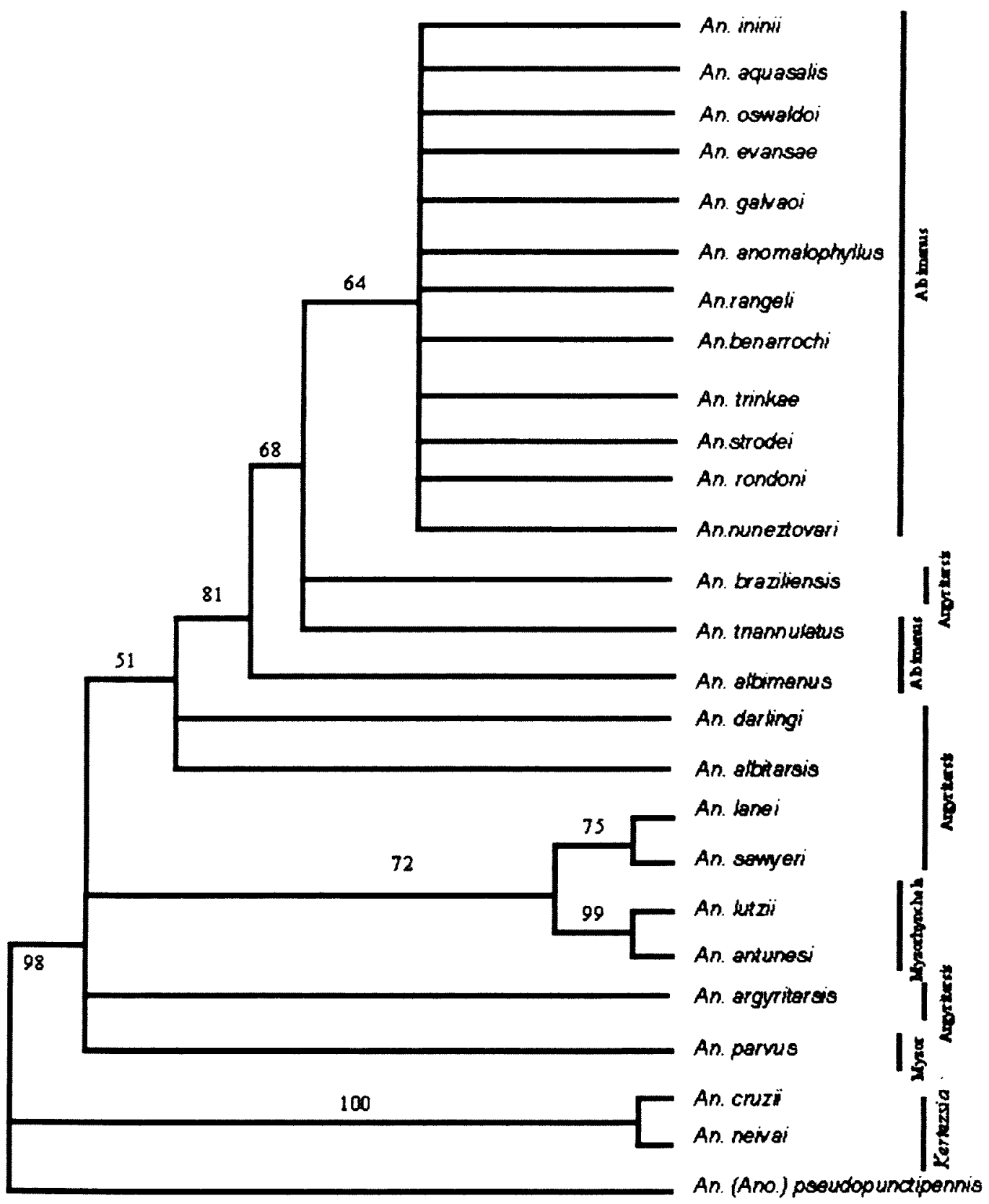

Fig. 13. Cladograma de consenso de maioria obtido a partir dos cladogramas gerados na análise de bootstrap. O número acima dos ramos indicam as porcentagens obtidas a partir da análise de bootstrap nos quais os nós são sustentados. 


\subsubsection{Comentários sobre as topologias obtidas}

Os resultados das análises realizadas neste estudo corroboram o monofiletismo de Nyssorhynchus (Figs. 12, 13, 14), conforme as propostas de PEYTON et. al (1992); CONN (1998); SALLUM et. al (2000, 2002a); KRZYWINSKI et. al (2001a, 2001b). Além disso, de acordo com o conjunto de caracteres morfológicos utilizados nas análises do presente trabalho, as seções Argyritarsis e Myzhorhynchella, são polifiléticas, o que corrobora as hipóteses prévias de CONN (1998) e SALLUM et. al (2000) sobre polifiletismo das Seções Argyritarsis, e Myzorhynchella. Entretando, a seção Albimanus mostrou-se parafilética. As relações entre Nyssorhynchus e os grupos-externos utilizados não foram resolvidas. No entanto, corroborar a hipótese de parentesco entre Nyssorhynchus e os grupos-externos não está incluso nos objetivos deste estudo.

O monofiletismo do subgênero Nyssorhynchus tem $98 \%$ de suporte de bootstrap é sustentado por várias sinapomorfias da terminália masculina: coloração inteiramente clara do tarsômero 5 da perna posterior; processo do esternito $\mathrm{X}$ fortemente esclerotizado; conexão ventromediana do gonocoxito desenvolvida em processo truncado; cerdas tergomediais estendendo-se até a metade basal do gonocoxito; presença da cerda apicomedial; cerdas acessórias presentes, inseridas na metade basal do gonocoxito; tubérculo da parabasal em posição perpendicular ao gonocoxito; borda dorsomedial do gonocoxito bastante desenvolvida, formando apódema longo; claspete ventral curto e desenvolvido em lobo mediano único; ausência de espículas no claspete ventral, cerdas foliáceas apicais do claspete dorsal sinuosas na porção basal; edeago largo; ápice do edeago com expansão dorsoapical. Além dessas, dão suporte ao monofiletismo do subgênero as seguintes sinapomorfias dos imaturos: ausência da cerda 10-VI, na pupa; Cerda 1-P em forma de leque na larva; Cerda 3-T em forma de leque; Cerda 1-X muito longa, na larva; células coriônicas sem margens definidas, paredes da franja subiguais e disposição irregular dos tubérculos do convés, no ovo.

As análises realizadas com pesagem sucessiva resultaram em 3 topologias, com variações apenas nas posições de An. braziliensis e An. triannulatus. Dessa 
forma, a topologia obtida por consenso estrito dos três cladogramas obtidos por pesagem sucessiva foi escolhida para discussão dos agrupamentos. No cladograma de consenso oberva-se dois grupos, um com uma única espécie, representada por $A n$. parvus, que está posicionada como a espécie mais basal dentro do grupo e outro maior, Grupo-Argyritarsis ${ }^{+}$sustentado pelas seguintes apomorfias: presença de tufo de escamas posterolaterais no tegito $\mathrm{VI}$; presença de projeção subtriangular ventromediana do edeago; presença de um par de foliolos serrilhados subapicais no edeago; Cerda 1-A longa na larva; superfície dorsal do ovo plana; ausência de tubérculos lobados do no pólo anterior do ovo; contorno irregular dos tubérculos do convés. O posicionamento de Anopheles argyritarsis basal dentro do GrupoArgyritarsis $^{+}$indica que a espécies não apresenta estreita relação de parentesco com as demais espécies consideradas integrantes da Seção Argyritarsis.

As demais espécies formam dois grupos, um clado formado pelo GrupoLutzii $^{+}$e Grupo-Lanei ${ }^{+}$que aparece irmão do Grupo-Albitarsis ${ }^{+}$que é suportado pela sinapomorfia haste da cerda 4-P grossa. O clado formado pelo Grupo-Lutzii ${ }^{+}$e Grupo-Lanei $^{+}$apresenta $72 \%$ de valor de bootstrap e é sustentado pelas sinapomorfias: claspete ventral alongado; margem lateral do claspete ventral reta, margem lateral do clapete ventral constrita na região mediana; lobo basal do claspete ventral estreito; porção apical do claspete ventral definida, claramente separada da porção basal; porção basal do lobo basal do claspete ventral arredondada; fenda mediana do claspete ventral curta; duas cerdas foliáceas apicais no claspete dorsal, garra do gonóstilo espatulada, estrutura coriônica formando formando "bolhas arrebentadas" e flutuadores dorsais

O clado Gurpo-Lutzii ${ }^{+}$é sustentado com suporte de bootstrap de $99 \%$ tendo como sinapomorfias: ausência de tufo de escamas posterolaterais do tegito VI, margem lateral do claspete ventral arredondada; presença de cerda espiniforme subapical do claspete dorsal; ausência de projeção subtriangular ventromediana do edeago; espículas da margem externa da paleta natatória não alcançando a cerda 1-P; Cerda 6-IV simples; flutuador longo; ausência de franja na região anterior do ovo e flutuadores fundidos anteriormente. O Grupo-Lanei ${ }^{+}$é suportado com $75 \%$ de valor 
de bootstrap, com as seguintes sinapomorfias: presença de lobo apicolateral triangular, paralelo ao eixo mediano do claspete ventral; fenda mediana do claspete ventral longa; sulco mediano profundo, Cerda $2-\mathrm{V}$ longa e margens das células coriônicas definidas. O posicionamento das espécies Anopheles lanei e An. sawyeri, tradicionalmente incluídas na seção Argyritarisis, formando um clado com An. lutzii e An. antunesi, consideradas membros da Seção Myzorhynchella, juntamente com An. parvus, indicam que ambas as seções são polifiléticas.

O Grupo-Albitarsis ${ }^{+}$tem baixo valor de bootstrap (51\%) como suporte, pois é sustentado po várias sinapomorfias homoplásticas: ausência de folíolos subapical no edeago; Cerda 2-C distal em relação à linha mediana longitudinal da cabeça; presença de extensão lateral da placa mediana do aparelho espiracular, , superficie dorsal do ovo plana, flutuadores em posição dorsal, colar da micrópila tocando a franja e tubérculos do convés dipostos irregularmente. No entando, os estados dos caracteres 48,43 e 64 , cerda 3-T palmada, Cerda 0-III fortemente desenvolvida e Cerda 1-X longa, respectivamente, encontrados nas larvas são sinapomorfias exclusivas. Neste agrupamento estão presentes $A n$. darlingi e An. albimanus, principais espécies vetoras de Plasmodium spp, causadores de malária humana na Região Neotropical. Além dessas, An. nuneztovari, An. aquasalis, An. trinkae, A. strodei, An. rangeli, An. triannulatus e espécies do Complexo Albitarsis que são vetores locais de agentes causadores de malária.

O Grupo-Darlingi ${ }^{+}$é suportado pelas sinapomorfias: presença de tufo de escamas posterolaterais no tergito II; presença de placa pré-apical do claspete ventral pouco desenvolvida no claspete ventral; Cerda 2-V longa; contorno dos tubérculos do convés liso, sendo que a estrutura coriônica do ovo formando montículos definidos e espículas da margem externa da paleta natatória ultrapassando a cerda 1 P são exclusivas desse grupo. No entanto, na análise de bootstrap este clado não apresenta-se definido, sendo que $A n$. darlingi encotra-se numa politomia com $A n$. albitarsis.

O Grupo-Albimanus ${ }^{+}$tem alto valor de suporte de bootstrap (81\%), pois é sustentado por várias sinapomorfias: faixa basal escura no Tarsômero 5 da perna 
posterior; claspete ventral longo; lobo apicolateral do claspete ventral arredondado; porção apical do claspete ventral definida, claramente separada da porção basal; porção basal do lobo basal do claspete ventral arredondada; haste da cerda 4-P delgada; flutuador longo; lobo basal do claspete ventral globuloso, com pouca expansão lateral e Cerda 1-P palmada, sendo as duas últinas não homoplásticas.

O Grupo-Braziliensis tem baixo suporte de bootstrap (68\%), pois é sustentado pelos estados de caracteres presença da estrutura refringente do claspete ventral e colar da micrópila não tocando a franja, ambos homoplásticos. No entanto, além dessas sinapomorfias, fenda mediana larga do claspete ventral e cerda 4-M curta são sinapomorfias exclusivas do clado. A espécie An. braziliensis considerada pertencente à Seção Argyritarsis, encontra-se, nesta análise, posicionada entre as espécies da Seção Albimanus o que torna o grupo parafilético.

O grupo Nuneztovari ${ }^{+}$apresenta como suporte de bootstrap $64 \%$, sendo sustentado pelas seguintes sinapomorfias não homoplásticas: presença de espícula na superficie ventral do claspete ventral da base ao ápice, presença de placa pré-apical bastante desenvolvida no claspete ventral e placa pré-apical em posição distal em relação à borda apical do claspete ventral. O grupo Nuneztovari ${ }^{+}$representa o Subgrupo Oswaldoi (Fig. 1B) proposto por FARAN (1980). Entretanto, as relações filogenéticas entre as espécies propostas pelo autor diferem das encontradas neste trabalho, exceto entre An. galvaoi e An. evansae que encontram-se posicionadas como espécies-irmãs.

O Grupo-Rondoni ${ }^{+}$tem como sinapomorfias: o lobo basal globuloso, com grande expansão lateral do claspete ventral; longas espiculas da margem basal do claspete ventral, ambas sinapomorfias não homoplásticas; Cerda 2-C proximal em relação à linha mediana longitudinal da cabeça e paredes da franja mais altas medianamente do que lateralmente

O Grupo-Strodei ${ }^{+}$está posicionado como grupo-irmão do Grupo-An anomalophyllus ${ }^{+}$sendo suportados pelas sinapomorfias: plastrão cobrindo o pólo posterior do ovo e franja formando corola dorsal no pólo anterior do ovo. O Grupo- 
Strodei ${ }^{+}$é corroborado por duas sinapomorfias, a presença de lobo apicolateral triangular, perpendicular ao eixo mediano e flutuadores fundidos anteriormente, ambos homoplásticos.

O Grupo-Trinkae ${ }^{+}$é sustentada pela margem distal reta do claspete ventral; Cerda 1-A curta; posição da cerda $2-C$ proximalem relação à linha mediana longitudinal da cabeça e plastrão na extremidade posterior cobrindo o pólo posterior do ovo. A relação entre An. rangeli e An. benarrochi é sustentada pelo tubérculo da cerda parabasal longo; posição descontínua da franja em relação à margem anterior do flutuador e paredes da franja subiguais, sendo todos homoplásticos.

O grupo-Anomalophyllus ${ }^{+}$é suportado por apenas uma sinapomorfia homoplástica, fenda mediana curta do claspete ventral. O clado formado pelo GrupoEvansae $^{+}$e Grupo-Oswaldoi ${ }^{+}$, tem como sinapomorfias: a Cerda 2-C distal em relação à linha mediana longitudinal da cabeça; presença de franja não formando corola no pólo anterior do ovo e plastrão cobrindo o pólo na extremidade posterior do ovo.

O grupo-Oswaldoi é sustentado pela Cerda $2-\mathrm{V}$ curta e por apresentar a parede da franja mais baixa medianamente do que lateralmente. As espécies GrupoAquasalis $^{+}$apresenta como sinapomorfia a presença de espículas ultrapassando a metade basal do claspete ventral.

Os valores de bootstrap obtidos para alguns clados foram baixos (Fig. 14), provavelmente devido ao grande número de "missing data", devido a falta de dados de larva, pupa e ovos para algumas espécies. No cladograma de consenso de maioria, as relações entre as espécies de Nyssorhynchus foram pouco resolvidas, apresentando uma politomia com An. parvus, An. argyritarsis, Grupo-Lutzii ${ }^{+}$e Grupo-Lanei ${ }^{+}$e Grupo-Albitarsis ${ }^{+}$observado no cladograma de consenso das árvores obtidas por pesagem não foram confirmadas. O grupo Braziliensis ${ }^{\dagger}$ e seus subgrupos não foram sustentadosa na análise de bootstrap, provavelmente devido à presença de muitos caracteres homoplásticos. É provavel que os caracteres de larva, pupa e ovos, 
que muitas vezes apresetaram homoplásticos, tenham influenciado os baixos valores de bootstrap.

A existência de vários vetores no subgênero Nyssorhynchus, bem como em algumas espécies de Kerteszia, grupo-irmão de Nyssorhynchus, e em outros subgêneros de Anopheles sugerem que a capacidade de transmissão de Plasmodium é plesiomórfica em Nyssorhynchus. Sendo assim, nas espécies de Nyssorhynchus, que não possuem habilidade para a transmissão, pode ter ocorrido uma perda secundária dessa capacidade. No entanto, para se entender as relações entre Nyssorhynchus e as várias espécies de Plasmodium seriam necessários estudos de co-evolução, envolvendo caracteres morfológicos, moleculares, ecológicos e epidemiológicos.

Apesar da vasta quantidade de estudos que vêm sendo realizados para Nyssorhynchus, esta é a primeira proposta filogenética englobando todo o subgênero. No entando, é importante ressaltar que um cladograma representa uma hipótese de relação filogenética entre espécies, obtida a partir de determinado conjunto de caracteres. É provável que, à medida que novos conhecimentos sobre o subgênero Nysorhynchus forem adquiridos e que os problemas relacionadas à existência dos complexos de espécies e taxonomia do grupo sejam resolvidos, as relações entre as espécies propostas neste trabalho sejam modificadas. 


\subsection{Distribuição geográfica}

4.3.1 Distribuições geográficas obtidas para as espécies de Nyssorhynchus

O subgênero Nyssorhynchus está amplamente distribuido desde o sul dos Estado Unidos até a América do sul e Ilhas do Caribe. As distribuições conhecidas, obtidas a partir de localidades presentes na literatura, para as espécies do subgênero Nyssorhynchus, serão apresentadas a seguir: 
An. ininii

A distribuição de $A n$. ininii é conhecida somente para a localidade-tipo Minas de Saint-Ellie, na Guiana Francesa, e para localizadas no Pará, região norte do Brasil (Fig. 14).

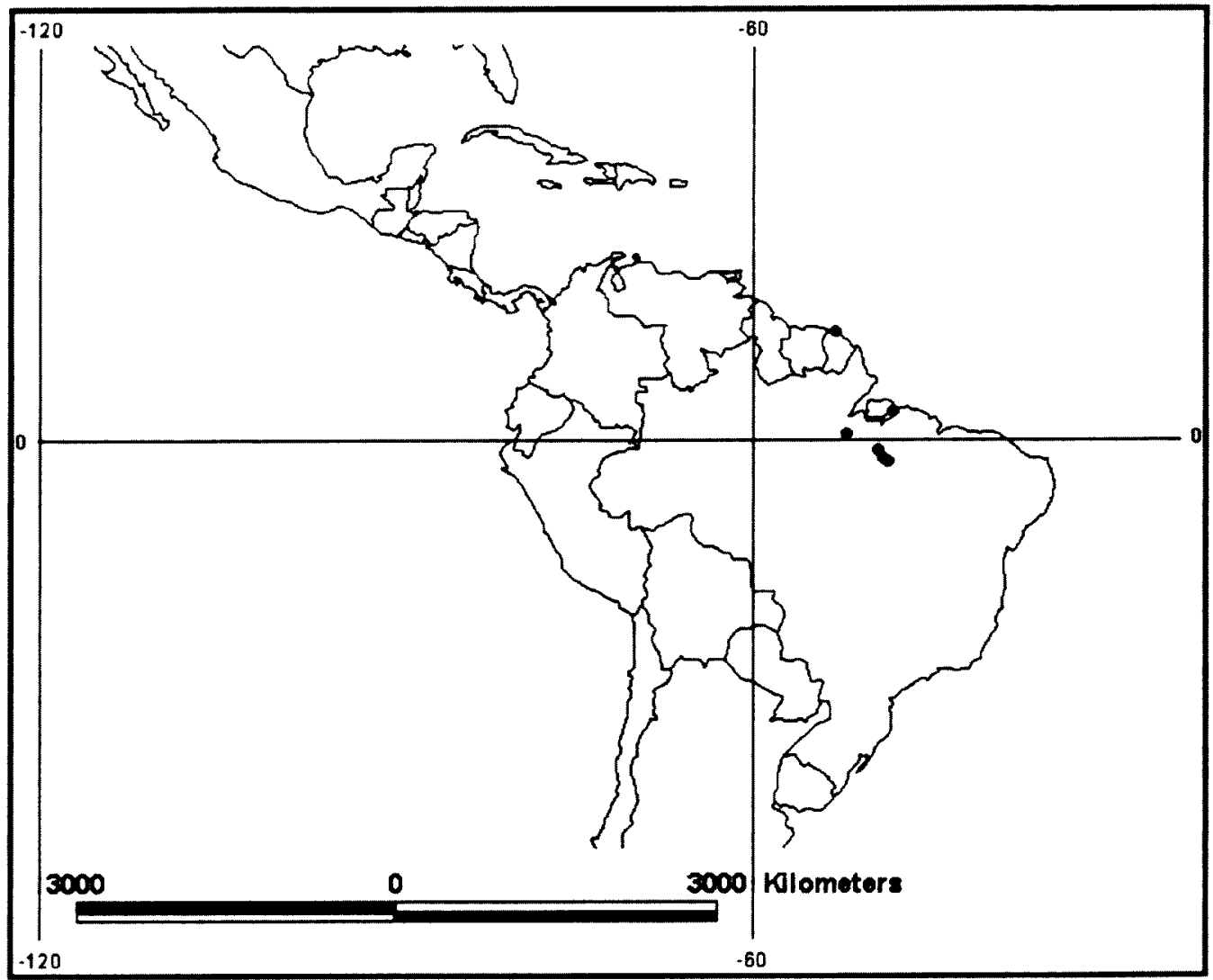

Fig. 14. Distribuição geográfica de An. ininii para a Região Neotropical. 
An. aquasalis

An. aquasalis está amplamente distribuída, principalmente, ao longo da Costa do Atlântico desde a Costa Rica até o sudeste do Brasil e em Ilhas do Caribe (Trinidade e Tobago, Guadeloupe, Martinica, Montserrat, Grenada, Antígua, Dominica, Saint Lucia, Saint Kitts, Saint Vincent), mas pode ser encontrado em regiões mais afastadas do litoral (Fig.15).

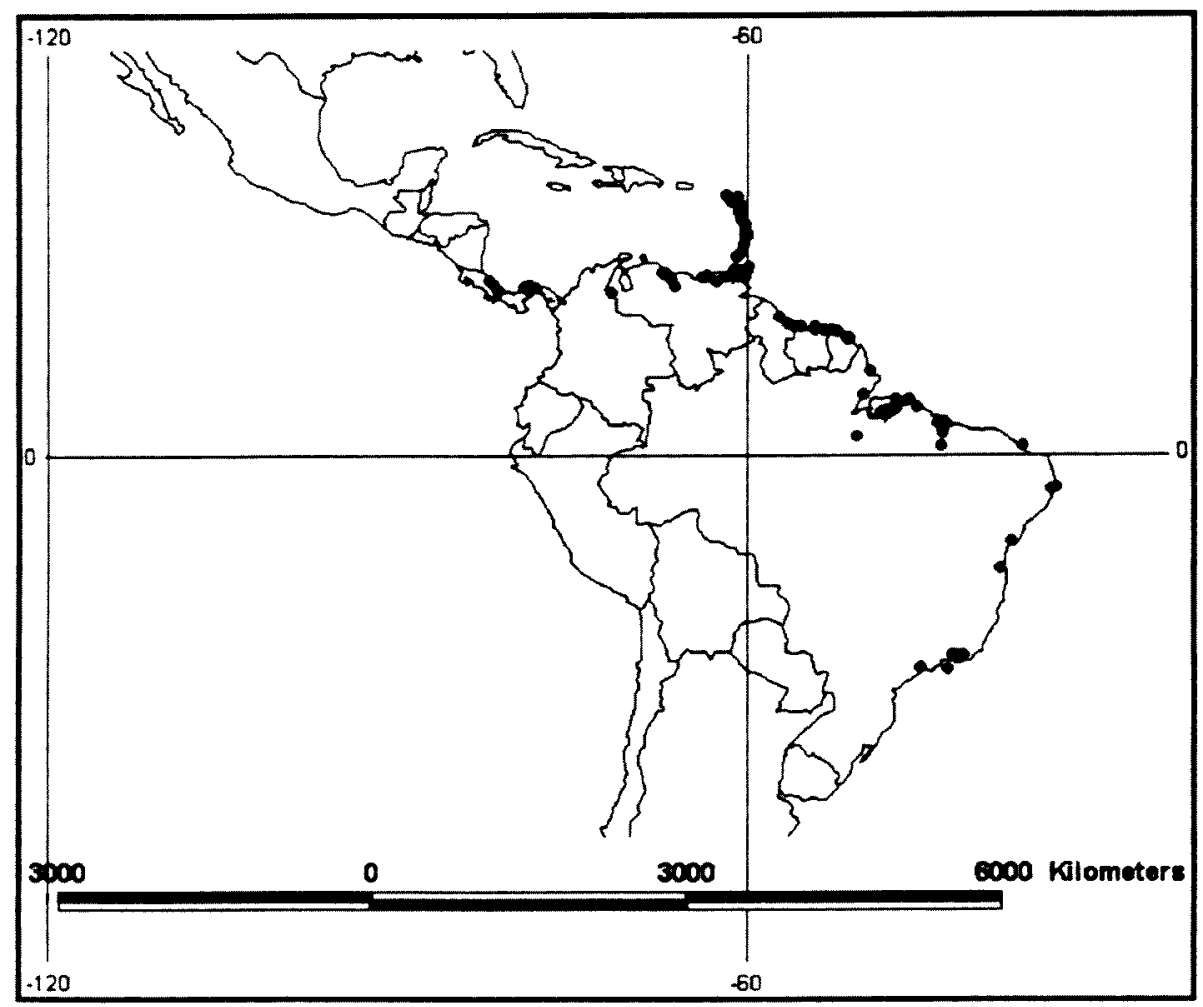

Fig.15. Distribuição geográfica de An. aquasalis para a Região Neotropical. 
An. oswaldoi

An. oswaldoi apresenta-se amplamente distribuída desde o Panamá até o sudeste brasileiro, exceto no Equador (Fig. 16).

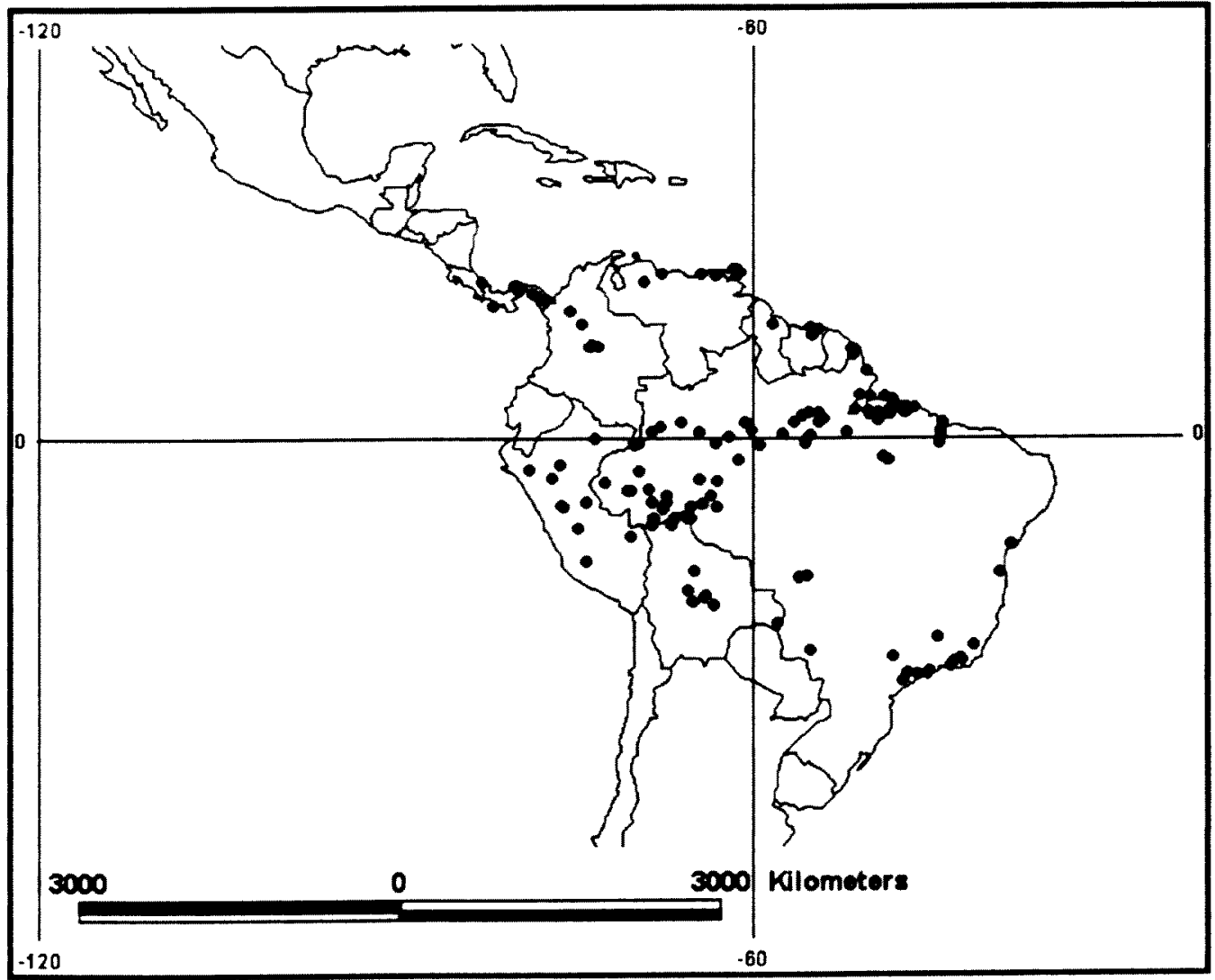

Fig. 16. Distribuição geográfica de An. oswaldoi para a Região Neotropical. 
An. konderi

A presença de An. konderi é conhecida na região norte do Brasil, para sua localidade-tipo Coarí, Amazonas, e para a Bolívia (Fig. 17).

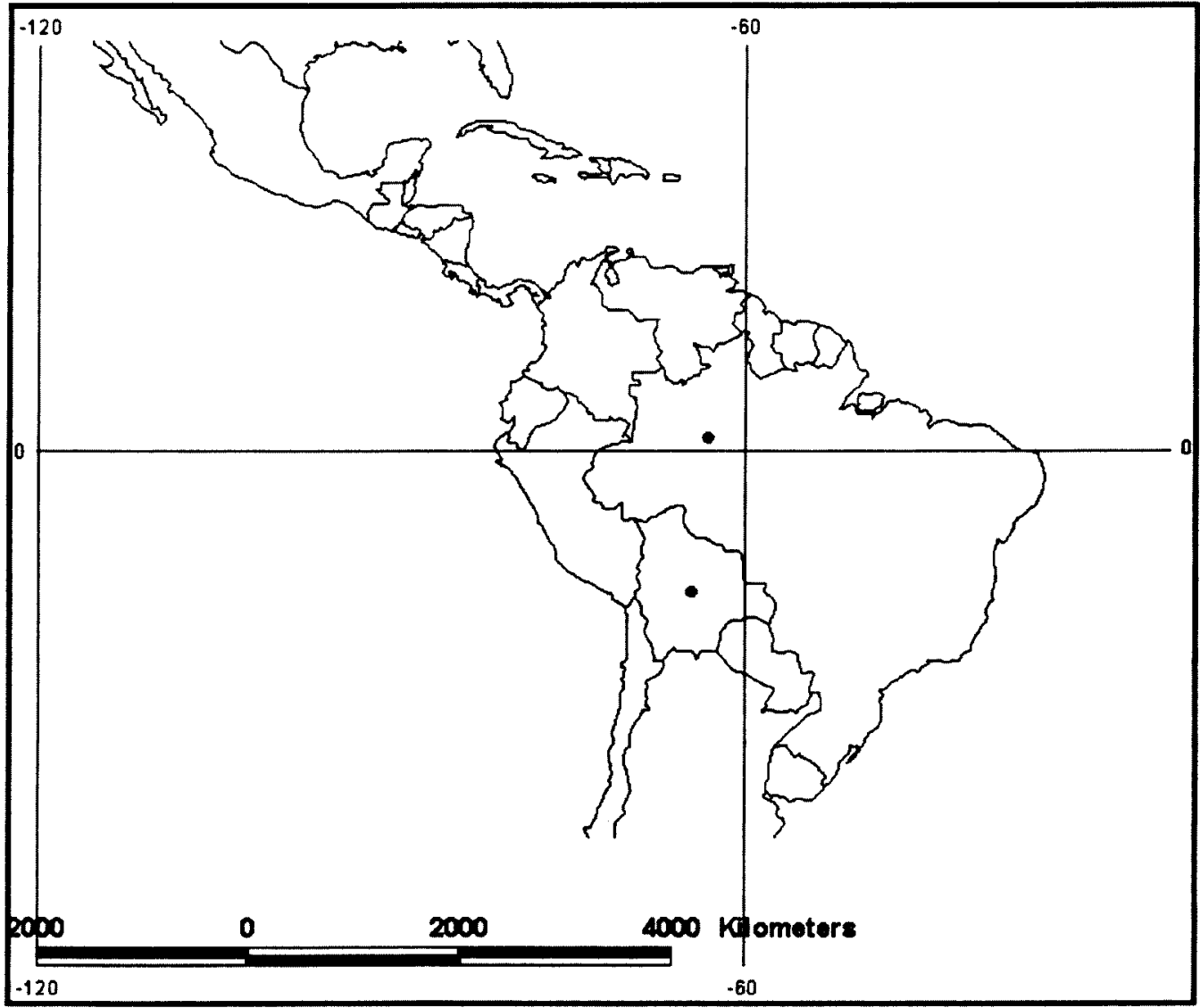

Fig. 17. Distribuição geográfica de An. konderi para a Região Neotropical. 
An. evansae

An. evansae apresenta-se distribuida no Brasil, numa faixa extensa que se estende do Maranhão até sul de São Paulo e em Rondônia. Esta espécie também está presente do norte do Peru até o noroeste da Argentina (Fig. 18).

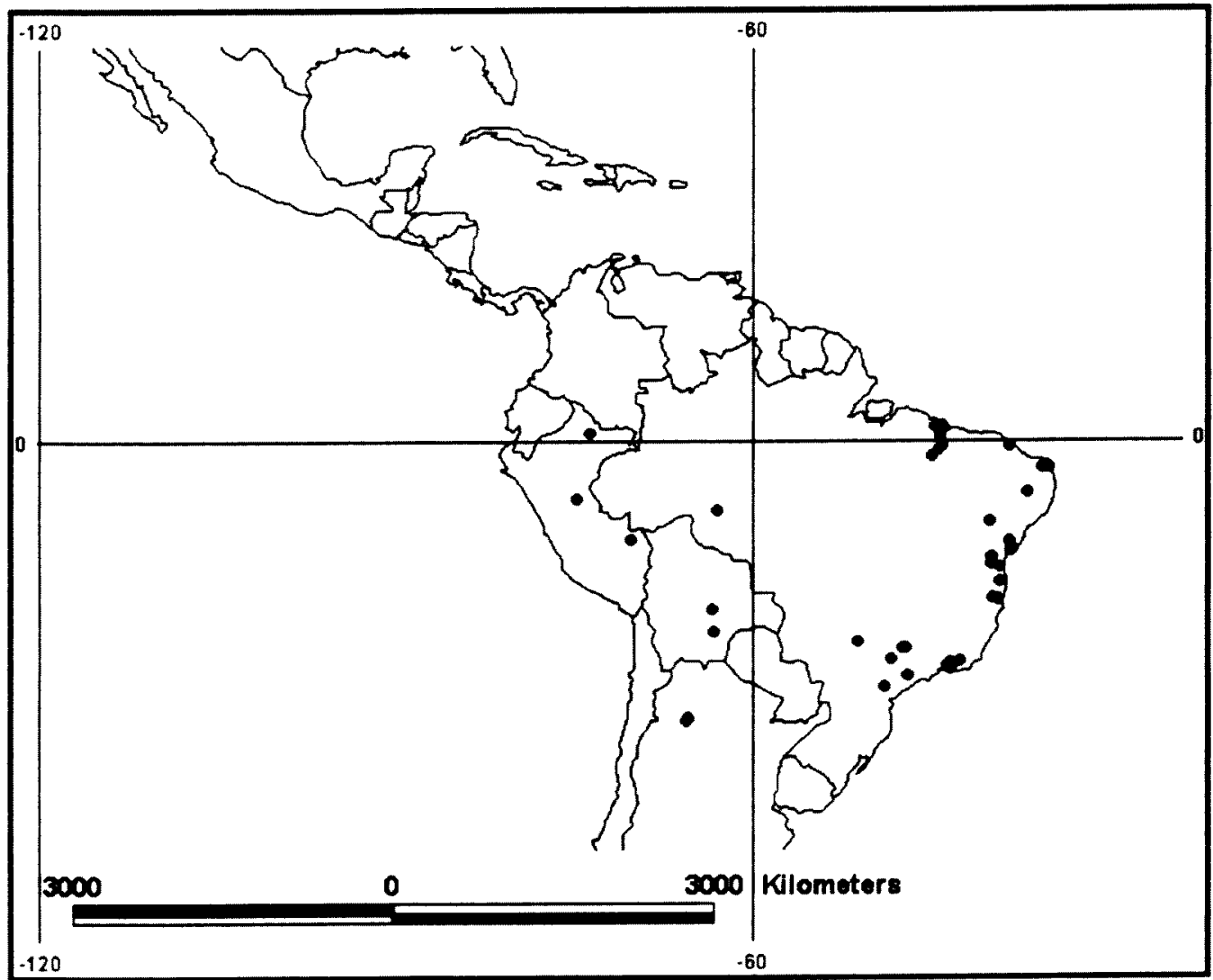

Fig. 18. Distribuição geográfica de An. evansae para a Região Neotropical. 
An. galvaoi

An. galvaoi apresenta-se distribuída numa faixa que vai do sudoeste do Perú até o Acre e Rondônia no Brasil, sendo encontrada, também, no sudeste brasileiro e no Maranhão (Fig. 19).

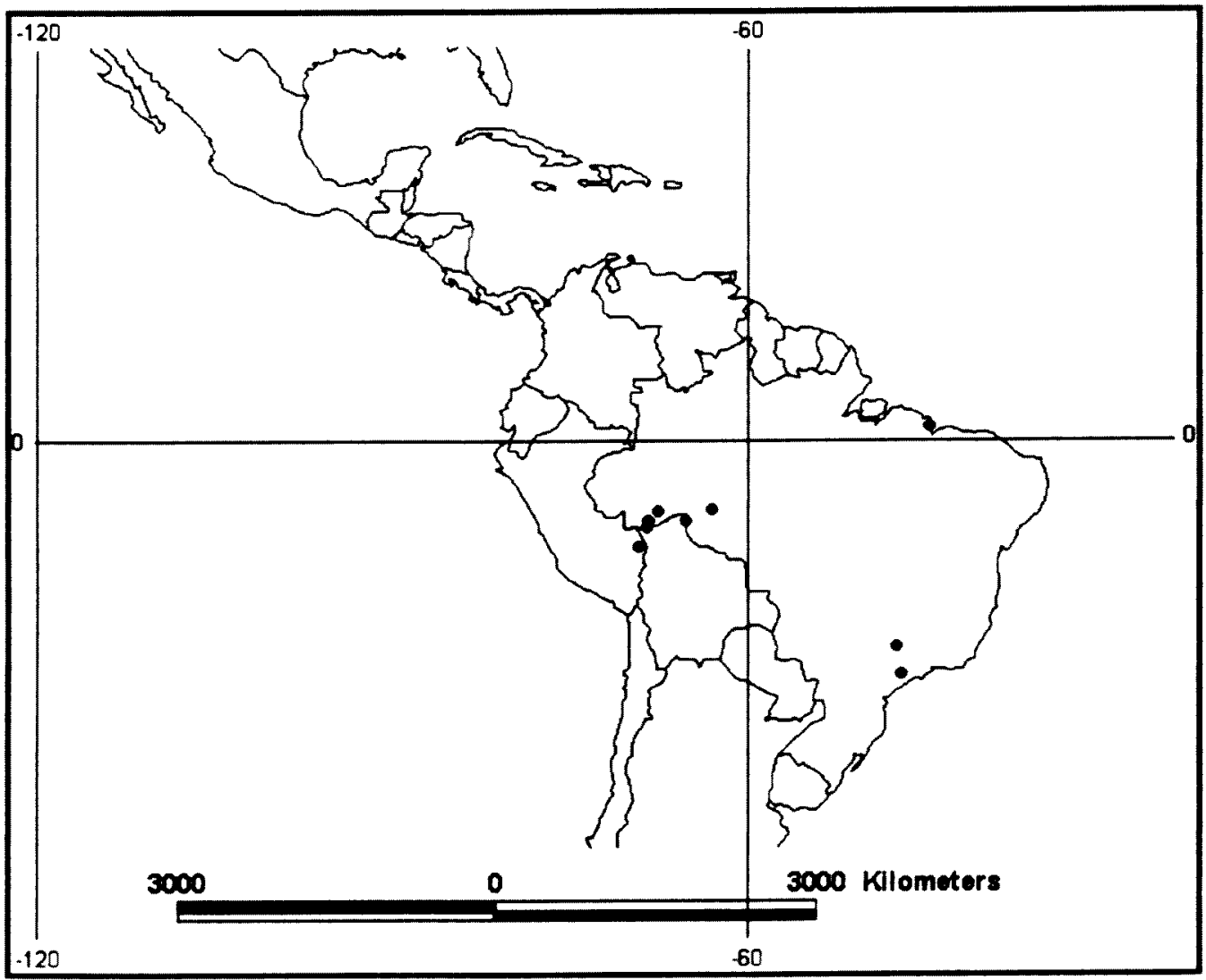

Fig. 19. Distribuição geográfica de An. galvaoi para a Região Neotropical. 
An. anomalophyllus

An. anomalophyllus parece estar restrita à América Cetral, estando presente na Costa Rica e Panamá (Fig. 20).

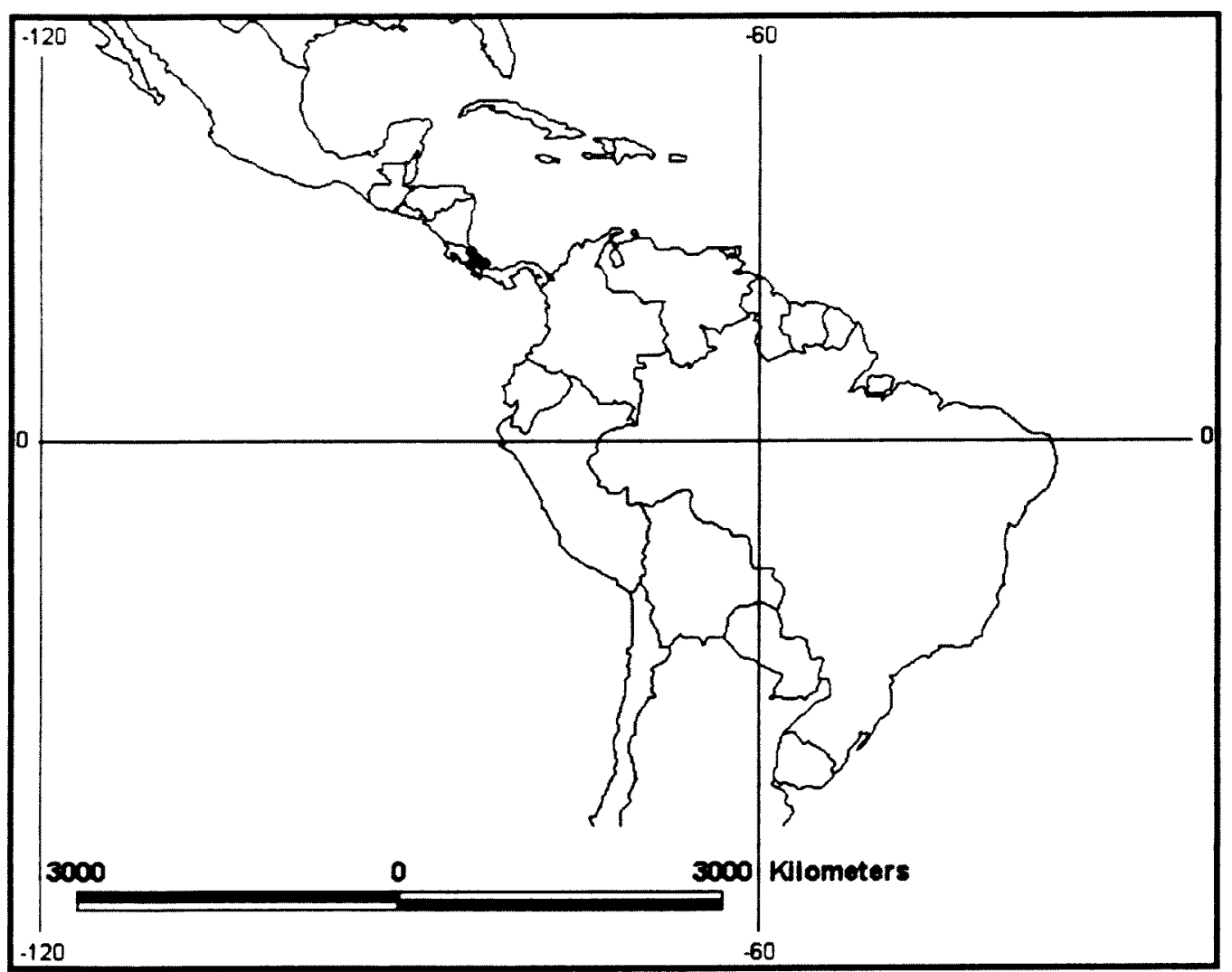

Fig. 20. Distribuição geográfica de An. anonalophyllus para a Região Neotropical. 
An. rangeli

An. rangeli está amplamente distribuída desde a Venezuela, norte do Brasil, Colômbia, Equador, Peru até o Bolívia (Fig. 21).

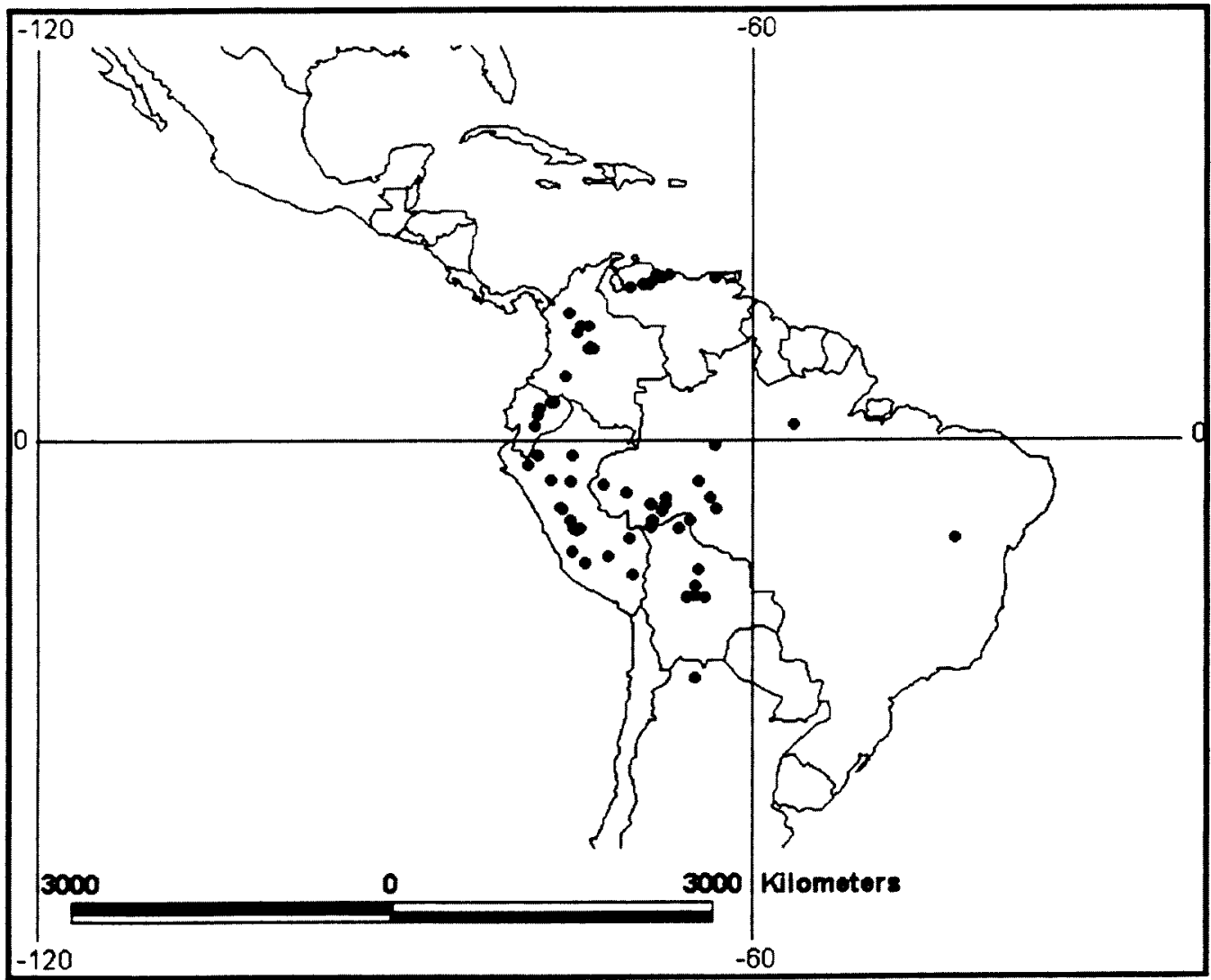

Fig. 21. Distribuição geográfica de An. rangeli para a Região Neotropical. 
An. benarrochi

An. benarrochi apresenta-se amplamente distribuida no Peru, podendo ser encontrada na Colômbia e Venezuela. Para o Brasil existem registros na região noroeste e no estado de São Paulo (Fig. 22).

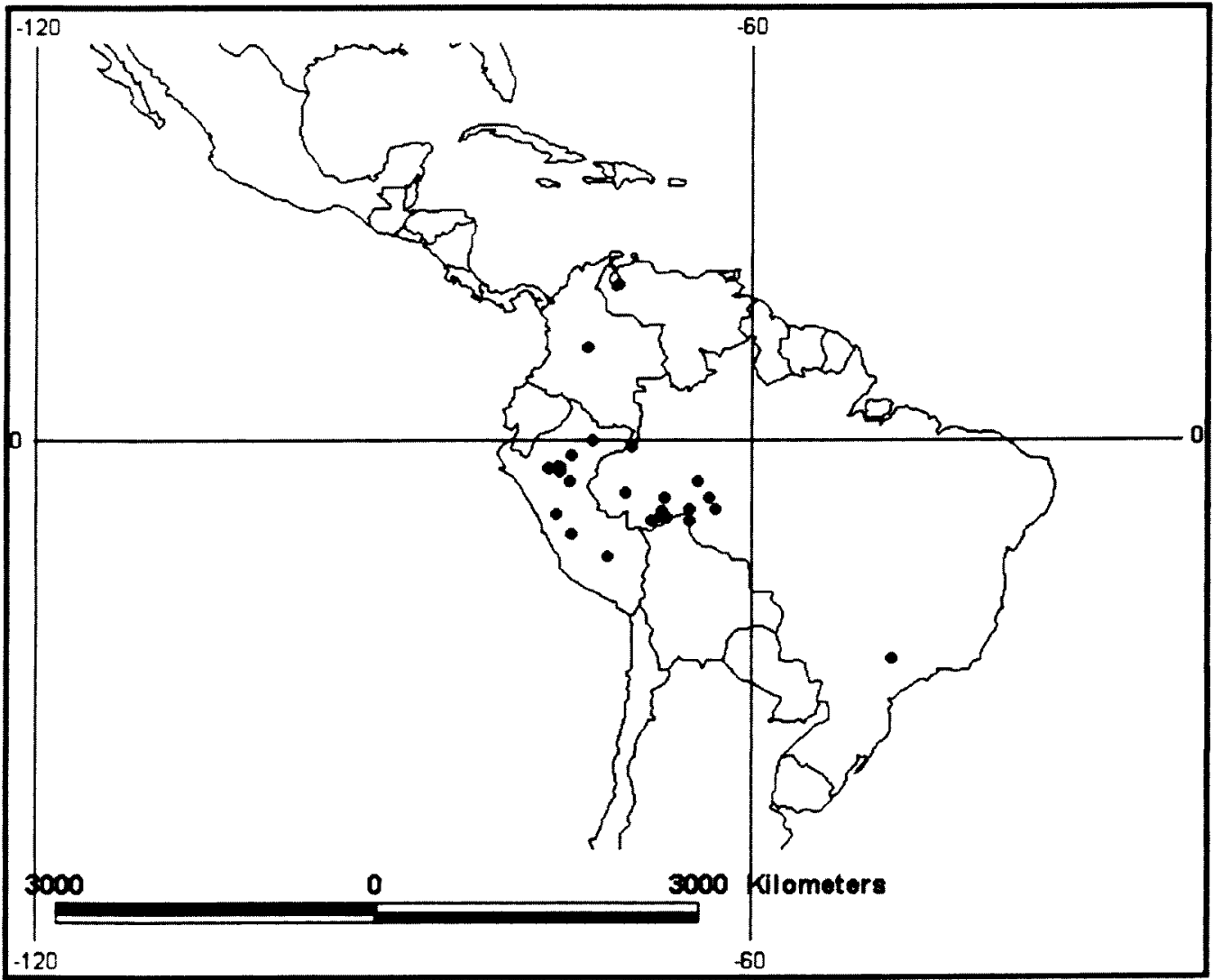

Fig. 22. Distribuição geográfica de An. benarrochi para a Região Neotropical. 
An. trinkae

An. trinkae ocorre numa faixa que vai da Colômbia até a Bolívia (Fig. 23).

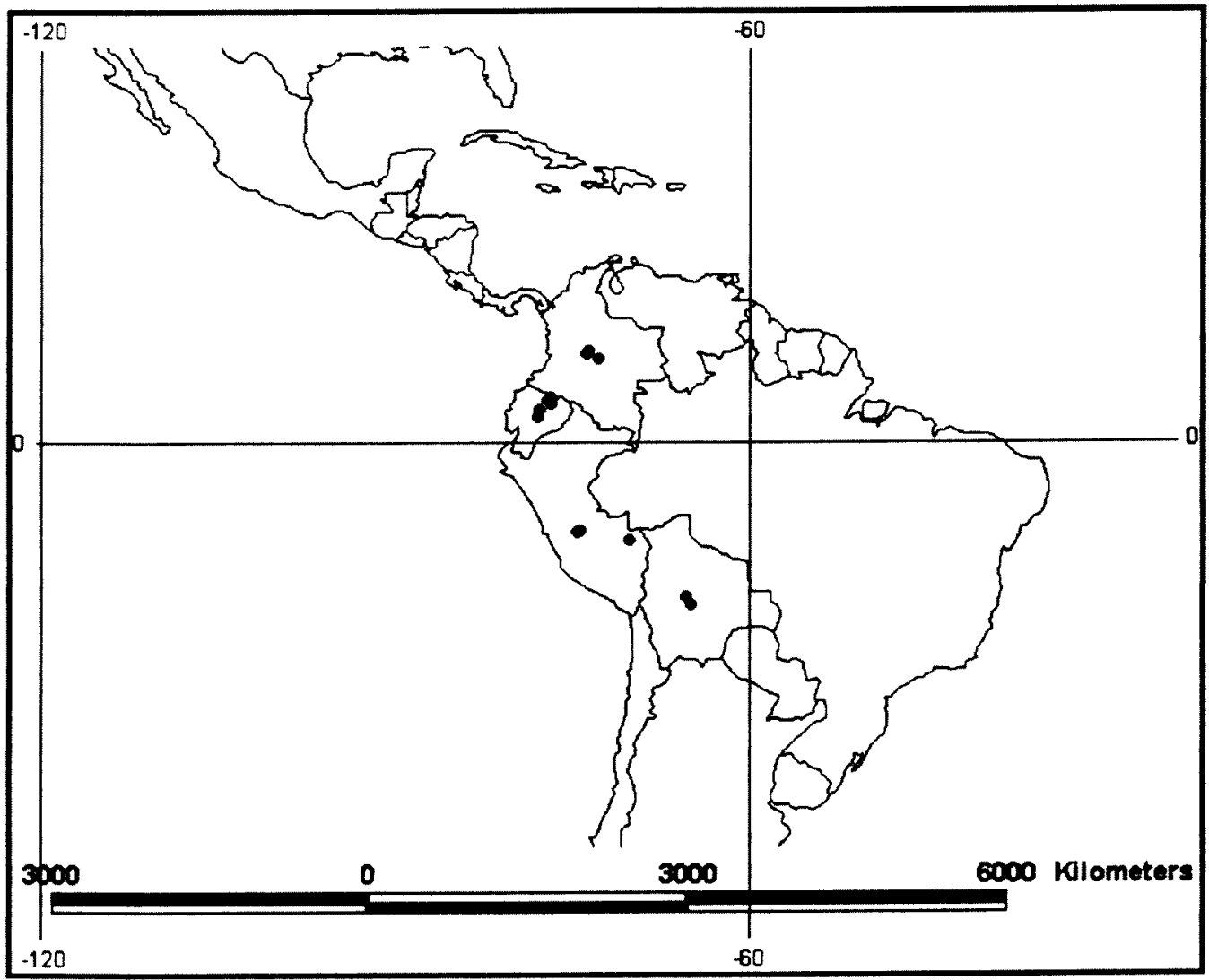

Fig. 23. Distribuição geográfica de An. trinkae para a Região Neotropical. 
An. strodel

An. strodei apresenta-se amplamente distribuída, desde o Panamá, Venezuela, Colômbia, alcançando o norte da Argentina e sudeste do Brasil (Fig. 24).

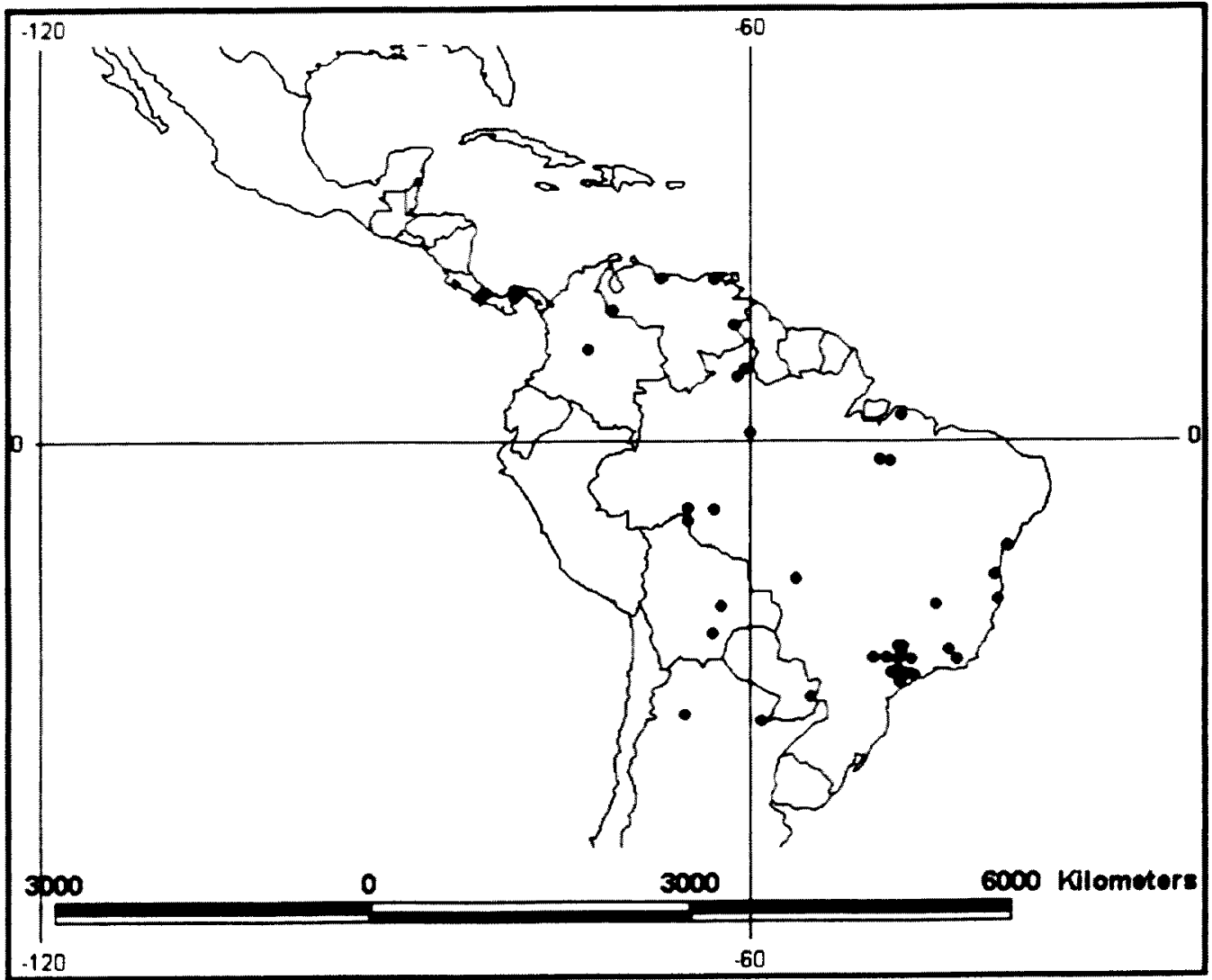

Fig. 24. Distribuição geográfica de An. strodei para a Região Neotropical. 
An. rondoni

An. rondoni está distribuída numa faixa que vai do Acre, norte do Brasil, até o norte da Argentina, atingindo a região sudeste brasileira (Fig. 25).

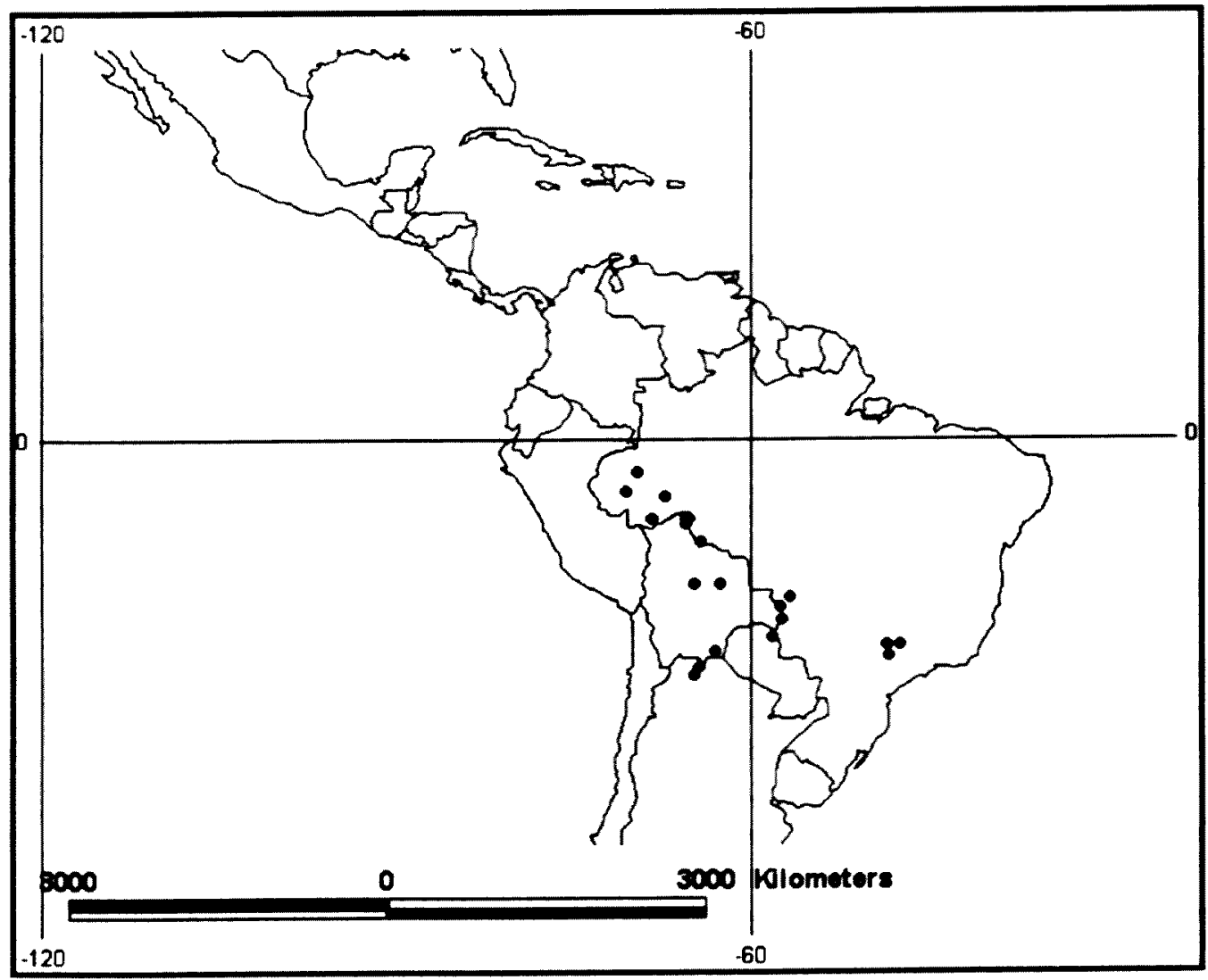

Fig. 25. Distribuição geográfica de $A n$. rondoni para a Região Neotropical. 
An. nuneztovari

An. nuneztovari está amplamente distribuída desde o Panamá até a Bolivia e Norte do Brasil, exceto no Equador (Fig. 26).

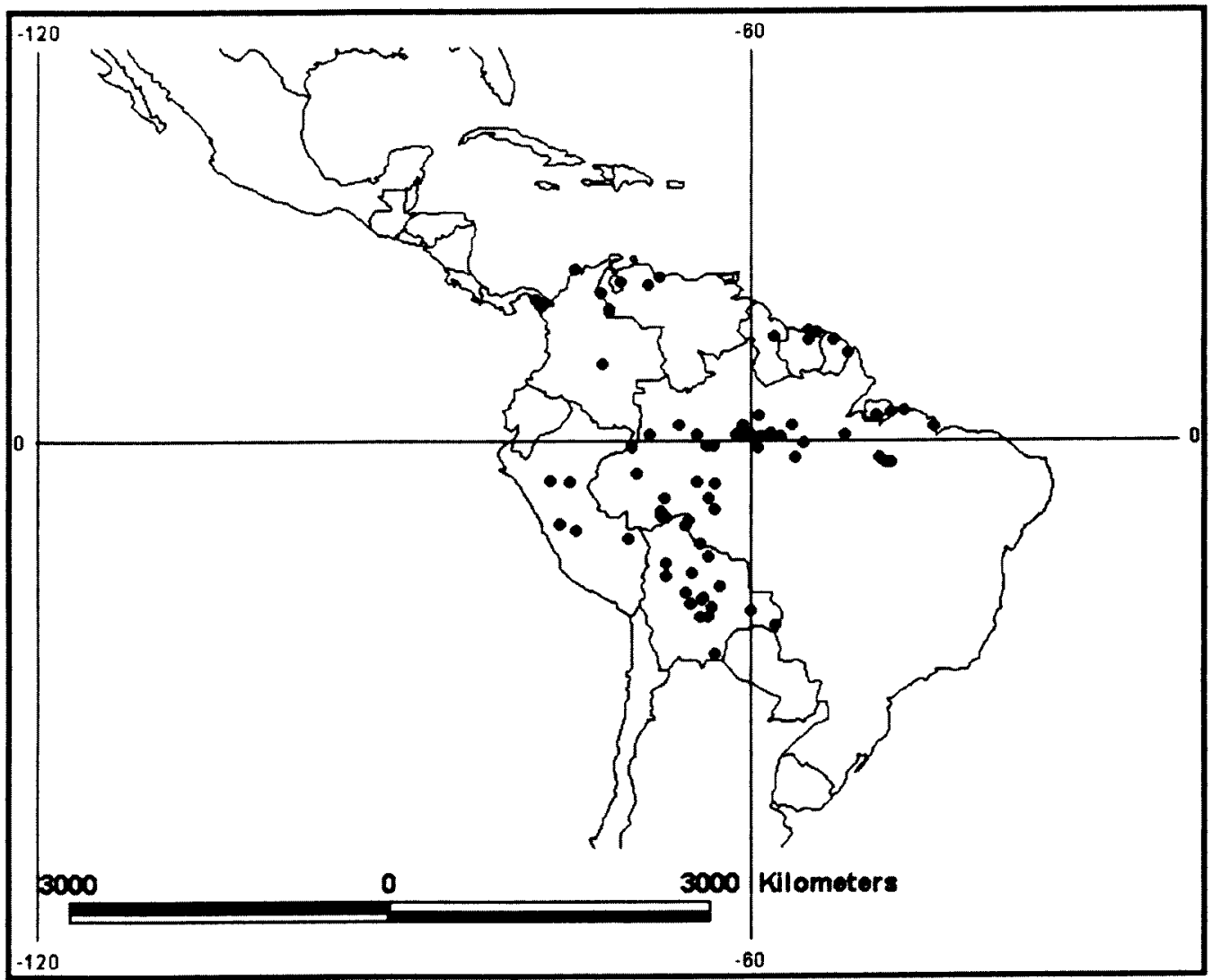

Fig. 26. Distribuição geográfica de An. nuneztovari para a Região Neotropical. 
An. braziliensis

An. braziliensis apresenta-se amplamente distribuída do norte da América do sul até a Bolívia e Brasil (Fig. 27).

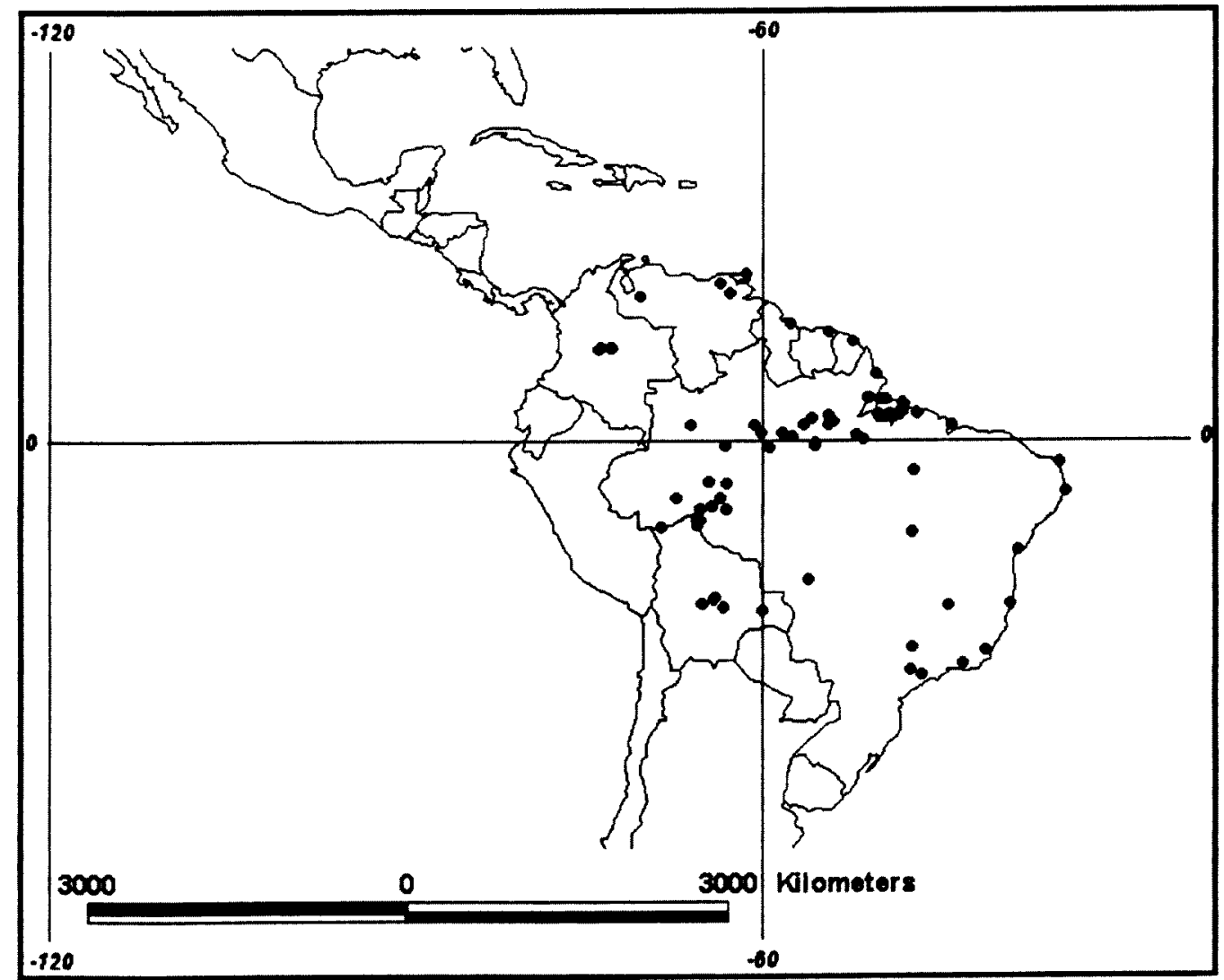

Fig. 27. Distribuição geográfica de An. braziliensis para a região Neotropical. 
An. triannulatus

An. triannulatus está amplamente distribuída desde o Panamá até a Guiana Francesa, alcançando o norte da Argentina, o Paraguai e o sudeste do Brasil (Fig. 28).

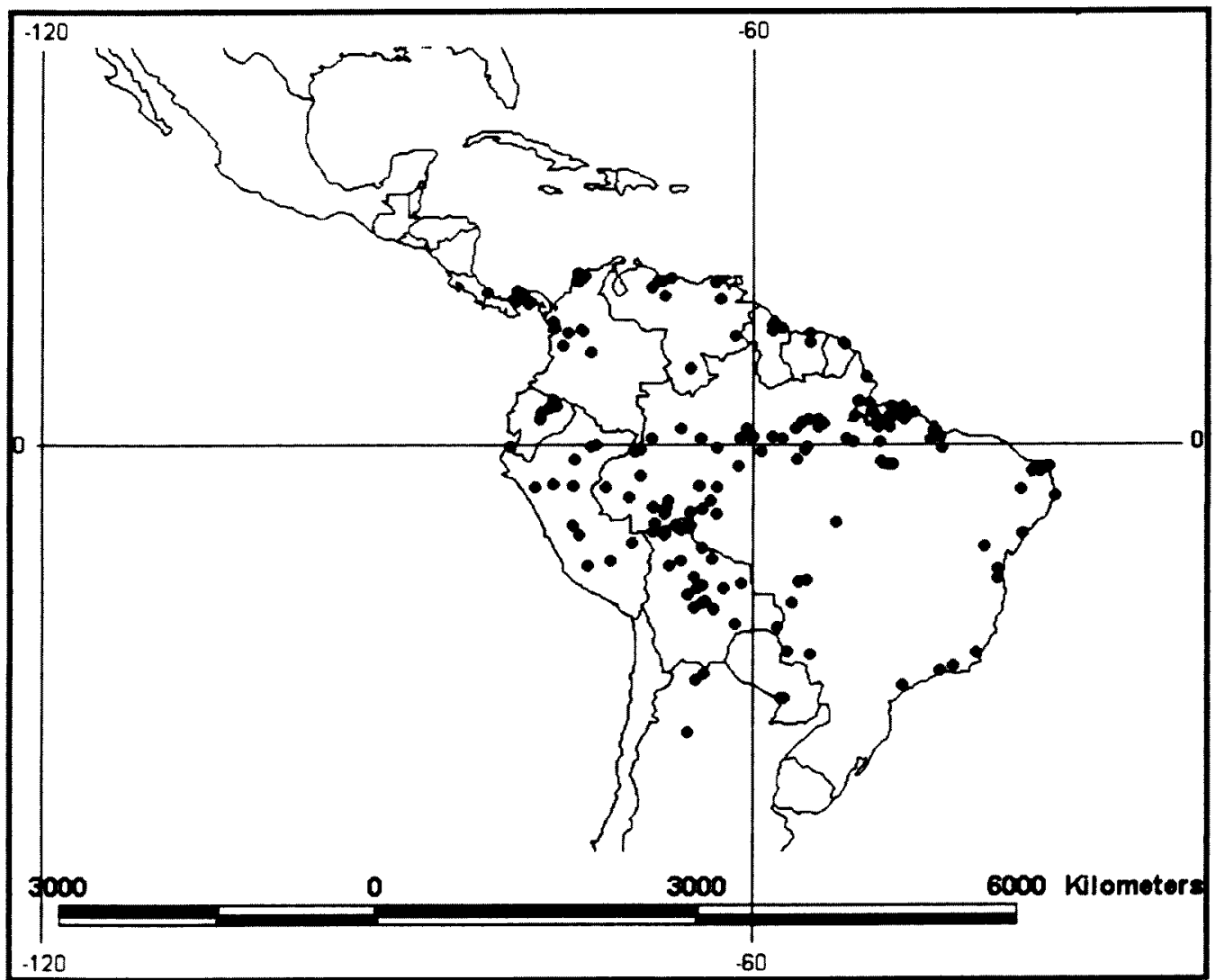

Fig. 28. Distribuição geográfica de An. triannulatus para a Região Neotropical. 
An. halophyllus

An. halophyllus é somente conhecida na sua localidade-tipo, Salobra, Mato Grosso do Sul, no Brasil (Fig. 29).

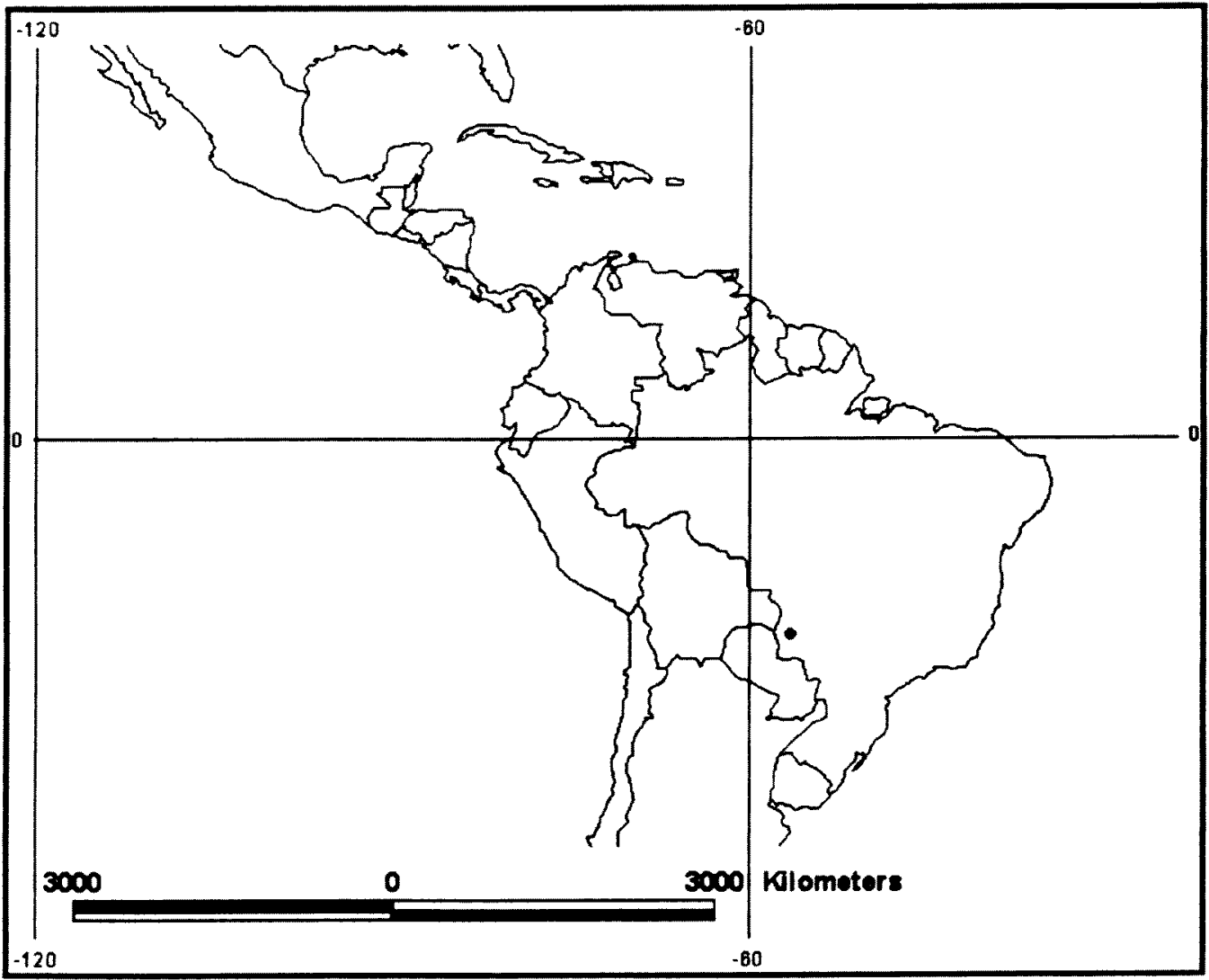

Fig. 29. Distribuição geográfica de An. halophyllus para a Região Neotropical. 
An. albimanus

A espécie An. albimanus é encontrada no extremo sul dos Estados Unidos (Texas e Flórida) e norte do México, estando amplamente distribuída desde os litorais leste e oeste do México até a região noroeste da América do Sul (Venezuela, Colômbia, Equador e Peru) e nas ilhas do Caribe (Fig. 30).

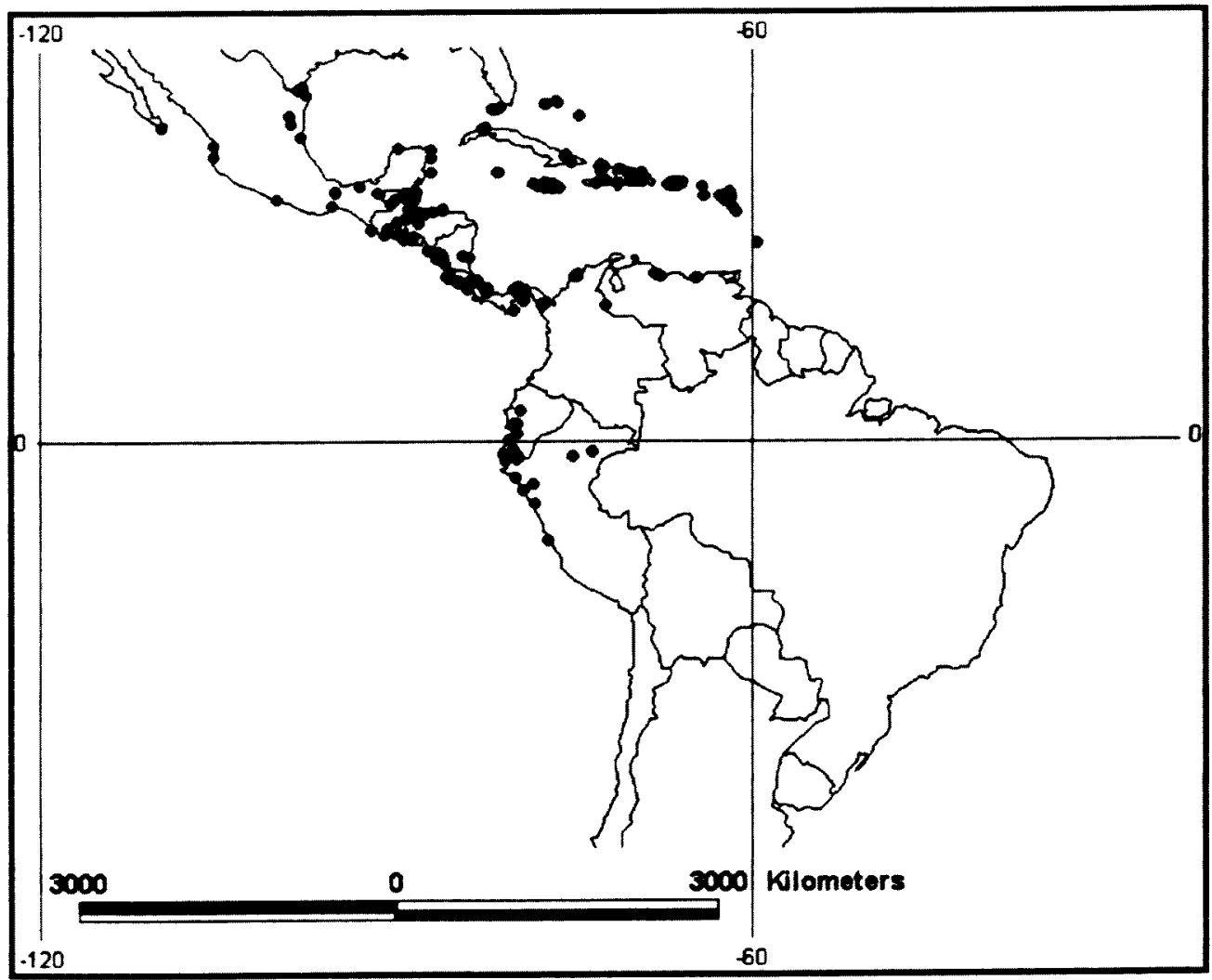

Fig.30. Distribuição geográfica de An. albimanus para a Região Neotropical. 
An. darlingi

Esta espécie apresenta-se distruibuída do sul do México, Belize, El Salvador, Guatemala até Honduras, não sendo registrada ainda para os outros países da América Central. Na América do sul, está amplamente distribuída na Venezuela, Colômbia, Guiana, Suriname, Guiana Francesa, Peru, Bolivia, Colômbia, Brasil e norte da Argentina (Fig. 31).

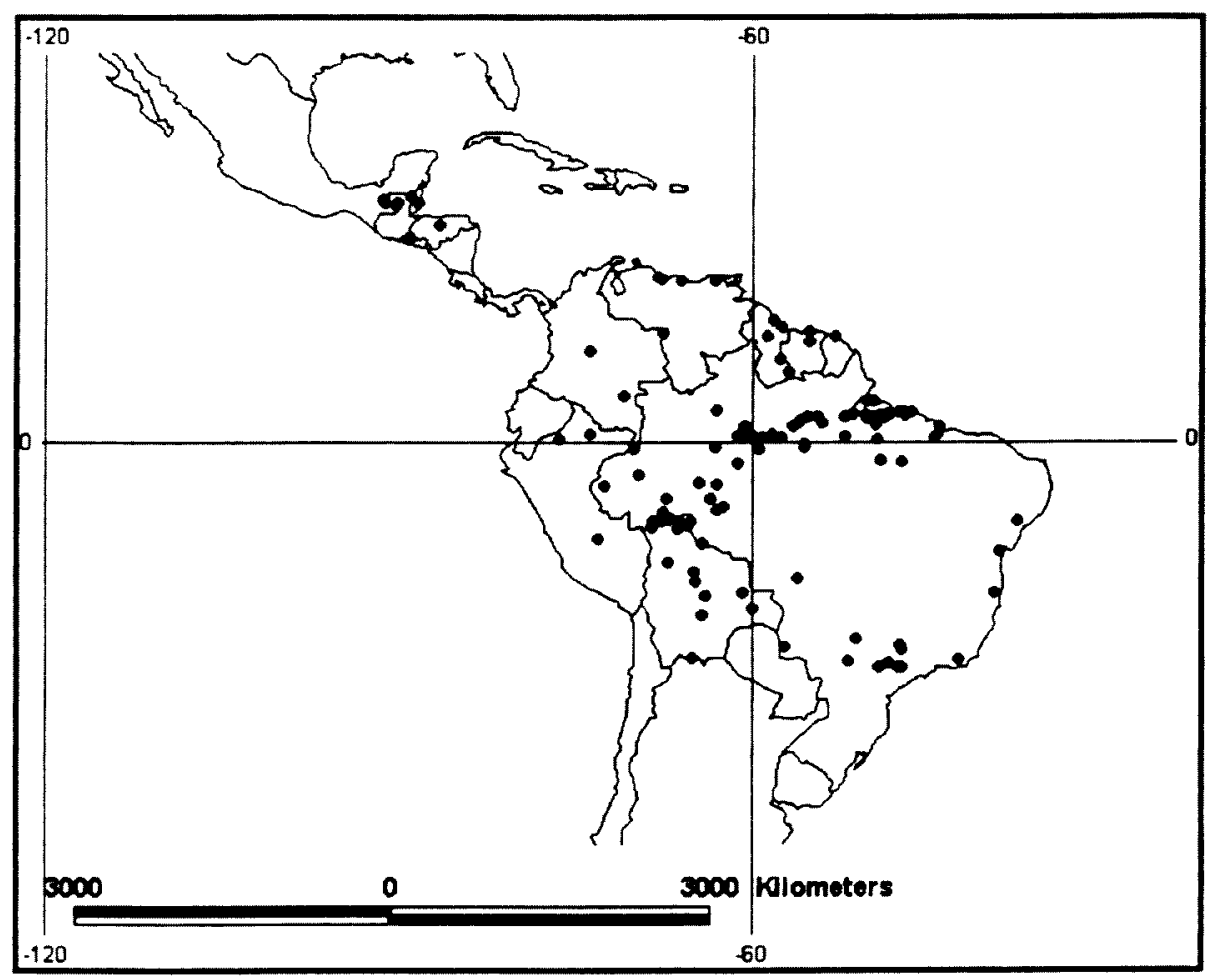

Fig. 31. Distribuição geográfica de An. darlingi para a Região Neotropical. 
An. albitarsis s.s.

An. albitarsis está distribuida desde a Argentina (na região de Corrientes, Posadas e Baradero), sudeste do Paraguai (na região do Alto Paraná) até o Brasil, na região do litoral sul de São Paulo e Norte do Paraná (Fig. 32).

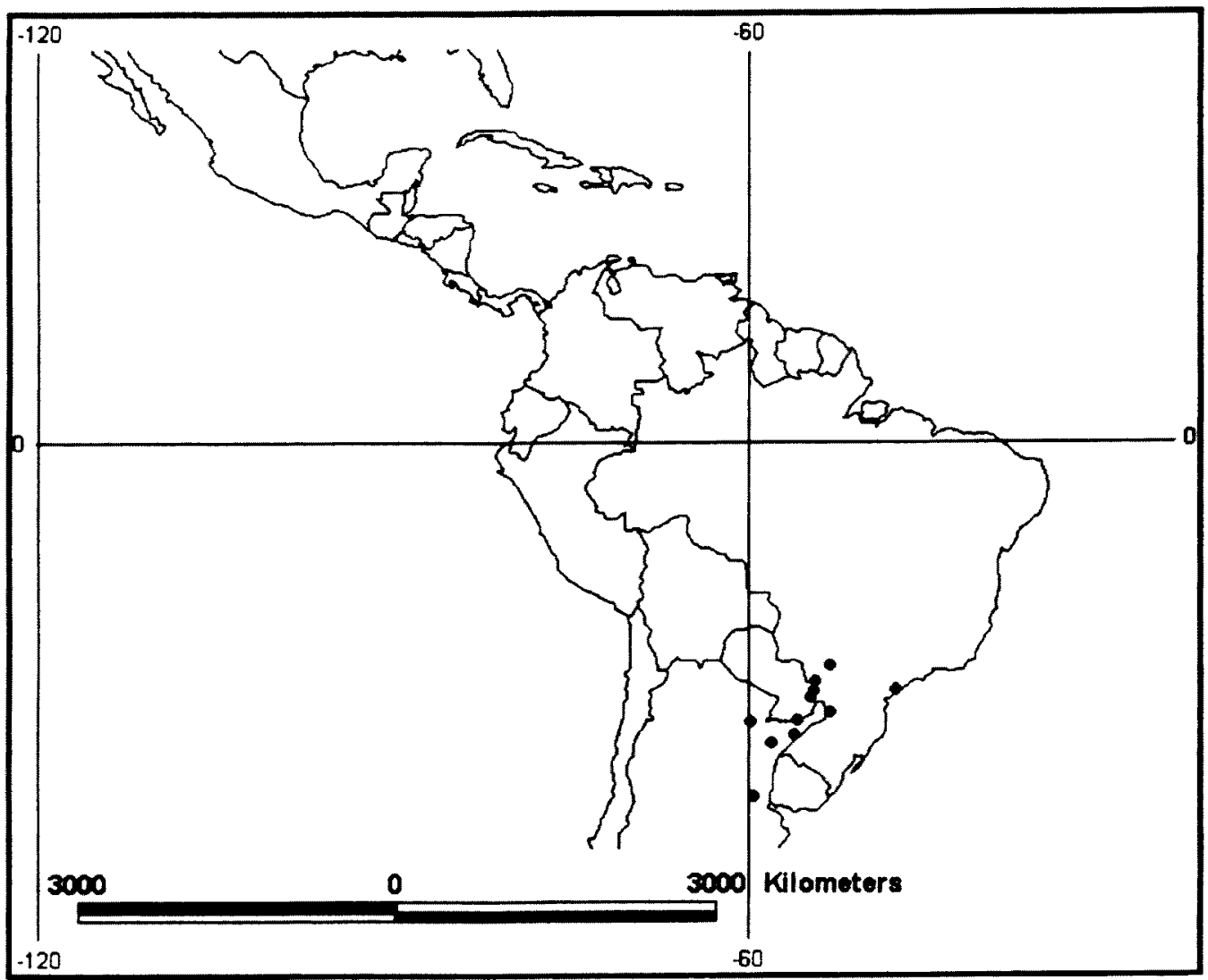

Fig. 32. Distribuição geográfica de An. albitarsis s.s para a Região Neotropical. 
An. albitarsis B

An albitarsis B apresenta-se amplamente distribuida no Brasil, sendo encontrada na costa brasileira, desde o Pará até o litoral sul de São Paulo, e no Mato Grosso e Paraná (Fig. 33).

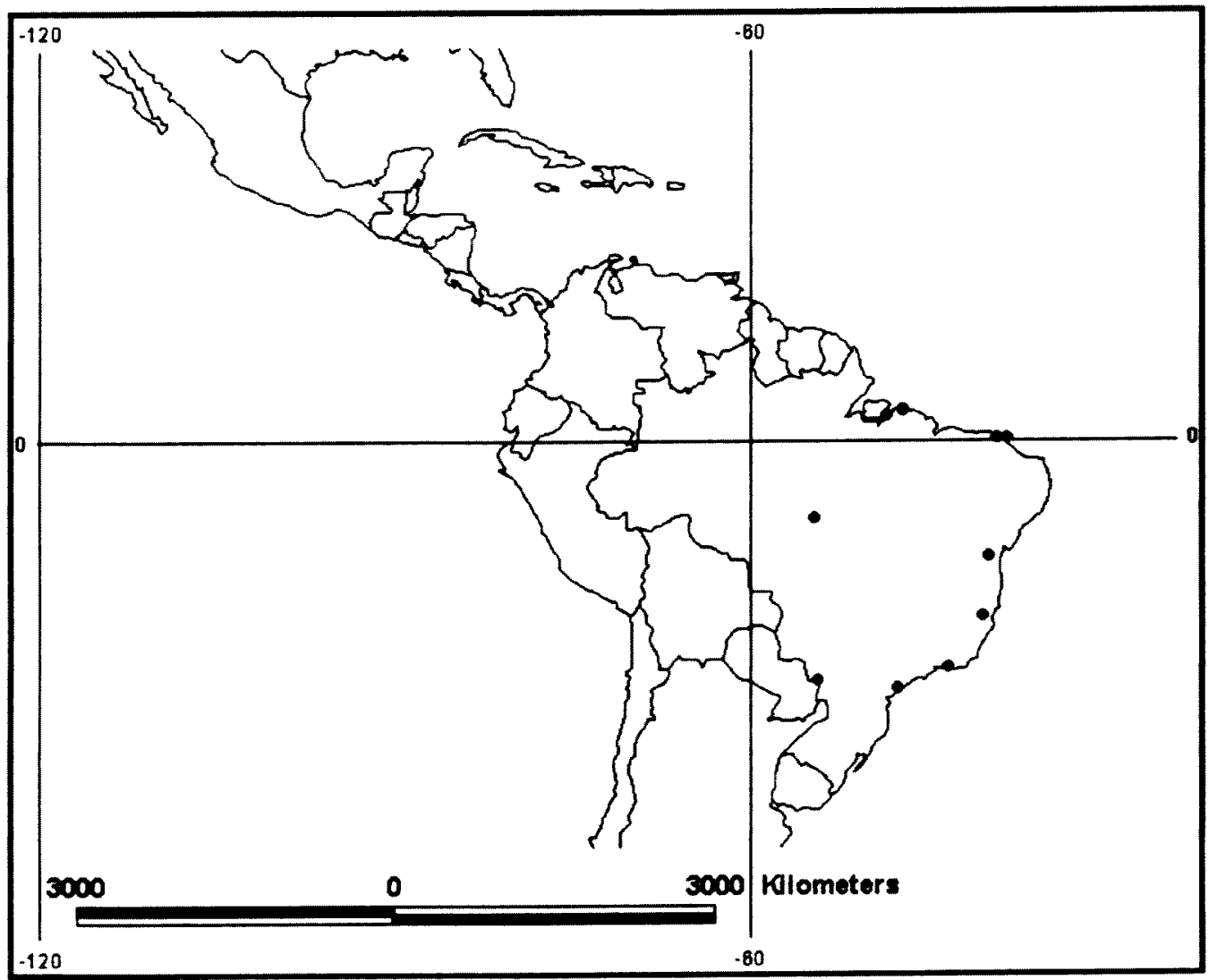

Fig. 33. Distribuição geográfica de An. albitarsis B- espécie do Complexo Albitarsis para a Região Neotropical. 
An. deaneorum

An. deaneorum apresenta-se distribuida no nordeste da Argentina e no Brasil em Rondônia, Acre e Paraná (Fig. 34)

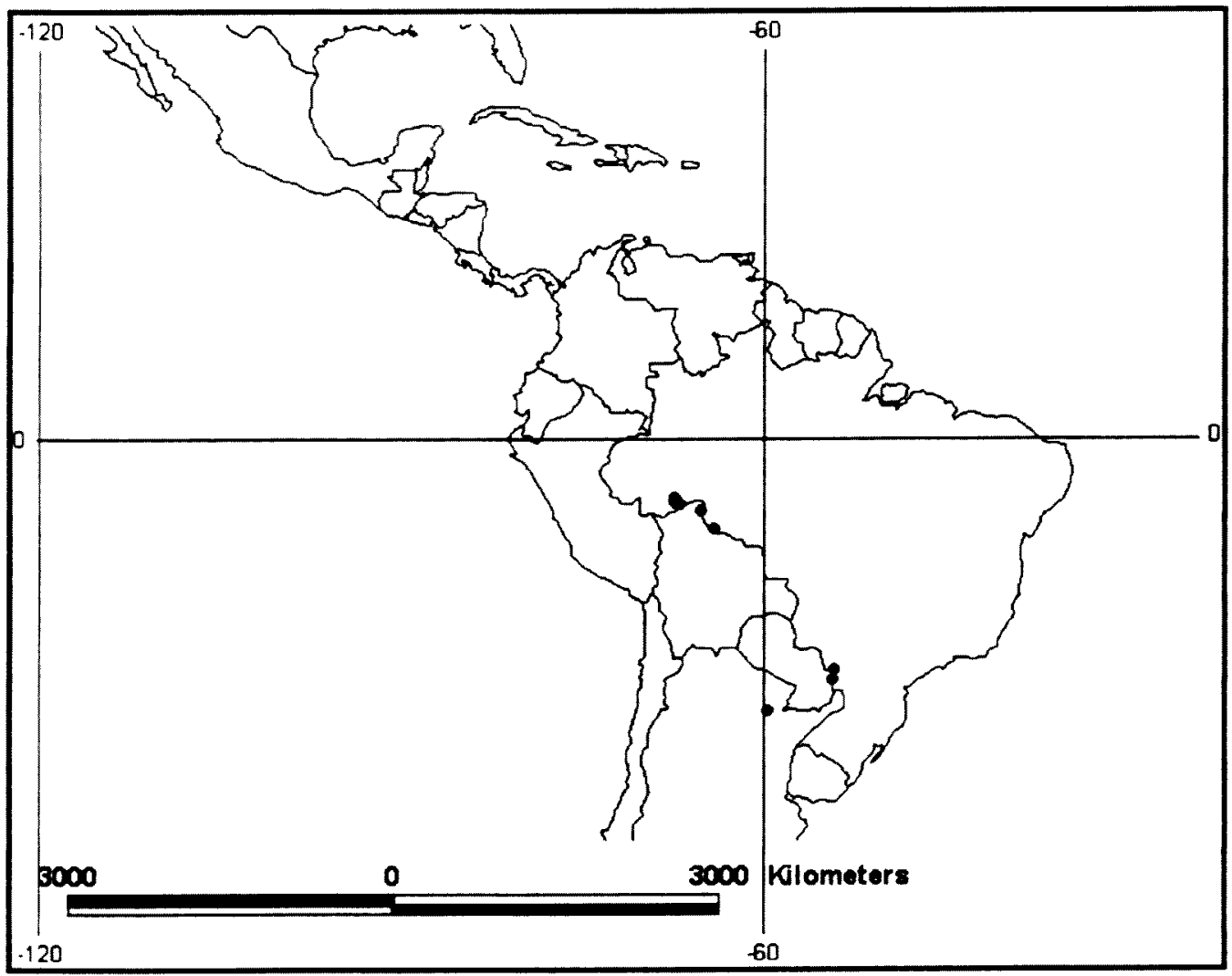

Fig. 34. Distribuição geográfica de An. deaneorum para a Região Neotropical. 
An. marajoara

An. marajoara, que se encontra distribuida na região norte do Brasil, numa faixa que vai de Roraima (Amazonas, Rondônia e Pará) até o sudeste (litoral sul de São Paulo), e na Venezuela (regiões de Zulia, Cojedes e Barinas) (Fig. 35).

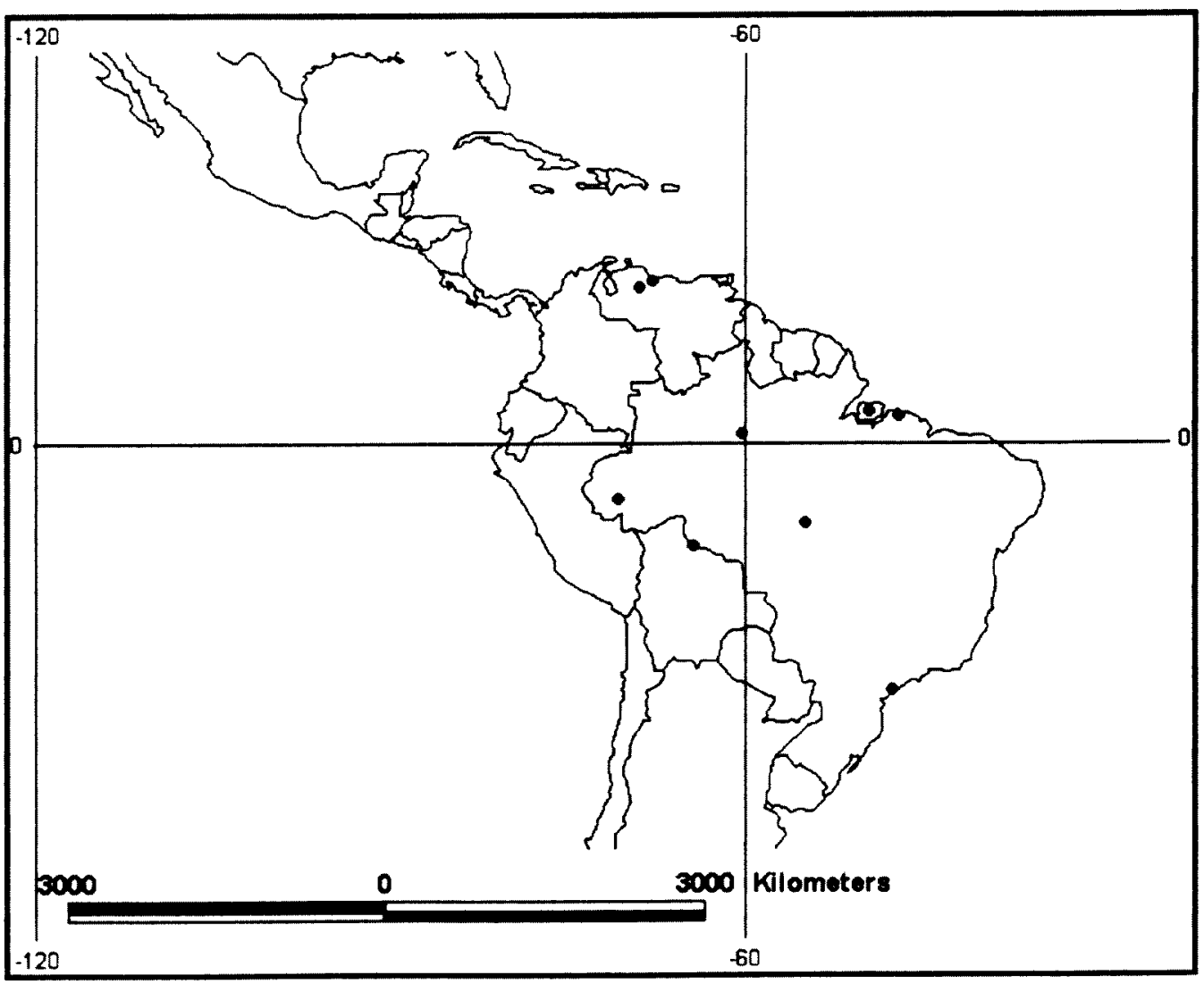

Fig. 35. Distribuição geográfica de An. marajoara para a Região Neotropical. 
An. lanei

A distribuição de An. lanei é conhecida apenas para a localidade-tipo, Campos do Jordão, São Paulo, Brasil (Fig. 36).

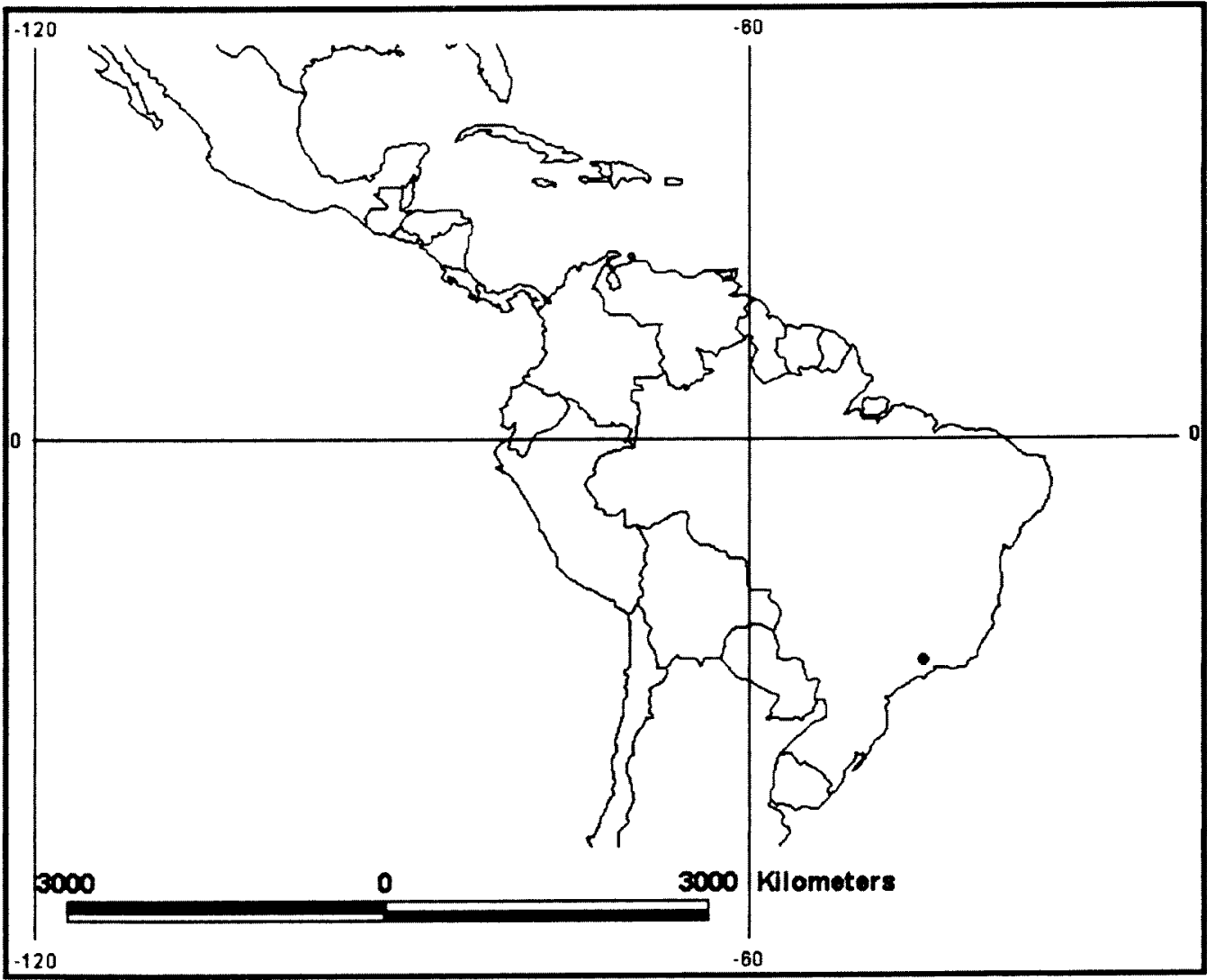

Fig. 36. Distribuição geográfica de An. lanei para a Região Neotropical. 
An. sawyeri

An. sawyeri está restrita à sua localidade-tipo, São Benedito, no estado do Ceará, Brasil (Fig. 37)

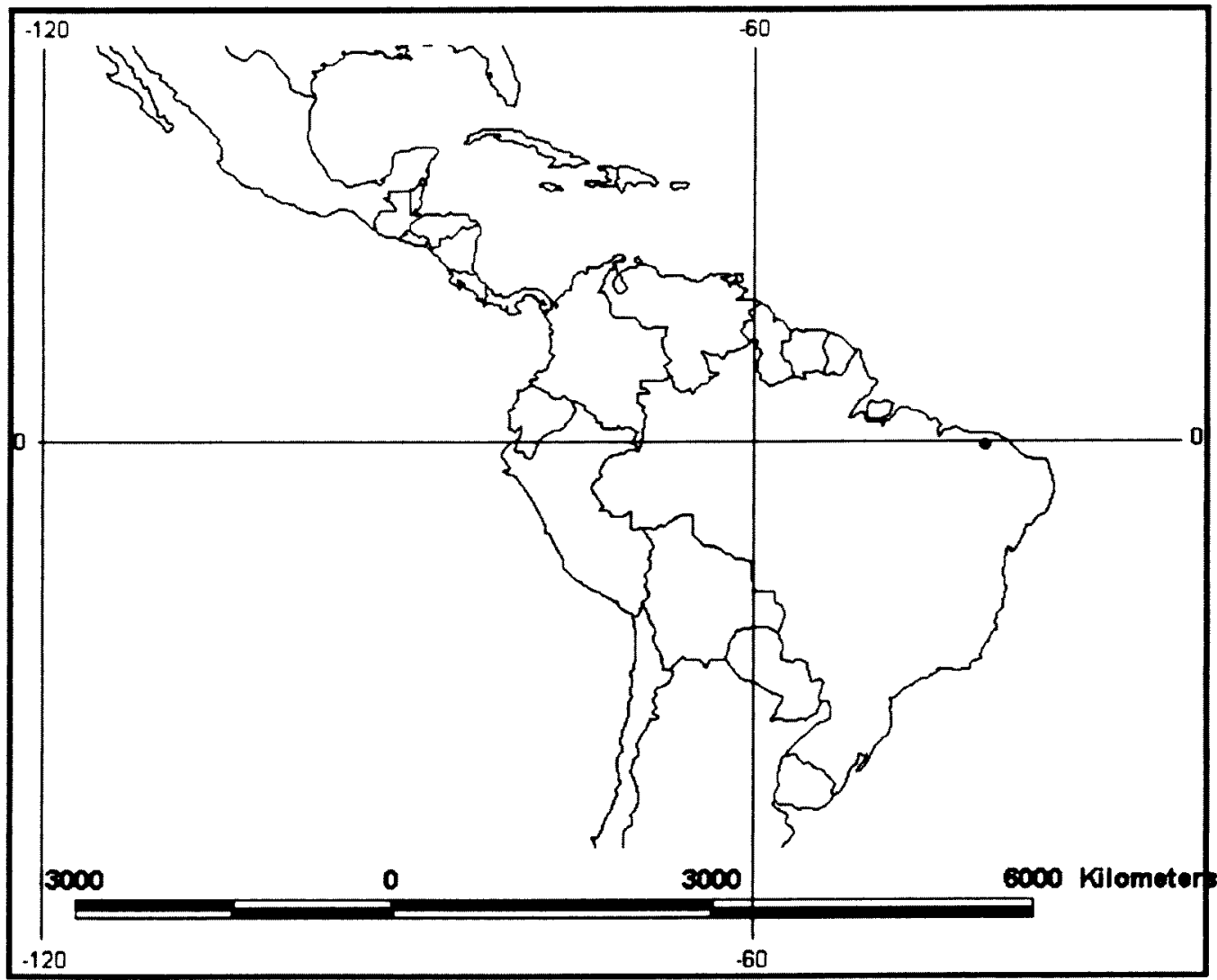

Fig. 37. Distribuição geográfica de An. sawyeri para a Região Neotropical. 
An. lutzii

A espécie An. lutzii ocorre numa faixa que vai do sudoeste do Perú até o norte do Brasil, alcançando a região de Iguaçu no Paraná e o sudeste brasileiro (Fig. $38)$.

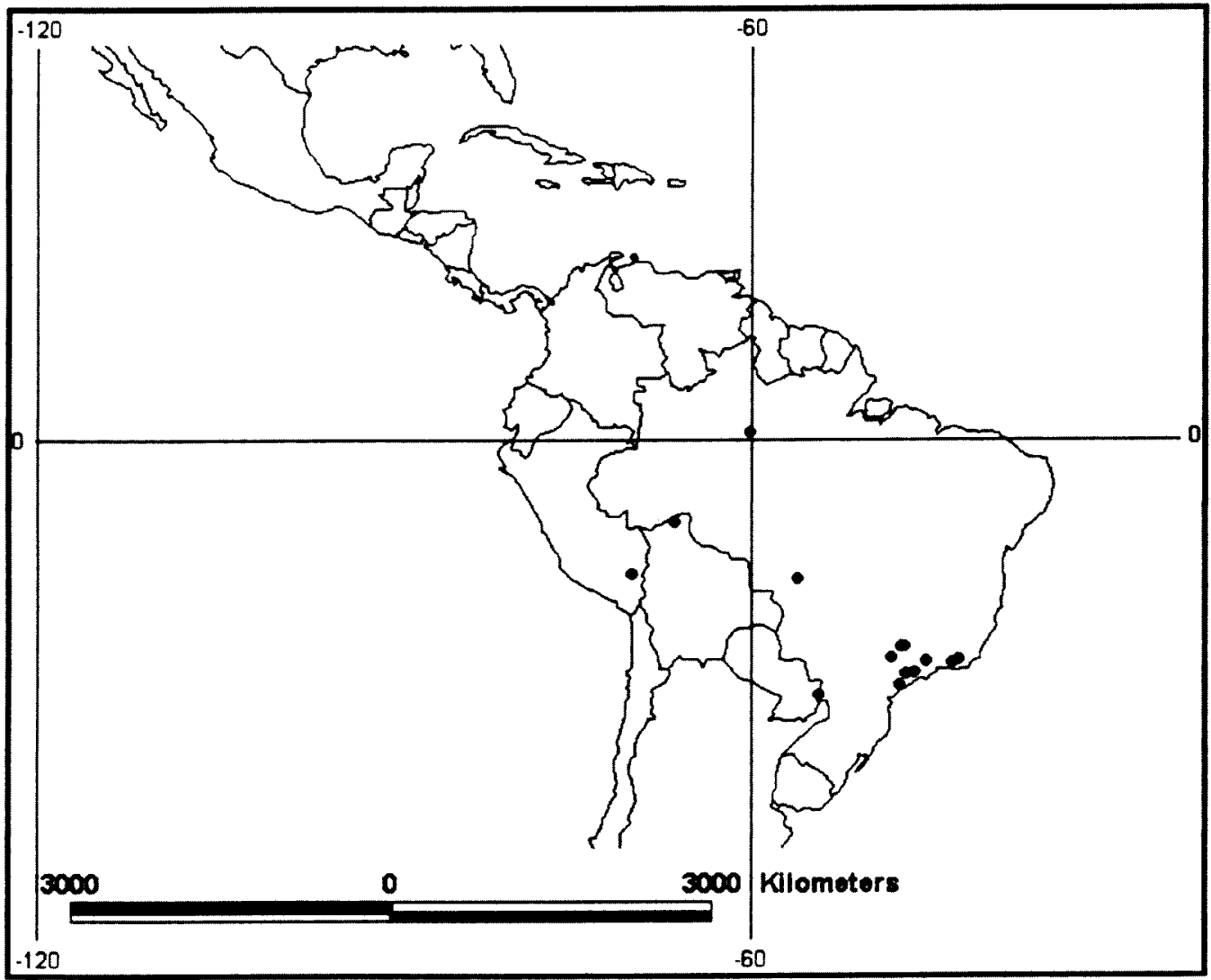

Fig. 38. Distribuição geográfica de An. lutzii para a Região Neotropical. 
An. antunesi

An. antunesi parece estar restrita ao Estado de São Paulo, Brasil (Fig. 39).

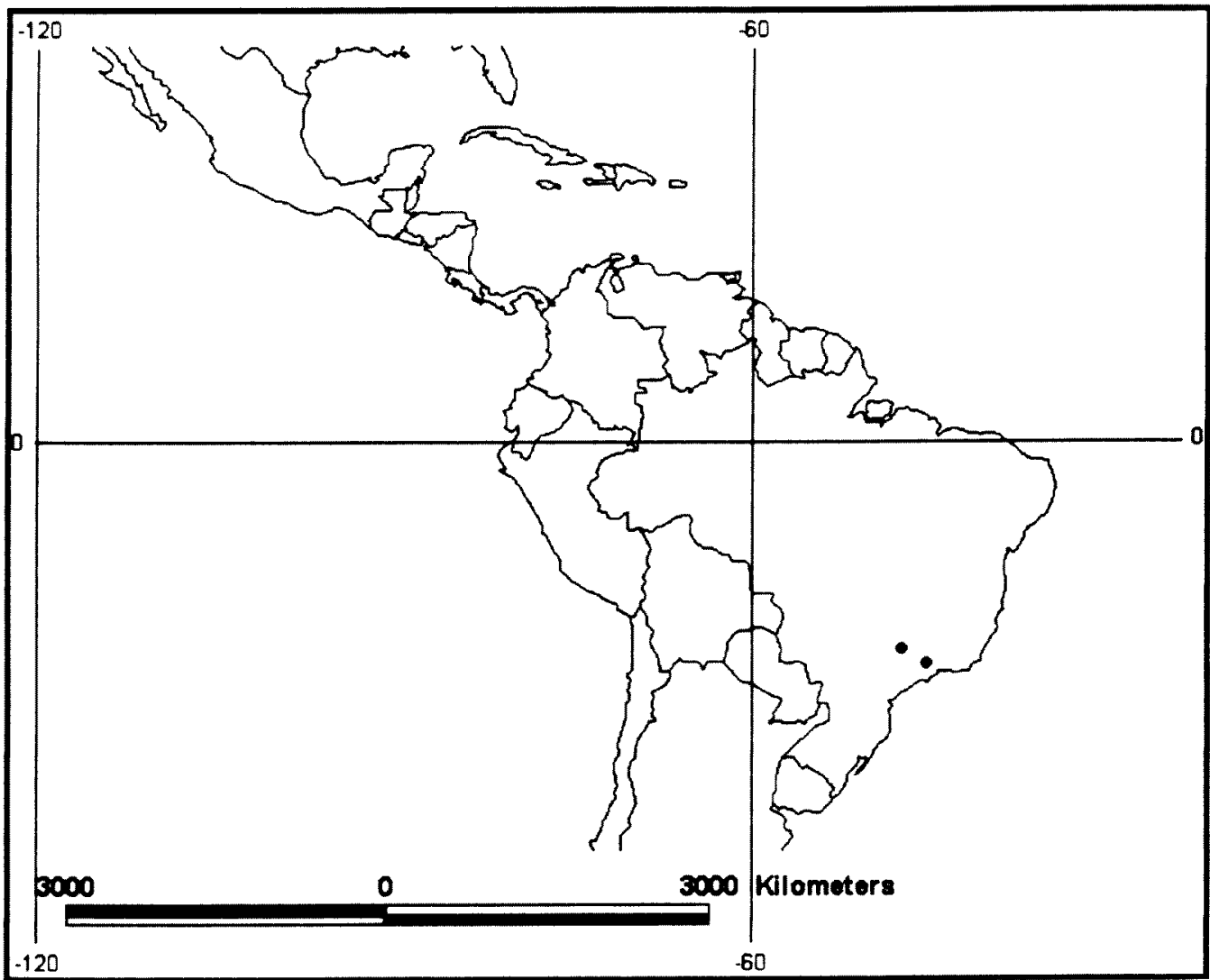

Fig. 39. Distribuição geográfica de An. antunesi para a Região Neotropical. 
An. argyritarsis

An. argyritarsis apresenta-se amplamente distribuído nas ilhas do Caribe (Trinidad, Martinica, Montserrat, Grenada, Antígua, Dominica, Saint Lucia, Saint Vincent) e desde o sul do México até as regiões norte da Argentina e centro-oeste e sudeste do Brasil, exceto na Nicarágua, Guiana Francesa e Suriname (Fig. 40).

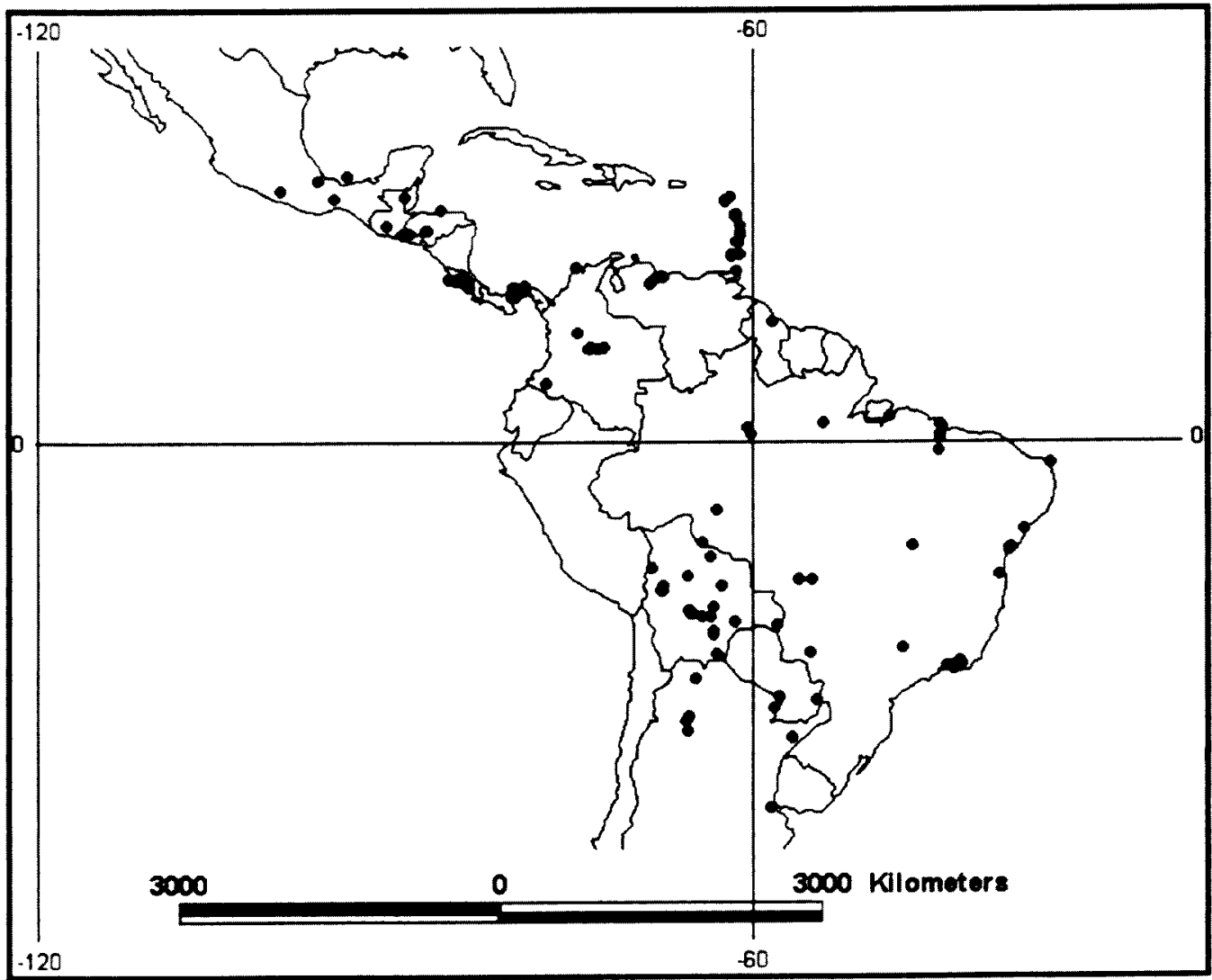

Fig. 40. Distribuição geográfica de An. argyritarsis para a Região Neotropical . 
An. parvus

A distribuição de $A n$. parvus é conhecida para o Brasil, nas regiões sudeste e centro-oeste, mas sua ocorrência também é registrada para localidades no Peru (Fig. 41).

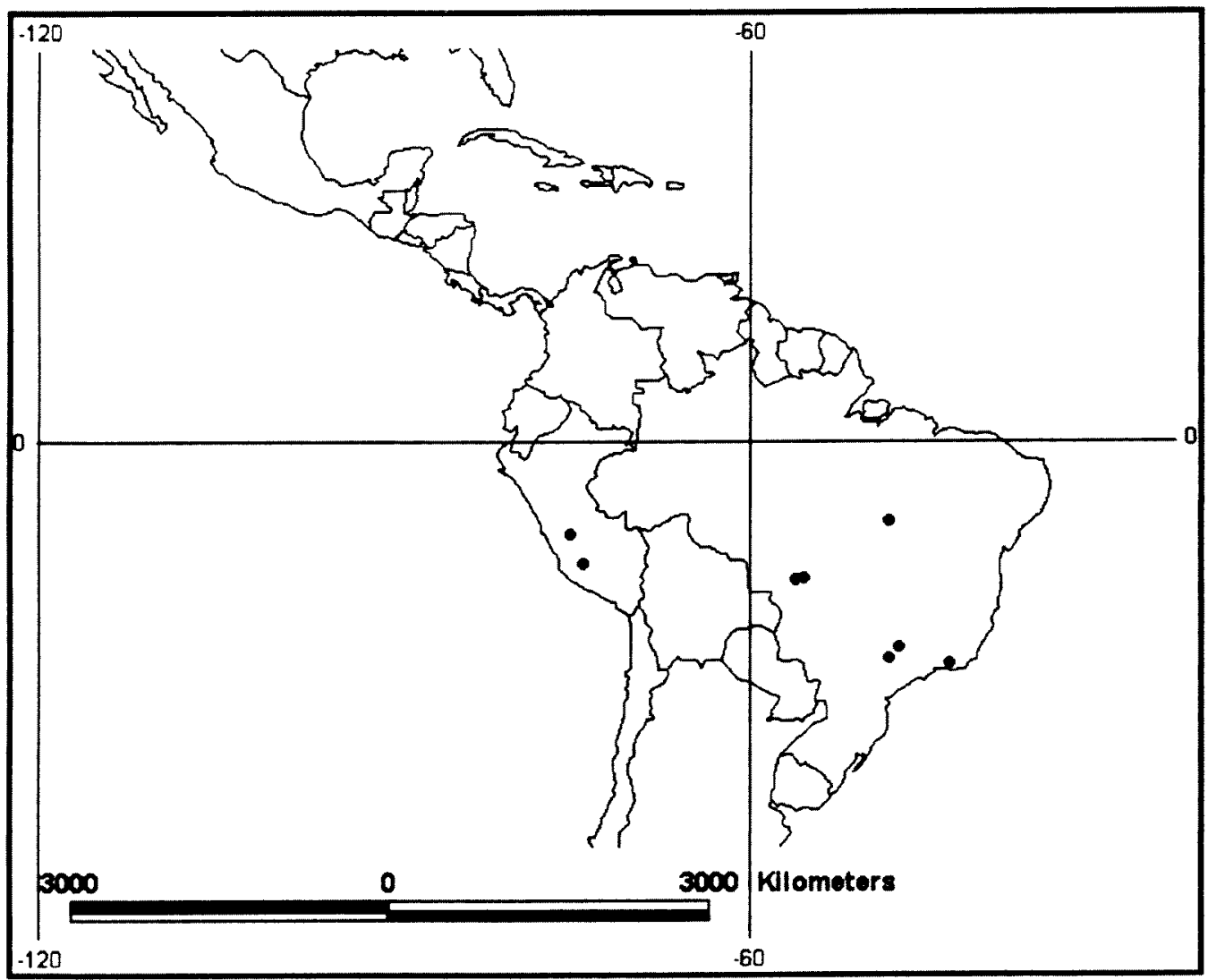

Fig. 41. Distribuição geográfica de $A n$. parvus para a Região Neotropical 
An. dunhami

A espécie An. dunhami está restrita à região noroeste do Amazonas (Fig. 42).

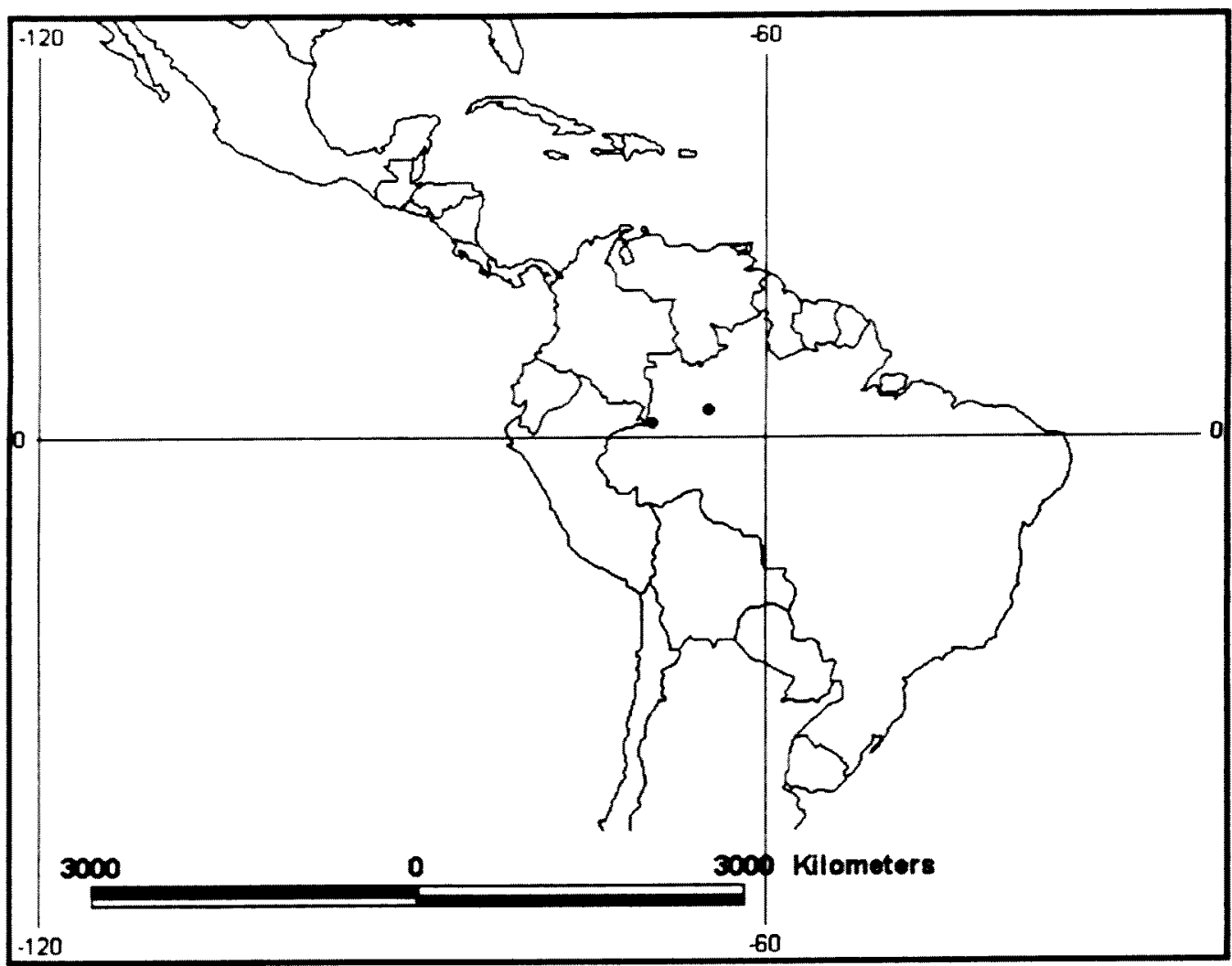

Fig. 42. Distribuição geográfica de An. dunhami para a Região Neotropical. 
An. nigritarsis

A ocorrência de An. nigritarsis está registrada apenas para sua localidade-tipo (Oliveira, Minas Gerais) e outra no Paraná, ambas no Brasil (Fig. 43).

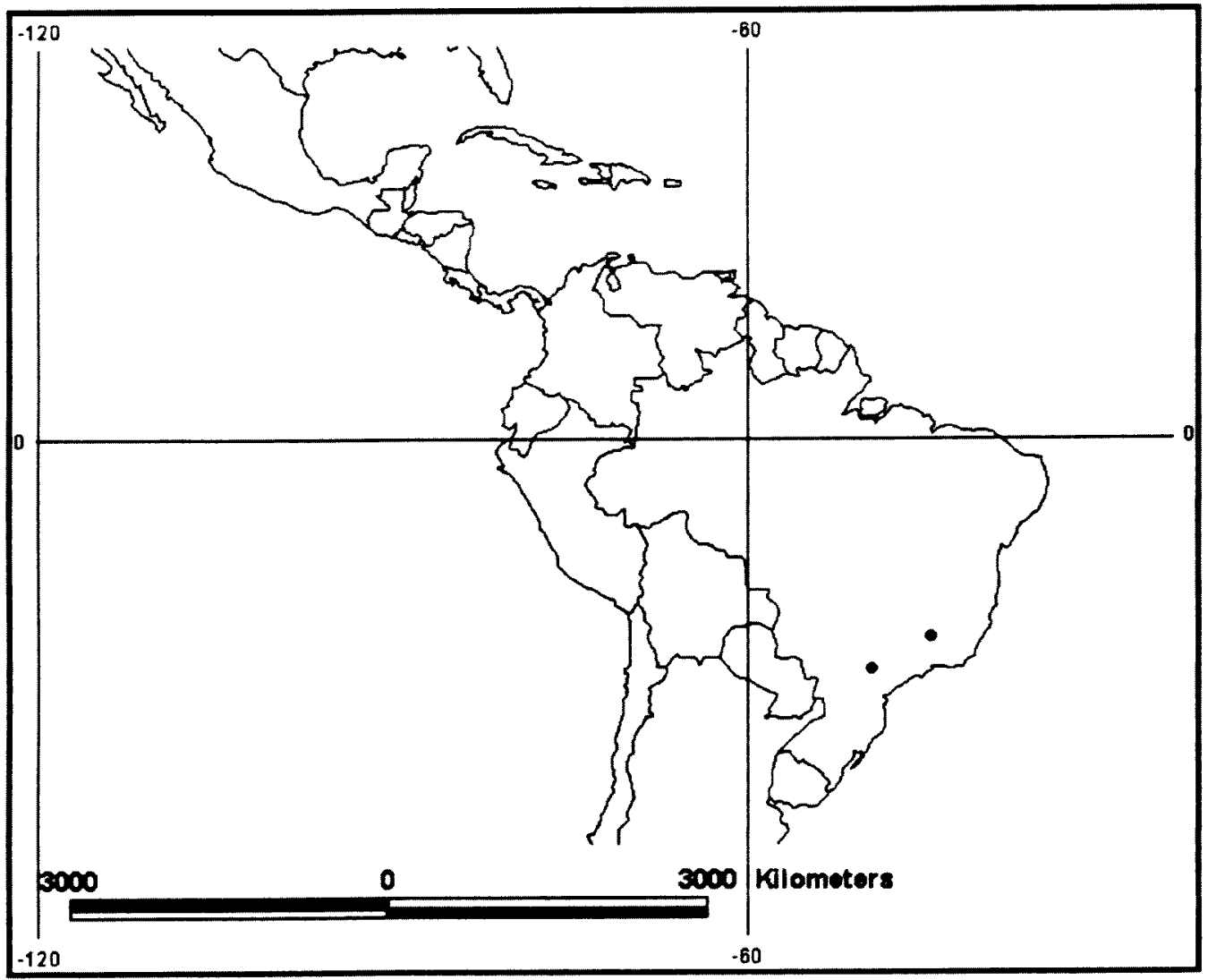

Fig. 43. Distribuição geográfica de An. nigritarsis para a Região Neotropical. 
An. sanctielii

A distribuição de $A n$. sanctieili está restrita à sua localidade-tipo, Minas de Saint-Elie no Rio Sinnamary, região de Ininii, na Guiana Francesa (Fig. 45).

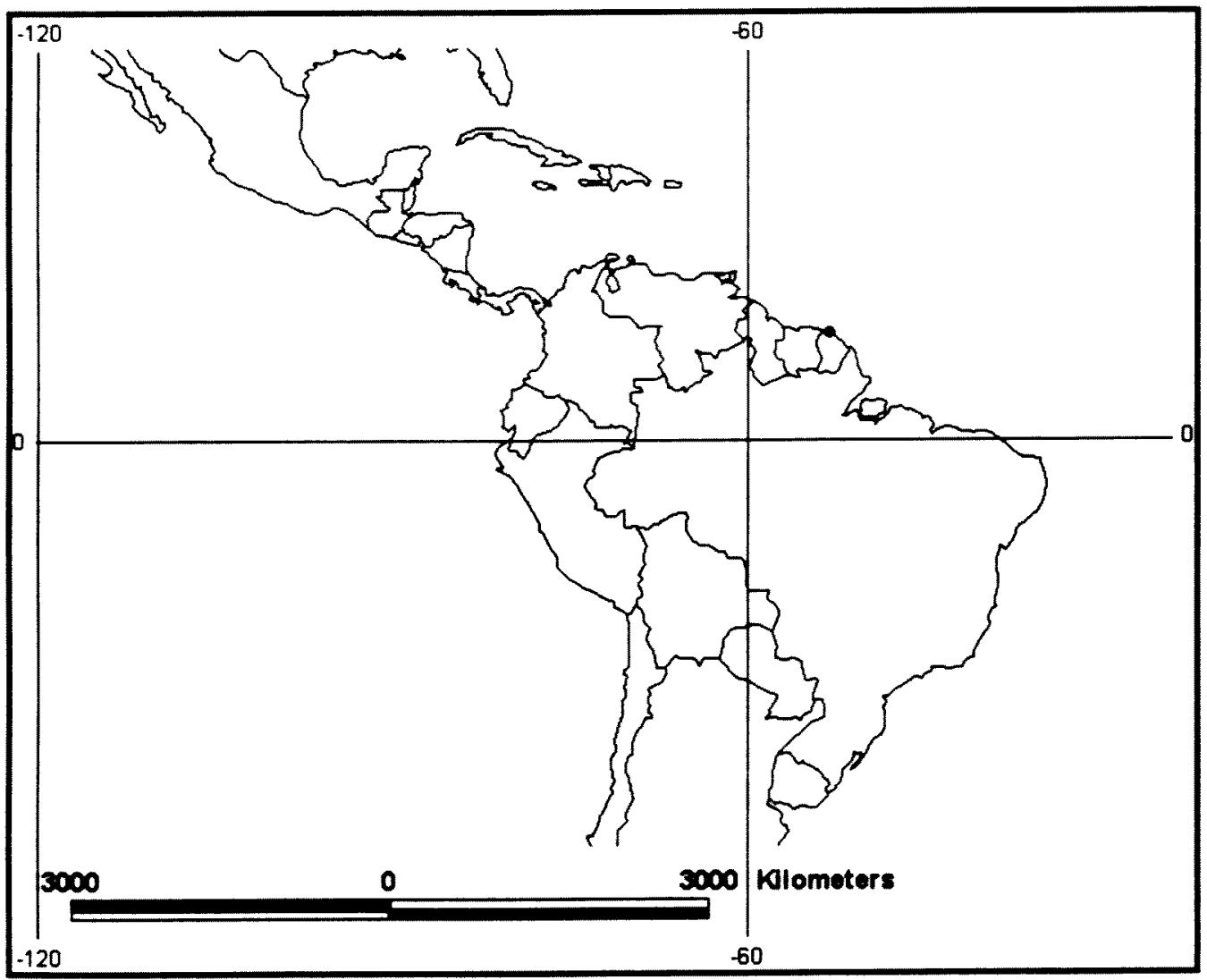

Fig.- 45. Distribuição geográfica de An. sanctielli para a Região Neotropical. 
An. sanctielii

A distribuição de $A n$. sanctieili está restrita à sua localidade-tipo, Minas de Saint-Elie no Rio Sinnamary, região de Ininii, na Guiana Francesa (Fig. 45).

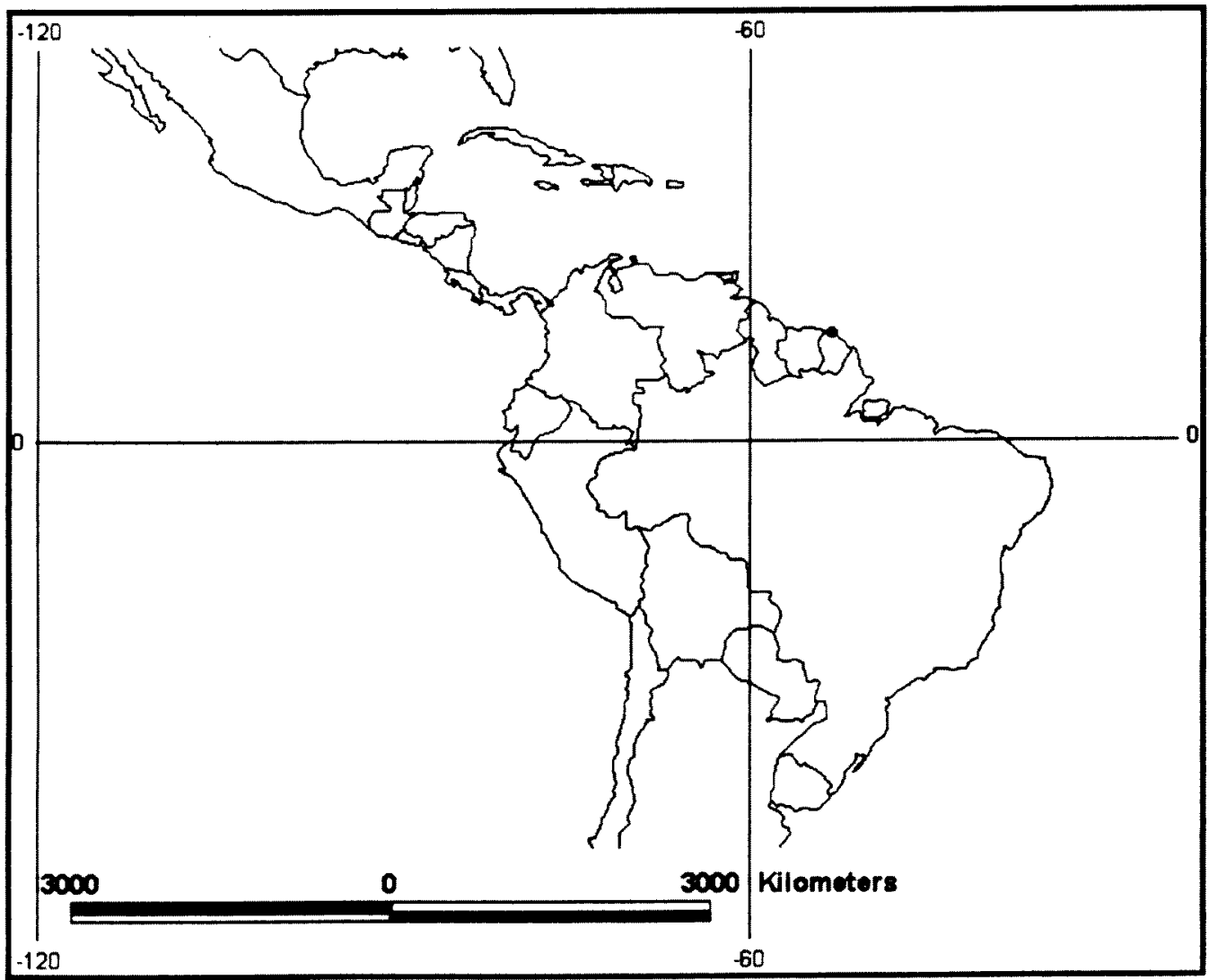

Fig.- 45. Distribuição geográfica de An. sanctielli para a Região Neotropical. 


\subsubsection{Comentários sobre a distribuição geográfica das espécies de Nyssorhynchus}

O presente trabalho, apresentou algumas restrições metodológicas originadas a partir do uso de informações presentes na literatura. Obviamente, um estudo completo e comparativo, envolvendo material originário de várias subregiões da Região Neotropical, seria necessário para alcançar um melhor conhecimento da distribuição do grupo. A importância epidemiológica de membros de Nyssorhynchus tornam supercoletadas as áreas onde a malária é endêmica, sendo o número de localidades de coleta bem como a quantidade de estudos voltados para Nyssorhynchus bem menor nas regiões onde a doença não apresenta grande importância. Dessa forma, a presença de Nyssorhynchus em determinados locais pode estar sendo superestimadas ou subestimadas, o que afeta o próprio conhecimento do grupo.

O subgênero Nyssorhynchus, por possuir varias espécies de interesse epidemiológico, aparentemente, apresenta-se bem conhecido. Nyssorhynchus tem sido estudado de forma sistemática e exaustiva por vários grupos de pesquisa. Dessa forma, existe uma série de estudos e dados disponíveis em vários niveis do conhecimento, desde básicos como taxonomia $\alpha$, ecologia $\mathrm{e}$ importância epidemiológica das espécies até estudos envolvendo modernas técnicas de biologia molecular.

Apesar da existência de grande quantidade de dados disponíveis, principalmente das espécies envolvidas na transmissão de agentes causadores de malária, o subgênero Nyssorhynchus ainda requer muitos estudos, de forma a se entender os processos envolvidos na evolução do grupo. No que concerne à distribuição das espécies de Nyssorhynchus, quando as localidades conhecidas para as espécies desse subgênero são reunidas e organizadas, visualiza-se um complexo padrão. A distribuição geográfica apresentada por algumas espécies precisa ser revista e para isso é preciso considerar alguns fatores externos, tais como a existência de dispersão de origem antrópica, os problemas taxonômicos e a identificação incorreta de material. 
O subgênero Nyssorhynchus é reconhecido como um grupo monofilético restrito à Região Neotropical. Entretanto, a distribuição de An. albimanus contraria essa distribuição. Anopheles albimanus apresenta uma distribuição ampla pois além de estar presente ao longo de toda a região Caribenha, ao norte alcança a Região Neártica, estando presente nas regiões quentes do Sul dos Estados Unidos e Norte do México, e ao sul atinge a região do Equador e Perú (Fig. 30). Muitas variações morfológicas têm sido encontradas nas formas adultas e larvais de An. albimanus, entretanto, segundo RODRÍGUEZ et. al (1992), essas formas variantes não representam um complexo de espécies.

Algumas espécies de Nyssorhynchus que apresentam ampla distribuição na Região Neotropical, muitas vezes são consideradas espécies cripticas ou complexos de espécies, ou seja, "dificilmente diferenciáveis sob o ponto de vista morfológico". Muitos esforços têm sido feitos para o reconhecimento e separação dos complexos de espécies, entretanto ainda não se tem um conhecimendo satisfatório sobre essa questão.

Anopheles aquasalis é considerado altamente polimórfico e pode representar complexo de espécies (ROSA-FREITAS et. al 1998). Anopheles aquasalis está amplamente distribuído ao longo da região costeira atlântica (Fig. 15). Vale ressaltar que as larvas dessa espécie se desenvolvem em criadouros com alto teor de salinidade, entretanto em determinadas localidades podem ser encontradas em água doce, em áreas distantes da região litorânea. Segundo MALDONADO et. al (1997), devido à vasta extensão latitudinal de An. aquasalis, existe variação morfológica e comportamental em diferentes populações, conforme as condições locais. Estes autores diagnosticaram diferenças na morfologia dos ovos, as quais consideraram variação intra-especifica. Por outro lado, LINLEY et. al (1993) consideraram que as diferenças genéticas encontradas em populações proveinentes de várias regiões poderiam ser suficientes para considerar ao menos três espécies, uma que estaria distribuída na Venezuela e Trinidad, outra na ilha de Marajó e a terceira no sudeste brasileiro. Realmente, diferenças comportamentais e polimorfismo são fortes indícios de existência de complexo de espécies. 
Pelo levantamento das localidades feitos para An. darlingi, esta espécie está distribuída em quase toda a extensão da região Neotropical, exceto na Nicarágua, Panamá, Costa Rica e Equador (Fig. 31). Anopheles darlingi também ocorre na Argentina, segundo dados do material depositado na coleção do NMNH. Segundo ROSA-FREITAS et. al 1998, An. darlingi apresenta diferenças comportamentais na Amazônia. Entretanto, estudos comportamentais, isoenzimáticos e de DNA mitocondrial têm demonstrado a condição monotípica da espécie. No entanto, considerando a distribuição de $A n$. darlingi ao longo da Região Neotropical, a não ocorrência dessa espécie numa faixa extensa da América Central, representando uma quebra na distribuição, merece ser melhor avaliada. Em se tratando de uma única entidade monotípica, essa distribuição discontínua poderia ser explicada pela ausência de coletas na área ou por dispersão, sendo que a espécie poderia ter se estabelecido secundariamente ao norte da Região Caribenha.

Para o Complexo Oswaldoi, atualmente são reconhecidas duas espécies distintas, $A n$. oswaldoi e $A n$. konderi, sendo que a primeira apresenta-se amplamente distribuida (Fig. 16) e An. konderi apresenta distribuição conhecida restrita (Fig. 17). Dessa forma, é provável que a distribuição de $A n$. konderi esteja subestimada devido a problemas de identificação de material.

Outra espécie com ampla distribuição e que também representa um complexo é An. triannulatus (Fig. 28), a qual, segundo ROSA-FREITAS et. al (1998) compreende pelo menos duas espécies. Recentemente, NASCIMENTO e LOURENÇO (2002) descreveram a espécie An. halophyllus, integrante do complexo, a partir de exemplares de Salobra, Mato Grosso do Sul, no Brasil (Fig. 29), onde ocorre em simpatria com An. triannulatus. Vale ressalta, que os autores não encontraram An. halophyllus ocorrendo em simpatria com An. triannulatus em outras localidades estudadas.

Um dos complexos de espécies mais importantes de Nyssorhynchus é o Complexo Albitarsis formado por An. albitarsis (Fig. 32), An. albitarsis B (Fig. 33), An. deaneorum (Fig. 34) e An. marajoara (Fig. 35). As distribuições das espécies do complexo, reconhecidas aqui, foram restritas às localidades apresentadas por 
WILKERSON et. al (1995a,b), devido a dúvidas quanto à identificação do material, proveniente principalmente de regiões onde as espécies estão ocorendo em simpatria. Quanto a An. marajoara, também pode ocorrer no Panamá, conforme material do NMNH.

A distribuição de An. argyritarsis é bem ampla, atingindo desde o sul do México até a Argentina (Fig. 40). Anopheles benarrochi apresenta-se distruibuida na região norte do Brasil (Rondônia, Amazonas e Acre), ocorrendo também no sudeste brasileiro, na Colômbia, no Peru e na Venezuela (Fig. 20). Anopheles rangeli está amplamente distribuída na faixa norte da América do sul, da Venezuela e Região Amazônica brasileira até o norte da Argentina (Fig. 21).

Anopheles strodei apresenta-se amplamente distribuído ao longo da Região Neotropical desde o Panamá até o norte da Argentina (Fig. 24). Esta espécie está presente também na Costa Rica, confome material depositado no NMNH.

Anopheles nuneztovari que está amplamente distribuído na região noroeste da América do Sul (Fig. 26) é, possivelmente, complexo de duas espécies crípticas, estando uma distribuída na Venezuela e nordeste da Colômbia e outra na Amazônia. Diferenças morfológicas, comportamentais, citogenéticas e isoenzimáticas apresentadas dão suporte a essa hipótese (ROSA-FREITAS et. al 1998).

A espécie An. lutzii está presente em várias localidades no Brasil, Bolívia e Peru. Na coleção do MNNH, existe depositado material dessa espécie proveniente da região de Missiones, Argentina. Anopheles nigritarsis é conhecida apenas para duas localidades do Brasil, Minas Gerais e Paraná (Fig. 43). Essa espécie é considerada válida, mas segundo GALVÃO (1941b), pode se tratar de uma forma anômala de $A n$. lutzil, com marcação nos $3^{\circ} \mathrm{e} 4^{\circ}$ tarsômeros posteriores.

A distribuição de An. parvus é conhecida para o Brasil (Fig. 41), mas sua ocorrência também é registrada para localidades no Peru. Essa espécie também está presente na Colômbia, conforme material depositado na coleção do NMNH. Existe também, nessa mesma coleção, uma pupa identificada com An. parvus proveniente 
de São Benedito, Ceará, no Brasil, mas este material difere do material examinado de Villavicencio, por caracteres da paleta da pupa. A comparação entre exemplares dessas e de outras localidades seria necessária para a constatação de que se tratam ou não da mesma espécie.

Algumas espécies do subgênero Nyssorhynchus são provavelmente restritas. A distribuição de An. ininii é conhecida somente para a localidade-tipo Minas de Saint-Ellie, na Guiana Francesa e na região de Altamira e Marabá, localizadas no Pará, região norte do Brasil (Fig. 14). Anopheles anomalophyllus parece estar restrita à América Central sendo encontrada na Costa Rica e Panamá (Fig. 20). Esta espécie também está presente na Nicarágua, conforme material depositado na colecão do NMNH.

Anopheles antunesi parece estar restrita à Região de Campos do Jordão, São Paulo (Brasil), apesar da existência de registro desta espécie fora da localidade-tipo (Fig. 39). A coleção do NMNH apresenta material de estágios imaturos identificados como An. antunesi proveniente do Suriname. Este material, provavelmente, trata-se de outra espécie, pois diferem do material estudado proveniente do Brasil, quanto a caracteres da paleta da pupa e da forma da cerda 1-P da larva. Anopheles lanei é restrita a Campos do Jordão (Fig. 36) e An. sawyeri à Serra de Ibiapaba, no Ceará, Brasil (Fig. 37). Vale ressaltar que Campos do Jordão é considerado uma área endêmica bem definida dentro da Região Neotropical, sendo um componente da Mata Atlântica, onde ocorrem as espécies An. antunesi e An. lanei. A Serra do Ibiapaba também está situada na faixa de Mata Atlântica. A distribuição dessas três espécies, mostra-se interessante, pois na análise filogenética de Nyssorhynchus apresentam-se como um grupo monofilético, juntamente com An. lutzii, única espécie com distribuição mais ampla dentro do agrupamento (Fig. 38). A presença de An. pictipennis está registrada para a região Chilena Central, estando, portanto, localizada na Região Andina da América do Sul (Fig. 44). A presença de $A n$. picitpennis no Chile, apresenta-se particularmente interessante, pois trata-se da única espécie representante de Nyssorhynchus nesta área. Apesar de Russel (1943) citado em LINTHICUM (1988,p.170), apontar sua ocorrência na Argentina e Brasil, An. 
pictipennis parece estar restrita apenas à região chilena. Vale ressaltar que não existem registros recentes de An. pictipennis na literatura e o material-tipo desta espécie encontra-se desaparecido. A espécie An. pictipennis, devido a falta de material não foi incluída na análise filogenética, entretanto essa espécie compartilha caracteres com An. lanei, An. sawyeri, An. lutzii e An. antunesi, como duas cerdas apicais do claspete dorsal, compartilhando com as duas últimas a presença de uma cerda espiniforme subapical no claspete dorsal (LINTHICUM 1988,p.167). O estudo e posicionamento filogenético de An. pictipennis, seria importante para entender o padrão de distribuição das espécies basais, caso se confirme sua posição junto as demais citadas acima.

An. trinkae e An. dunhami que foram consideradas sinônimas por PEYTON (1993), foram consideradas espécies diferentes por LOUNIBOS et. al (1998), de acordo com caracteres dos ovos. Dessa forma, An. trinkae está distribuída da Venezuela até a Bolívia (Fig. 23) e Anopheles dunhami está restrita à região noroeste da Amazônia, no Brasil (Fig. 42). No entanto, para FORATTINI (2002), An. dunhami ocorre ao longo do lado oriental da cordilheira dos Andes, desde a Colômbia até o Peru. A distribuição de An. sanctielli está restrita à localidade-tipo na região de Ininii, Guiana Francesa (Fig. 45). Não existem referências a coletas recentes dessa espécie.

Distribuição ampla, pode ser devida à identificação incorreta de material, conforme já citado e também pode estar relacionada com a complexidade do uso e definição do conceito de espécie. Segundo NOONAN (1998), distribuição ampla observada em determinas espécies pode ser resultado de combinações variadas de dispersão e de não resposta a eventos vicariantes.

Para as espécies de Nyssorhynchus parece haver prevalência da dispersão passiva, relacionada à antropofilia, sobre a dispersão ativa. Convém ressaltar que as formas adultas apresentam baixa capacidade de vôo, sendo a dispersão ativa representada por movimento individual em curtas distâncias em busca de alimento. Além disso, a ação do vento pode ser responsável por movimentos migratórios de determinadas espécies. Entretanto, esse fator parece não estar relacionado com 
processos evolutivos (pressões seletivas) e sim com evento de ordem natural. Quanto à dispersão passiva, esta torna-se um importante fator quando se trata de espécies de interesse epidemiológico, pois o transporte passivo pode ser responsável pela invasão de espécies vetoras em determinadas regiões. Um exemplo disso, é a "chamada malária de aeroporto", podendo estar relacionada ao tráfego aéreo de vetores de uma região a outra. Outra questão que merece destaque é a capacidade de domiciliação apresentada pelos culicídeos em geral e a capacidade das larvas de se desenvolverem em recipientes artificias (FORATTINI 2002). As espécies An. argyritarsis, An. aquasalis, An. albimanus e An. albitarsis s.l. já foram encontrados em recipientes artificiais (FORATTINI 1998).

Estudos englobando vários aspectos seriam interessantes para se entender a evolução de Nyssorhynchus bem como a sua interação com Plasmodium. Fatores geográficos, ambientais, ecológicos, fisiológicos e históricos integrados estão relacionados à transmissão dos agentes causadores de malária, segundo ANTHONY et. al (1999). Dessa forma, a reunião destes dados juntamente com a resolução dos problemas taxonômicos do subgênero Nyssorhynchus seria de grande importância para o conhecimento da dinâmica de transmissão dos agentes causadores da malária por algumas espécies. 


\section{CONCLUSÕES}

\subsection{Análise filogenética}

Os resultados obtidos na análise filogenética realizada para o subgênero Nyssorhynchus permitem concluir que o subgênero Nyssorhynchus é monofilético, corroborando resultados de estudo prévies e que as Seções Argyritarsis e Myzorhynchella são polifiléticas e a Seção Albimanus é merofilética. Anopheles braziliensis, previamente considerada pertencente à Seção Argyritarsis, ficou posicionada entre as espécies da Seção Albimanus, no entanto, se transferida, a Seção Albimanus torna-se monofilética; permanecendo as demais seções polifiléticas. Anopheles argyritarsis não apresenta estreita relação de parentesco com as demais espécies alocadas da Seçao Argyritarsis. Anopheles lanei e An. sawyeri, tradicionalmente consideradas pertencentes à Seçao Argyritarsis, são espécies-irmãs e formam um clado com An. lutzii e An. antunesi, consideradas membros da Seção Myzorhynchella. Anopheles parvus é a espécie mais basal dentro de Nyssorhynchus.

\subsection{Distribuição geográfica}

Os resultados do estudo da distribuição geográfica das espécies do subgênero Nyssorhynchus permitem concluir que o subgênero Nyssorhynchus possui distribuição essencialmente Neotropical, com An. albimanus ocorrendo, também, na região sul dos Estados Unidos. Algumas espécies apresentam um complexo padrão de distribuição, estando amplamente distribuídas na Região Neotropical, podendo estar relacionado a alguns fatores como a identificação incorreta de material, complexidade do uso e definição do conceito de espécie e combinações variadas de dispersão e de não resposta a eventos vicariantes. As espécies Anopheles anomalophyllus, Anopheles antunesi, Anopheles lanei An. sanctielli e An. sawyeri são provavelmente restritas a determinadas regiões geográficas da região Neotropical. Anopheles pictipennis é a única espécie representante de Nyssorhynchus no Chile, podendo ser restrita dessa área. 


\section{6- REFERÊNCIAS}

Agromonte A. Los mosquitos malaricos. Progr med 1900; 10:455-465.

AMORIM DS. Elementos Básicos de Sistemática Filogenética. $2^{\mathrm{a}}$ ed. São Paulo: Editora Holos e Sociedade Brasileira de Entomologia; 1997.

AMORIM DS. Classificação por seqüenciação: Uma proposta para a denominação dos ramos retardados. Revta Bras Zool 1982; $1(1)$ : $1-9$.

AMORIM DS. Group : An aditional artifact fo phylogentic sequenced classifications. Revta nordest Biol 1994; 8(1): 35-38.

ANThony TG, HaRbach RE, KrTching IJ. Phylogeny of the Pyretophorus Series of Anopheles subgenus Cellia (Diptera: Culicidae). Systm Ent 1999; 24: 193-205.

ANDUZE PJ. Notas entomólogicas I. Dos variedades nuevas de An. aquasalis. Bol med 1948; 1:17-19.

BAtes M. The Natural History of Mosquitoes. New York: Macmillan Co.; 1949.

Blanchard E. Ordem IX. Dípteros. Pp. 327-468. In: Gay, C., ed. Historia fisica y politica de Chile. Zoologia, Vol. 7, 471 pp. Paris. 1852.

BLANCHARD R. Les moustiques. Historie naturelle et medicale. 673 pp. illus. Paris. 1905

BRĖTHES, J. Description provisoire de deux espèces nouvelles d'Anophelinae argentins. Prensa med argent 1926; 13:106-107.

CAUSEY OR. Description of Anopheles (Nyssorhynchus) dumhami, a new species from the Upper Amazon Basin. J nat Malar Soc 1945; 4:231-234, illus.

CAUSEY OR, DEANE, LM, DEANE. MP. Descrição de um novo anofelino da parte alta do Vale do Amazonas Anopheles (Nyssorhynchus) galvaoi n. sp. Revta Paul Med 1943; 23:293-296, illus.

CAUSEy OR, DEANE LM, DEANE MP, SAMPaio MM. Anopheles (Nyssorhynchus) sawyeri, a new anopheline mosquito from Ceará. Brazil. Ann ent Soc Am 1943; 36:11-20, illus.

Chagas C. O novo gênero Myzorhynchella de Theobald. Duas novas anophelinas brasileiras pertencentes a êste gênero. Brasil-méd 1907; 21(30): 291-293, 303-308.

ColluCCI E, SALLUM MAM Phylogenetic analysis of the subgenus Kerteszia of Anopheles (Diptera: Culicidae: Anophelinae) based on morphological characteres. Insect Syst. Evol. 2003; 34: 361-372. 
CONN JE. Systematics and Population level analysis of Anopheles darlingi. Mem Inst Osw Cruz 1998: 93 (5): 647-650.

CONN JE, COCKBURN AF, MrTCHELl SE. Population differentiation of the malaria vector Anopheles using mitochondrial DNA. J Hered 1993; 84: 248-253.

CONN JE, Mrtchell SE, COCKBURN AF. Mitochondrial DNA analysis of the neotropical malaria vector Anopheles nuneztovari. Genome 1998; 41 (3) 313-327.

CORRÊA RR, RAMOS AS. Descrição de uma nova subespécie de anofelino do subgênero Nyssorhynchus Blanchard, 1902 (Diptera, Culicidae). Revta Paul Med 1943; 22: 246-248.

COVA-GARCIA P, PULIDOFJ, AMARISTA JRM. Anopheles (Nyssorhynchus) deltaorinoquensis n.sp. (Diptera, Culicidae) de Venezuela. Bol Direc Malariol San Amb 1977; 17:150-161.

CRUz 0G. Contribuição para o estudo dos culicidos do Rio de Janeiro. Brazil-med $1901 ; 15: 423-426$, illus.

CURRY DP. Some observations on the Nyssorhynchus group of the Anopheles (Culicidae) of Panama. Am. J. Hyg. 1932;15:566-572, illus.

DonoghUE MJ, CANTINO PD. The logic and limitations of the outgroup substitution approach to cladistic analysis. Syst Bot 1984; 9:192-202.

DYAR HG, KNAB F. Descriptions of new species from the Panama Canal Zone. J. N. Y. ENT. SOC. 1907; 15: 197-212

FARAN ME. Anopheles (Nyssorhynchus) trinkae, a new species in the Albimanus section (Diptera: Culicidae). Mosq Syst 1979; 11:26-39.

FARAN ME. Mosquito studies (Diptera, Culicidae) XXXIV. A revision of the Albimanus Section of the subgenus Nyssorhynchus of Anopheles. Contr Am Ent Inst (Ann Arbor) 1980; 15 (7): 1-215.

FARAN ME, LINTHICUM KJ. A handbook of the Amazonian species of Anopheles (Nyssorhynchus) (Diptera: Culicidae). Mosq Syst 1981; 13: 1-81.

FARRIS, JS. A successive approximations approach to character weigting. Syst Zool $1969 ; 18: 374-385$.

FELSENSTEIN J. Confidence limits on phylogenies: an approachusing the bootstrap. Evolution 1985; 39: 783-791

FOLEY DH, BRYAN JH, YEATES D, SAUL A. Evolution and systematics of Anopheles: insights from a molecular phylogeny of Australian mosquitoes. Mol Phylogenet Evol 1998; 9: 262-275. 
FORATTINI OP. Entomologia médica. São Paulo: Faculdade de Higiene e Saúde Pública, 1962. V.1.

FORRATINI OP. Culicidologia médica. São Paulo: ESUSP; 1996. V.1.

FORATTINI OP. Culicidologia médica. São Paulo: EDUSP; 2002. v.2

FORATTINI OP, SALLUM MAM, MARQUES GRAM, FlORES DC. Description of the eggs of Anopheles (Kerteszia) laneanus and Anopheles (Nyssorhynchus) antunesi (Diptera: Culicidae) by scanning electron microscopy. J Am Mosq Control Assoc $1997 ; 13(4): 368-374$.

FORATTINI OP, SALLUM MAM, BERGO ES, FLÔRES DC. Ultrastruture of eggs of Anopheles rondoni, Anopheles lutzii and Anopheles parvus, three species of the subgenus Nyssorhynchus. J Am Mosq Control Assoc 1998; 14(3):256-265.

FRITZ GN, CONN J, COCKBURN AF, SEAWRIGHT J. Sequence analysis of the ribosomal DNA internal transcribed spacer 2 from populations of Anopheles nuneztovari (Diptera: Culicidae). Mol Biol Evol 1994; 11: 406-416.

GABALDón, A. Estudios sobre anofelinos. Serie I. 1. Descripción de Anopheles (Nyssorhynchus) nunez-tovari n. sp. y consideraciones sobre una sub-división del grupo Nyssorhynchus (Diptera, Culicidae). Publ Div Malar 1940; 5:3-7, illus.

Gabaldón, A., Cova CaRCia P, LOPEZ JA. Estudios sobre anofelinos. Serie I. 2. Anopheles (Nyssorhynchus) rangeli, una nueva especie de la subserie oswaldoi (Diptera, Culicidae) de amplia distribución en Venezuela. Publ Div Malar 1940; 5:9-23, illus.

Gabaldón A, Cova CARCia P, LOPEZ JA. Estudios sobre anofelinos. Serie II. 1. Anopheles (Nyssorhynchus) benarrochi una especie de la subserie triannulatus. Publ Div Malr 1941; 7:3-24, 2 pls.

GALVÃo ALA. Notas sobre alguns anofelinos do sub-gênero Nyssorhynchus do norte do Brasil. Revta Biol Hyg 1941a;11:92-96, illus.

GalVão AlA. Contribuição ao conhecimento das espécies de Myzorhynchella (Diptera, Culicidae). Arch Zool S. Paulo 1941b; 2:505-576, 13 pls.

Galvão, AlA, Amaral, A. D. F. Sobre um novo anofelino de Campos do Jordão, Estado de São Paulo, Anopheles (Nyssorhynchus) lanei n. sp. (Diptera, Culicidae). Revta Biol Hyg. 1938 9:8-16, 4 pls

GALVÃo ALA, AMARALA DF. Estudos sobre os anofelinos do grupo Myzorhynchella com a descrição de uma espécie nova, Anopheles (Nyssorhynchus) antunesi n. sp. (Dipt., Culicidae). Folia clin biol 1940; 12:150-160. 
Galvão ALA, Damasceno RG. Anopheles (Nyssorhynchus) konderi nova espécie de Anopheles do vale do Amazonas e considerações sobre as espécies do complexo tarsimaculatus (Diptera, Culicidae). Folia clin biol. 1942a. 14:115-135, illus.

Galvão AlA, Damasceno RG. Sobre um novo anofelino da Ilha de Marajó, Anopheles (N.) marajoara n. sp. Ann paulist Med Cir 1942b; 44:424-427.

GALVÃo ALA, DAMASCENO RG. Observações sobre anofelinos do complexo albitarsis (Diptera: Culicidae). Ann Fac Med 1944; 20:73-87, illus.

GALVÃo ALA, LANE J. Nota sobre os Nyssorhynchus de S. Paulo. VII. Estudo sobre as variedades deste grupo com a descrição de Anopheles (Nyssorhynchus) albitarsis Arrib., 1878 var. limai n. var. Ann Fac Med 1937a; 13:211-238, illus.

Galvão ALA, LANE J. Notas sobre os Nyssorhynchus de S. Paulo. II. Descrição de uma nova espécie Anopheles (Nyssorhynchus) pessoai (Diptera, Culicidae). Revta Biol Hyg 1937b; 7:67-79, illus.

Galvão AlA, LANE J, CORRÊA R. Notas sobre os Nyssorhynchus de S. Paulo. V. Sobre os Nyssorhynchus de Novo Oriente. Revta Biol. Hyg. 1937; 8:37-45, illus.

Goeldi, E. A. Os mosquitos no Pará. Mem Mus Goeldi (Paraense) 1905; 4154 pp., illus.

GrEEN CA. Cladistic analysis of mosquito chromosome data (Anopheles (Cellia) Myzomyia). J Hered 1982; 73: 2-11.

GUIMARÃES JH. Systematic database of Diptera of the America South of the United States: Family Culicidae. São Paulo: Plêiade; 1997.

HARBACH RE. Rewiew of the internal classification of the genus Anopheles (Diptera: Culicidae): the foundation for comparative systematics and phylogenetic research Bull Entomol Res 1994; 84: 331-342.

HARBACH RE, KITCHING IJ. Phylogeny and classification of the Culicidae (Diptera). Systm Ent 1998; 23 (4) 327-370.

HENNIG W. Phylogenetic Systematics. University of Illinois Press, Urbana; 1966.

HofFMAN CC. La formación de razas en los Anopheles mexicanos II. Anopheles albimanus y sus variedades en la Rep. Mexicana. An. Ins. Biol. Mex. 1938; 9:167180.

JUDD DD. Rewiew of the systematic and phylogenetic relationships of the Sabethini (Diptera: Culicidae). Systm Ent 1996; 21: 129-150.

KITCHING IJ, Forey PL, HuMPHRIES CJ, Williams BM. Cladistics: The Theory and Pratice of Parsimony Analysis. $2^{\mathrm{a}}$ ed. New York: Oxford University Press; 1998. 
KNIGTH KL, StONE A. A catalog of the mosquitoes of the world (Diptera: Culicidae) $2^{a}$ ed. Maryland: Entomological Society of America; 1977. v. 6.

KOMP WHW. The species of Nyssorhynchus confused under tarsimaculatus Goeldi, and a new name, A. emilianus, for one species found in Pará, Brazil (Diptera, Culicidae). Ann ent Soc Am 1941; 34:791-807, illus.

KOMP WHW. Anopheles (Nyssorhynchus) anomalophyllus, a new species of Nyssorhynchus from Panamá and Costa Rica (Diptera: Culicidae). Proc ent Soc Wash 1936; 38:160-164, illus.

KOMP WHW. Anopheles clarki, a new species of Nyssorhynchus of wide distribution in South America. (Diptera: Culicidae). Proc ent Soc Wash 1942(1943); 44:196201, illus.

KREUTZER RD, KITZMILLER JB, RABBANI MG. Cytogenetically distinguishable populations of the mosquito Anopheles albitarsis. Acta Amazon 1976; 6: 473-481.

KRZYWINSKI J, WILKERSON RC, BESANSKY NJ. Toward understanding Anophelinae (Diptera: Culicidae) phylogeny: insights from Nuclear single-copy Genes and the weigth of evidence. Syst Biol 2001a; 5 (4): 540-556.

KRZYWINSKI J, WILKERSON RC, BESANSKY NJ. Evolution of mitochondrial and ribosomal gene sequences in Anophelinae (Diptera: Culicidae): Implications for phylogeny reconstrution. Mol Phylogenet Evol 2001b; 18 (3): 479-478.

LINTHICUM KJ. A revision of the Argyritarsis Section of the subgenus Nyssorhynchus of Anopheles (Diptera: Culicidae). Mosq Syst 1988; 20:98-271.

LOUNIBOS LP, DUZAK D, LINLEY JR. Comparative egg morphology os six species of the Albimanus Section of Anopheles (Nyssorhynchus) (Diptera: Culicidae). J Med Entomol 1997; 34 (2): 136-155.

LOUNIBOS LP, WIIKERSON RC, CONN JE, HRIBAR LJ, FRITZ GN, DANOFF-BURG JA. Morphological, molecular, and chromosomal discrimination of cryptic Anopheles (Nyssorhynchus) (Diptera: Culicidae) from South America. J Med Entomol 1998; 35 (5): 830-838.

LYNCH ARRIBÁlZaGA, F. Descripción de tres nuevos Culicidae de Buenos Aires. Nat argent $1878 ; 1: 149-152$.

LINLEY JR. The eggs of Anopheles atropos and Anopheles darlingi (Diptera: Culicidae). Mosq Syst1992 24 (1): 40-50. 
LINLEY JR, LOUNIBOS LP. The eggs of Anopheles (Nyssorhynchus) rangeli and Anopheles (Nyssorhynchus) dunhami (Diptera:Culicidae). Mosq Syst 1993. 25: 157 169.

LOUNIBOS LP, DUZAK D, LYNLEY JR. Comparative egg morphology of six species of the albimanus section of Anopheles (Nyssorhynchus) (Diptera:Culicidae). J Med Entomol 1997. 34(2):136-155.

LOUNIBOS LP., WILKERSON RC, CONN JE, HRIBAR LJ, FRITZ GN, DANOFF-BURG JA. Morphological, molecular, and chromosomal discrimination of cryptic Anopheles (Nyssorhynchus) (Diptera:Culicidae) from South America. J Med Entomol 1998; 35(5):830-838.

MADDISON R, MADDISON WP. MacClade 4: Interactive Analysis of Phylogeny and Character Evolution. Sunderland: Sinauer; 2000.

MADDISON WP, DONOGHUE MJ, MADDISON DR. Outgroup analysis and parsimony. Syst Zool 1984; 33:83-103.

MALAFRONTE RS, MARRELLI, MT e MARINOTTI O. Analysis of ITS2 DNA sequences from Brazilian Anopheles darlingi (Diptera: Culicidae). J Med Entomol 1999. 36 (5): 631-634).

Maldonado V, Finol HJ, NavarRo JC. Anopheles aquasalis eggs from two Venezuela localities comparative by scanning electron microscopy. Mem Inst Osw Cruz 1997:93:4: 487-91

MANGUIN S, WILKERSON RC, CONN J, RuBIO-PALIS Y, DANOFF-BURG JA, ROBERTS DR. Population structure of the primary malaria vector in South America, Anopheles darlingi, using isozyme, random amplified polymorphic DNA, internal transcribed spacer 2, and morphologic markers. Am J Trop Med Hyg 1999; 60 (3): 364-376.

MARUCCI D, Estudo exocorial de Anopheles (Nyssorhynchus) albitarsis S.l. com a utilização de microscópio eletrõnico de varredura e sistema de análise de imagens. São Paulo; 1996. [Dissertação de Mestrado- Faculdade de Saúde Pública da USP].

NARANG SK, KLEIN TA, PERERA OP, LIMA JB, TANG AT. Genetic evidence for the existence of cryptic species in the Anopheles albitarsis complex in Brasil: alloymes and mitochondrial DNA restriction fragment length polymorphisms. Biochem Genet 1993; 32: 97-112. 
NASCIMENTO TFS, LOURENÇO DE OLIVEIRA R. Anopheles halophyllus, a new species of the subgenus Nyssorhynchus (Diptera: Culicidae) from Brazil. Mem. Inst. Osw. Cruz.2002; 97: 801-811

NAVARRO JC, LIRIA J. Phylogenetic relationships among eighteen neotropical Culicini species. J Am Mosq Control Assoc 2000; 16 (2): 418-422.

NeIva A, PINTo, C. Contribuição para o conhecimento dos anophelinas do estado de Mato Grosso, com a descrição de uma nova espécie. Brazil-med 1922a; 36:321-322.

NeIVA A, PINTO C. Considerações sobre o gênero Cellia Theobald, com a descrição de uma nova espécie. Brazil-med 1922b; 36:355-357, illus.

NeIva A, PINTO C. Sobre uma nova anophelina brazileira (Cellia cuyabensis nov. sp.). Brazil-med 1923, 37:235-236, illus.

NIXON KC. WinClada ver. 1.00.08 Publicado pelo autor, Ithaca, NY. 2002

NIXON K, CARPENTER JM. On outgroups. Cladistics 1993; 9: 413-426.

NOONAN GR. Biogeography of north american and Mexican insects, and critique of vicariance biogeography. Syst Zool 1998; 37:366-384.

PAPE, T. Cladystics analysis of mosquito chromosome data in Anopheles subgenera Cellia (Diptera, Culicidae). Mosq Syst 1992; 24: 1-11.

PATERSON GC, SHANNON RC. Mosquitos de Embarcación (Salta) con notas sobre la zona biológica del Chaco (Chaco Life Zone). Bol Inst Clinica Quirug. 1927; $\mathrm{n}^{\mathrm{os}}$. 2125,10 pp., illus.

PEYTON EL, WILKERSON RC, HARBACH RE. Comparative analysis of subgenera Kerteszia and Nyssorhynchus of Anopheles (Diptera: Culicidae). Mosq Syst 1992; 24 (1): 51-69, illus.

PEYTON EL. Anopheles (Nyssorhynchus) dunhami, ressurected from synomy with Anopheles nuneztovari as a senior synonymy of Anopheles trinkae (Diptera: Culicidae). Mosq. Syst. 1993; 25 (3): 151-156.

Póvoa, MM, Silva ANM, SANTos, CCB, Segura MNO, Machado RLD. Malarian Transmission. Ci Cult J Braz Ass Adv Sci 2000; 52 (4/5): 208-212.

Peryassú AG. Duas novas espécies de mosquitos do Brasil. Folha med 1922; 3:179.

PETROCCHI J. Description de un nuevo Anopheles. Revta Inst bact 1925; 4: 69-75.

PHIIIPPI, RA. Aufzahlung der chilenischen dipteren. Verh zool -bot Ges Wienna $1865,15: 595-782,7$ pls. 
RAMOS AS. Sobre uma variedade nova de Anopheles (Nyssorhynchus) oswaldoi Peryassú, 1922 (Diptera, Culicidae). Arq Hig 1942; 7(15): 61-67, illus.

RAMOS TC. Tree Gardener 2.2 para windows. São Paulo,1997

REINERT JF. Revised list of abbreviations for genera and subgenera os Culicidae (Diptera) and notes on generic and subgeneric changes. J Am Mosq Control Assoc 200117 (1): 51-55.

Robineau-Desvoidy JB. Essai sur la tribu des culicides. Mem Soc Hist nat Paris. 1827, 3:390-413, pl. 10.

Rodriguez MH, Chavez B, Orozco A, Loyola EG, Martinez-Palomo A. Scanning electron microscopic observations of Anopheles albimanus (Diptera: Culicidae). J Med Entomol 1992. 29(3):401-406.

Root FM. Studies on Brazilian mosquitoes. I. The anophelines of the Nyssorhynchus group. Am. J. Hyg. 1926; 6:684-717, 9 pls.

RoSA-Freitas M.G. Anopheles (Nyssorhynchus) deaneorum: a new species in the albitarsis complex (Diptera: Culicidae). Mem Inst Osw Cruz 1989, 84:535-543.

Rosa-Freitas MG, DEANE LM, MOMEN H. A morphological, isoenzymatic and behavioural study of ten populations of Anopheles (Nyssorhynchus) albitarsis LynchArribalzaga, 1878 (Diptera: Culicidae). Mem Inst Osw Cruz 1990; 85: 275-289.

Rosa-Freitas MG, Broomfield G, Priesten A, Milligan PJM, MOMEN H, MOLYNEUX DH. Cuticular, hydrocarbons, isoenzymes and behavior of three populations of Anopheles darlingi from Brazil. J Amer Mosq Control Assoc 1992; 8: 357-356.

Rosa-Freitas MG, Oliveira RL, Carvalho-Pinto CJ, Flores-MendonÇa C, SILVA-DO-NASCIMENTO, TF. Anopheline Species Complexes in Brazil. Current Knowledge of Those Related to Malaria Transmission. Mem Inst Osw Cruz.1998; 93 (5): 651-655.

Rosa-FretTAS-SibAJEV MG, CONN J, MrTCHEL SE, CocKBuRN JAS, MONEN H. Mitochondrial DNA and morphological analyses of Anopheles darlingi populations from Brazil (Diptera: Culicidae). Mosq Syst 1995; 27 (2): 78-99.

ROzEBOOM LE, GABALDÓN A. 1941. A summary of the "tarsimaculatus" complex of Anopheles (Diptera: Culicidae). Am J Hyg 1941, 33(C):88-100, 4 pls.

SALLUM MAM, SCHULTZ TR, WILKERSON RC. Phylogeny of Anophelinae based on the morphological characters. Ann Entomol Soc Am 2000; 93 (3): 745-775.

SALLUM MAM, SCHULTZ TR, FOSTER PG, ARONSTEIN K, WIRTS RA, WILKERSON RC. Phylogeny of Anophelinae (Diptera: Culicidae) based on nuclear ribosomal and mitochondrial DNA sequences. Systm Ent 2002a; 27 361-382. 
RAMOS AS. Sobre uma variedade nova de Anopheles (Nyssorhynchus) oswaldoi Peryassú, 1922 (Diptera, Culicidae). Arq Hig 1942; 7(15): 61-67, illus.

RAMOS TC. Tree Gardener 2.2 para windows. São Paulo,1997

REINERT JF. Revised list of abbreviations for genera and subgenera os Culicidae (Diptera) and notes on generic and subgeneric changes. J Am Mosq Control Assoc 200117 (1): 51-55.

Robineau-Desvoidy JB. Essai sur la tribu des culicides. Mem Soc Hist nat Paris $1827,3: 390-413$, pl. 10.

Rodriguez MH, Chavez B, Orozco A, Loyola EG, Martinez-PAlomo A. Scanning electron microscopic observations of Anopheles albimanus (Diptera: Culicidae). J Med Entomol 1992. 29(3):401-406.

RooT FM. Studies on Brazilian mosquitoes. I. The anophelines of the Nyssorhynchus group. Am. J. Hyg. 1926; 6:684-717, 9 pls.

RoSA-FretTAS M.G. Anopheles (Nyssorhynchus) deaneorum: a new species in the albitarsis complex (Diptera: Culicidae). Mem Inst Osw Cruz 1989, 84:535-543.

Rosa-Freitas MG, DEANE LM, MOMEN H. A morphological, isoenzymatic and behavioural study of ten populations of Anopheles (Nyssorhynchus) albitarsis LynchArribalzaga, 1878 (Diptera: Culicidae). Mem Inst Osw Cruz 1990; 85: 275-289.

Rosa-Freitas MG, Broomfield G, PRIESTEN A, Milligan PJM, MOMEN H, MOLYNEUX DH. Cuticular, hydrocarbons, isoenzymes and behavior of three populations of Anopheles darlingi from Brazil. J Amer Mosq Control Assoc 1992; 8: 357-356.

Rosa-Freitas MG, Oliveira RL, Carvalho-Pinto CJ, Flores-MendonÇa C, SILVA-DO-NASCIMENTO, TF. Anopheline Species Complexes in Brazil. Current Knowledge of Those Related to Malaria Transmission. Mem Inst Osw Cruz.1998; 93 (5): 651-655.

Rosa-FreItAS-SibAJEV MG, CONN J, MrTCHEL SE, CocKBuRN JAS, MONEN H. Mitochondrial DNA and morphological analyses of Anopheles darlingi populations from Brazil (Diptera: Culicidae). Mosq Syst 1995; 27 (2): 78-99.

ROZEBOOM LE, GABALDÓN A. 1941. A summary of the "tarsimaculatus" complex of Anopheles (Diptera: Culicidae). Am J Hyg 1941, 33(C):88-100, 4 pls.

SALLUM MAM, SCHULTZ TR, WILKERSON RC. Phylogeny of Anophelinae based on the morphological characters. Ann Entomol Soc Am 2000; 93 (3): 745-775.

SALLUM MAM, SCHULTZ TR, FOSTER PG, ARONSTEIN K, WIRTS RA, WILKERSON RC. Phylogeny of Anophelinae (Diptera: Culicidae) based on nuclear ribosomal and mitochondrial DNA sequences. Systm Ent 2002a; 27 361-382. 
SALlUM MA, BERgo ES, ForATtINI OP, Flores D. The eggs of Anopheles galvaoi and Anopheles evansae, two species of the subgenus Nyssorhynchus. J Am Mosq Control Assoc 2002, 18(1):10-15. 2002b

SÉNEVET G, ABONNENC E. Quelques anophelines de la Guyane Française. Arch Inst Pasteur Alger 1938, 16:486-512.

SHANNON RC, DEL PONTE E. 1927(1928). Los culicidos de la Argentina. Revta. Inst. bact. 1927(1928), 5:29-140, illus.

SILVA DO NASCIMENTO TFS, LOURENÇO DE OLIVEIRA R. Anopheles halophyllus, a new species of the subgenus Nyssorhynchus (Diptera: Culicidae) from Brazil. Mem Inst Osw Cruz 2002; 97: 801-811

SWOFFORD DL PAUP*. Phylogentic analysis using parsimony (*and other methods), version 4.0b10. Sunderland, Sinauer; 2002.

THEOBALd FV. A monograph of the Culicides os moaquitoes. V 1. 1901. 424 pp, illus.

THEOBALD FV. A monograph of the Culicides os moaquitoes. V 4. 1907. 639 pp.

UNTI 0. Anofelinos do vale do Paraiba. Nova variedade e ciclo evolutivo do Anofeles [sic] (Nyssorhynchus) osvaldoi var. ayrozai n. var. Ann paulist Med Cir 1940a; 40(11):377-392, illus.

UNTI 0. Anofelinos do vale do Paraiba. Nota III. Biologia do Anofeles [sic] (Nyssorhynchus) strodei Root, 1926 com a descrição d'uma variedade nova. Anofeles [sic] (Nyssorhynchus) strodei ramosi var. n. Ann paulist Med Cir 1940b; 40(12):489-505.

UNTI 0. Anofelinos do vale do Rio Paraiba, Anopheles (Nyssorhynchus) strodei Root 1926, com a descrição de três variedades novas. São Paulo. Serv Profil Mal Trab $1941 ; 33: 3-18$, illus.

WHITE GB. The identification of mosquitoes as vectors of malaria and filariasis. Symp Soc Parasitol 1979; 17: 103-143.

WIEDEMANN CRW., Diptera. Exotica. Kiliae 1821; 1:10

WILEY EO, SIEGel-Causey D, BRooks DR, FunK VA The Compleat Cladist A Primer of Phylogenetic Procedures. University of Kansas Museum of Natural History Special Publication No. 19. 1991. x+158 pp.

ZavORTINK TJ. Mosquito studies (Diptera: Culicidae) XXIX. A rewiew of the subgenus Kerteszia of Anopheles. Contr Am Ent Inst 1973; 9 (3): 1-54.

WILKERSON RC, GAFFGAN TV, LIMA JB. Identification of species related to Anopheles (Nyssorhynchus) albitarsis by random amplified polymorphic DNA- 
polymerase chain reaction (Diptera: Culicidae). Mem Inst Osw Cruz. 1995a; 90 : $721-732$.

WILKERSON RC, PARSONS TJ, KLEIN TA, GaFFigAN TV, BERgo E. CONSOLIM J. Diagnosis by random ampligied polymosphic DNA polymerase chain reaction of four cryptic species related to Anopheles (Nyssorhynchus) albitarsis (Diptera: Culicidae) from Paraguay, Argentina and Brazil. J Med Entomol 1995b; 32: 697704 .

WOOD DM, BORKENT A. Phylogeny and classification of the Nematocera. In: McAlpine, J.F. \& Wood DM editores. Manual of Nearctic Diptera. Ottawa: Research Branch Agricuture Canada Monograph. v.3. 1989. p. 1333-1370. 


\begin{abstract}
Anexo
Lista detalhada do material examinado

An. albitarsis s.s.

- Argentina, Cols. Wilkerson e Klein, adultos, 2 machos e 12 fêmeas. NMNH.
\end{abstract}

An. albimanus

- Jamaica- Col. Willian Page, 4 terminálias masculinas, 10 pupas e 10 larvas. NMNH.

- Haiti, Corail, 24-10-1953, 3 macho e 1 fêmea adultos; Les Cayes, 29-III-1954, 4 fềmeas adultas, Cap. Haitien, 9-VII-1954, 1 macho e 1 fêmea adulta. NMNH.

An. anomalophyllus

- Costa Rica- Amubre, 1946; Suerre, Mosq. Mid. Amer. e outra localidade 3 larvas; Chase, Col. W.H.W. Komp, I-1930, metátipo, 1 terminália masculina; Alajuela $10^{\circ} 58^{\prime} \mathrm{N} 84^{\circ} 28^{\prime} \mathrm{W}$, Col. Manguin e Andre, 6 terminálias masculinas e 2 pupas; Alajuela $10^{\circ} 58^{\prime} \mathrm{N} 84^{\circ} 27^{\prime} \mathrm{W}$, Col. Manguin e Andre, 2 pupas; Alajuela $10^{\circ} 58^{\prime} \mathrm{N} 84^{\circ} 33^{\prime} \mathrm{W}$, Col. Manguin e Andre, 4 pupas; Alajuela $10^{\circ} 49^{\prime} \mathrm{N} 84^{\circ} 33^{\prime} \mathrm{W}$, Col. Manguin e Andre, 1 larva; Alajuela, Los Chiles, $10^{\circ} 49,065 \mathrm{~N} 84^{\circ} 32.517 \mathrm{~W}, 3$ machos e 3 fềmeas adultos; Alajuela, San Carlos, $84^{\circ} 27.112 \mathrm{~W} 10^{\circ} 57.709 \mathrm{~N}, 1$ fêmea; Alajuela, $84^{0} 27.257 \mathrm{~W} 10^{\circ} 57.748 \mathrm{~N}, 1$ macho el fêmea adultos. NMNH.

- Nicarágua, Zelaya, El Rane, Cols. Roberts e Rivera. 1 terminália masculina, 2 pupas. NMNH.

- Panamá, Almirante, Wenham's Farm, 1-I-1929, 1 larva; Almirante, Col. W.H.W. Komp, Il-1929, parátipos- 2 terminálias masculinas; Almirante, Col. W.H.W. Komp, 1 larva; Almirante, 12- I-1929, 1 larva. NMNH.

An. antunesi

- Argentina: Misiones, Deseado, Col. Duret, 9-X-1948, 1 larva; Misiones, Alba Poe, Col. Duret, 16-X-1948, 3 larvas. NMNH.

- Brasil: Rio de Janeiro, Alto Itatiaia, Col. L. Gomes, 15-III-1941. 1 terminália masculina, 1macho adulto; Alto Itatiaia, Col. Shannon, 1 fêmea adultos; Rio de Janeiro, 1 pupa; São Paulo, Campos do Jordão, 1600 m, 1945, 1 larva;. 2 larvas; 
Rio de Janeiro, Itatiaia, Macieira, L. Gomes e I. Luz, 20-III-1941, 1 Fêmea. NMNH.

- Suriname: 10 pupas e 2 larvas. NMNH.

An. aquasalis

- British Guiana, 1941, 1 terminália masculina. NMNH.

- France West Indies: Maria Galante, 3 pupas; Martinique, 3 pupas; Martinique, Col. J. Clastier, 1 larva; 1 pupa; 2 larvas. NMNH.

- France West Indies, 13 terminálias masculinas. NMNH.

- Guiana, 3 terminálias masculinas. NMNH.

- Guiana Francesa, Col. J. Clastier, 3 terminálias masculinas. Col. J. Clastier, 5 larvas; Col. J. Clastier, 1 pupa. NMNH.

- Martinica, Riviera Sale, Col. Duret, 23-I-1957. NMNH.

- Martinique, Lanietin, Col. Duret, 21-I-1957. 1 fềmea adulta NMNH.

- Montserrat, 2 fềmeas adultas. NMNH.

- Panamá, Cols. Gorgas M. Lab., 2 machos e 28 fêmeas adultos. NMNH.

An. argyritarsis

- Belize, 1991, 10 pupas, 3 larvas; 1990, 2 machos e 1 fêmea adulta. NMNH.

- Bolivia, 3 machos e 9 fêmeas adultos. NMNH.

- Costa Rica, 8 terminálias masculinas; Cols. Hogue e Powder, 07-XI a 11-XII1962, 5 terminálias masculinas, 4 larvas. NMNH.

An. benarrochi

- Brasil, São Paulo, Bocaina, SP 255 Km 125, Fazenda Santa Leonor. Col. E. Bergo, 3-VIII-1995, 1 terminália masculina, FSP; Rondônia, Costa Marques, 4-II1993 e 5-II-1993, criação no laboratório, 10 machos e 9 fềmeas adultos; Rondônia, Costa Marques, Km 10, 13-I-1993, 3 fềmeas. NMNH.

- Colômbia, Villavicencio, Col. Rozeboom, 1947, 10 terminálias masculinas, 12 pupas; Villavicencio, Col. Rozeboom, 9 larvas. $\mathrm{NMNH}$.

- Peru, Iguitos, Col. R. C. Shannon, IV-1931 1 terminália masculina; Iguitos, Versalles, Col. A. Cornejo D., 1 larva. NMNH. 


\section{An. braziliensis}

- Bolivia, 24 fêmeas adutas. NMNH.

- Brasil, Bahia, 10 adultos. NMNH.

An. darlingi

- Argentina, Salta, Col. Eidivisadero, 13-IV-1960, 4 fêmeas adultas. NMNH.

- Belize, Distrito de Cayo, cerca de 10-15 Km NE de St. Thomas no Rio Sibun $17^{0}$ $09^{\prime} \mathrm{N} 88^{0} 37^{\prime} \mathrm{W}$. Col. R.E. Harbach, 25-V-1993, 7 pupas, 2 larvas; 23 milhas de Stan Creek, Col. B. Honduras, 2 fêmeas adultas; $1,5 \mathrm{Km}$ W da Hummingbird Highway em Roaring Creek $17^{0} 15^{\prime} \mathrm{N} 88^{\circ} 48^{\prime}$ W. Col. R.E. Harbach, 23-V-1993, 3 pupas, 8 larvas. NMNH.

- Bolivia, Cols. Peyton e Roberts, 17 fêmeas adultas. NMNH.

- Colômbia, 10 terminálias masculinas. NMNH.

An. deaneorum

- Argentina, Província de Corrientes, aproximadademente $90 \mathrm{Km}$. W Posadas, Col. R. Wilkerson, 31-I-1992,4 pupas, 4 larvas; Província de Corrientes, Corrientes, Laguna Brava $27^{0} 28^{\prime} \mathrm{S} 58^{\circ} 50^{\prime} \mathrm{W}$, Col. R. Wilkersn, 31-I-1992, 2 pupas, 2 larvas. NMNH.

- Brasil, 4 larvas; Rondonia, Costa Marques, 19-IV-1990, 26-IV-1990,20-IV-1990, 22-IV-1990, criação em laboratório, 2 machos e 2 fêmeas adultos; Acre, Rio Branco, Col. R. Lourenço de Oliveira, 07 e 09-X-1985, 4 fêmeas adultas; Rondônia, Guajará-Mirim, Col. P.S. Souza, 1986, 2 fêmeas e 1 macho. NMNH. An. evansae

- Argentina: Misiones, Iguazú, Col. Duret, 28-XI-1951, 1 larva; Argentina, Misiones, Iguazú, Col. Duret, 03-XII-1951, 1 larva; Misiones, Iguazú, Col. Duret, 10-XI-1951, 1 larva. NMNH.

- Bolívia, 11 pupas. NMNH.

- Brasil: São Paulo, Bocaina, SP 255 Km 125, Fazenda Santa Leonor. Col. E. Bergo, 3-VIII-1995, 1 terminália masculina, 1 pupa. FSP; Mato Grosso, Maracajú, MES. Bras., Serviço de Febre, 1937. 1 terminália masculina; 2 terminálias masculinas; Espírito Santo, Água Branca, Vila São José, Col. USAMRU-B, 20-I-1992, 6 machos e 7 fêmeas adultos. NMNH. 
- Venezuela, Maracay, Col. J.E.E., V-19(??), 4 larvas; 1950, 1 larva. NMNH. An. galvaoi

- Brasil, Acre, Rio Branco, 1 terminália masculina, 1 fêmea; Rondônia, Porto Velho, Col. Duret, 2-VIII-1964, 1 fêmea adulta; Pará, Belem, 29-V-1964, 3-II1964, 10-VIII-1964, 3 fêmeas adultas; São Paulo, Novo Oriente, 1938, 1 terminália masculina; São Paulo, 1944, 1 terminália masculina. NMNH. São Paulo, Bocaina, SP 255 Km 125, Fazenda Santa Leonor. Col. E. Bergo, 3-VIII1995, 9 larvas, 10 pupas, 2 terminálias masculinas.

- Paraguai, Coaguazú, Carayao, Col. Duret, 23-X-1955, 2 machos adultos, 2 terminálias masculinas. $\mathrm{NMNH}$.

An ininii

- Brasil, Pará, região de Marabá; Col. J.F. Reinert e cols.; Altamira, Col. J.F. Reinert e cols. 10 terminálias masculinas. NMNH.

- Brasil, Pará, 150 km de Altamira, Col. J.F. Reinert e cols. 5-XI-1974, 5 pupas; Pará, 158 km de Altamira, Col. J.F. Reinert e cols., 9-XI-1974, 1 pupa; Pará, 163 km de Altamira, Col. J.F. Reinert e cols., 6-XI-1974, 1 pupa, 3 larvas; Pará, região de Marabá, Col. J.F. Reinert e cols., 26-X-1974, 1 pupa; Pará, região de Marabá, Gleba 29 lote 03, Col. J.F. Reinert e cols., 20-X-1974, 1 pupa; Pará, região de Marabá, Gleba 29 lote 03, Col. J.F. Reinert e cols., 25-X-1974, 3 larvas; Pará, região de Marabá, Gleba 38 lote 02, Col. J.F. Reinert e cols., 29-X1974, 1 pupa. Pará, região de Marabá e Altamira, Col. J. F. Reinert e cols. 1974, 22 machos e 15 fêmeas adultos. NMNH.

An konderi

- Brasil, Costa Marques, 10 larvas, 10 pupas; Costa Marques Km 7, 3-X-1992 e 4X1992, criação em laboratório, 9 machos e 11 fêmeas adultos. NMNH. An. lanei

- Brasil, São Paulo, Campos do Jordão, Col. Amaral, 1 parátipo fêmea; Campos do Jordão, I-1940, 1 macho e 1 fèmea adultos. NMNH. An. lutzii

- Argentina, Missiones, Deseado, Col. Duret, 20-III-1951, 2 larvas. NMNH. 
- Bolivia, Chimore, Cochabamba, Chapare, Col. Torres, 30-IV-1944, 1 fêmea. NMNH.

- Brasil, São Paulo, Campos do Jordão, 1 terminália masculina; Mato Grosso, Maracajú, 7 fêmeas adultas; Maracajú, VI-1937, VII-1937, XII-1937 3 fềmeas adultas; Minas Gerais, Rio Doce, 1946, 2 fêmeas adultas. NMNH.

An. marajoara

- Brasil, Pará, Ilha de Marajó, 10 pupas, 5 larvas; Pará, Rio Arari, Fazenda Maria, aproximadamente 01'25" S 04'85' W, V-1989, Equipe do USAMRU, 4 machos e 10 fêmeas adultos; 5 larvas NMNH.

- Panamá, 1 terminália masculina. NMNH.

An. nuneztovari

- Brasil, Amazonas, Manaus, Col. R.C. Shannon, VI-1931, 1 terminália masculina; Pará, Fordlândia, Col. R.C. Shannon, VI-1931, 1 terminália masculina; Pará, Belém, Col. Aitken, 06-XI-1968, 1 terminália masculina; Pará, Belém, Col. Aitken e Toda, 06-XI-1968, 1 terminália masculina; Pará, Belém, Col. Aitken e Toda, 16-IX-1968, 1 terminália masculina; Pará, Belém, Col. Aitken e Toda, 2930-IX-1968, 1 terminália masculina; Pará, Marabá, São João do Araguaia, $5^{\circ} 23^{\prime} \mathrm{S}$ $48^{\circ} 46^{\prime} \mathrm{W}$ Col. D. Roberts, 17-III-1976, 1 terminália masculina; Pará, região de Marabá, Gleba 38 lote 02, Col. J.F. Reinert e cols., 29-X-1974, 10 pupas, 5 larvas; Pará, região de Marabá, Gleba 34 lote 02, Col. J.F. Reinert e cols., 28-X1974, 5 larvas; Pará, Jatobal, 4 $4^{0} 32^{\prime} \mathrm{S} 44^{0} 32^{\prime} \mathrm{W}$ Col. D. Roberts, 1 terminália masculina; Amazonas, Manaus, Col. Shannon, IX-1931, 3 machos e 19 fềmas adultos; Pará, Fordlândia, Col. Shannon, IX-1931, 6 machos e 25 fềmas adultos NMNH.

An. oswaldoi

- Bolívia, 1 pupa, 1 pupa. NMNH.

- Brasil, Pará, Região de Marabá, Gleba 34 lote 02, Cols. J.F. Reinert e cols., 28X-1974. 3 pupas; São Paulo, São Vicente, 1 pupa, 1 larva; 1 larva; Mato Grosso, Peixoto de Azevedo, $10^{\circ} 23^{\prime} \mathrm{S} 54^{\circ} 54^{\prime} \mathrm{W}$, Col. Equipe do WRAIR, II-1995, 7 machos e 9 fèmeas adultas. NMNH.

- Colòmbia, San Martin, 7-VI-1947. NMNH. 
- Panamá, Juan Diaz, Col. Rozeboom, 21-III-1935, 2 larvas; Pierce, 25-IX-1935, 2 larvas; Panamá, 1-VII-1949, 5 pupas. NMNH.

An. parvus

- Bolívia, Coripita, XII-1946. J.H. SCH. Of Hyg. Med. Entomol, 2 terminálias masculinas; 4 terminálias masculinas. NMNH.

- Brasil, Ceará, São Benedito, 12-VI-1942, 1 pupa; Minas Gerais, Água Limpa, 27III-1925, 1 larva, 10 fêmeas adultas. NMNH.

- Colômbia, Villavicencio, Col. RF. LAB, VII-1948, lot. 722, 2 terminálias masculinas, 4 pupas, 8 larvas. NMNH.

An. rangeli

- Bolivia, 10 pupas; 4 larvas. NMNH.

- Brasil, Acre, Sen. Guiomard, 16-DX-1992, criação no laboratório E.G. Miltrey, 5 machos e 16 fêmeas adultos. NMNH.

- Peru, Tingo Maria, Col. E. Vale. 1 larva; Col. E. Vale. 1 larva. NMNH.

- Venezuela, 6 terminálias masculinas; 3 larvas; Carabobo, Puerto cabelo, 7 terminálias masculinas; Trujillo, Pampito (?), 1 terminália masculina. NMNH.

An. rondoni

- Argentina, Ledesma, Jujuy, Col. C. Davis, 1 terminália masculina; Ledesma, Jujuy, Col. R.C. Shannon, 30-III-1927, 1 terminália. masculina dissecada; Col. C. Davis, 3 larvas; localidade não especificada, 5 terminálias masculinas; localidade não especificada, Col. Davis, 1 pupa. NMNH.

- Bolívia (?), localidade não especificada, J.H. SCH. Of Hyg. Med. Entomol, 5 terminálias masculinas. NMNH.

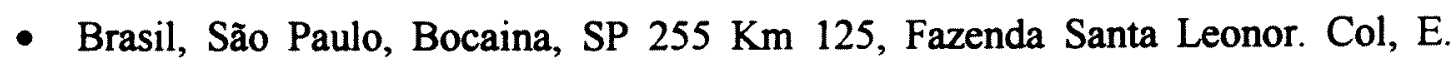
Bergo, 3-VIII-1995, 2 terminálias masculinas, 10 pupas, 10 larvas. FSP; Bahia, Col. Davis; Mato Grosso, Peixoto de Azevedo $10^{\circ} 23^{\prime} \mathrm{S} 54^{\circ} 54^{\prime} \mathrm{W}$, Col. E.G. Milstrey, 20-IV-1993, 10 pupas, 3 larvas; Wilkerson e Horosco, 1994, 10 machos e 10 fêmeas adultas. NMNH.

An. strodei

- Argentina, Missiones, Cerro Azul, Col. Duret, V-1949, 1 terminália masculina. Missiones, Iguazú, Col. Duret. 27-XI-1951, 1 terminália masculina; Missiones, 
Deseado, Col, Duret. 01-XII-1951, 1 terminália masculina; Tucuman, Medinas, Col. M.C. Davis. 1 terminália masculina. NMNH.

- Bolivia, 7 pupas. NMNH

- Brasil, São Paulo, Bocaina, SP 255 Km 125, Fazenda Santa Leonor. Col. E. Bergo, 3-VIII-1995, 3 terminálias masculinas, 3 pupa, 2 larvas. FSP; São Paulo, Itapira, 1 terminália masculina; Ceará, São Benedito, 2 exemplares; 1 terminália masculina; 1 terminália masculina; 4 larvas; 4 pupas. Rondônia, Costa Marques, 31-VIII-1989, criação no laboratório, 3 machos e 7 fêmeas. NMNH.

- Colômbia (?) $1946 \# 7.3,1$ terminália masculina. NMNH.

- Costa Rica, $10^{\circ} 54^{\prime} \mathrm{N} 86^{\circ} 28^{\prime} \mathrm{W}$, Cols. Manguin e Andrade, 1 terminália masculina. NMNH.

- Venezuela, Maracay, VI-1929, 2 terminálias masculinas. NMNH.

An. sawyeri

- Brasil, Ceará, São Benedito, 2 terminálias masculinas, 3 pupas, 6 larvas, 3 fềmeas adultas, 1 tipo e 1 parátipo. NMNH.

An. triannulatus

- Brasil, São Paulo, Bocaina, SP 255 Km 125, Fazenda Santa Leonor. Col. E. Bergo, 3-VIII-1995, 1 terminália masculina, 10 pupas, 10 larvas. FSP; Mato

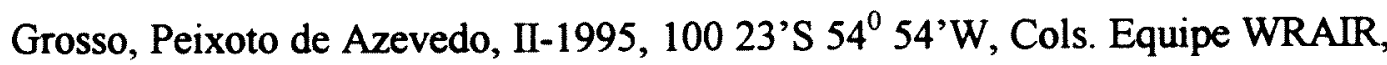
9 macho s e 8 fêmeas adultos; Paraíba, 20-VIII-1930, 1 terminália masculina. NMNH.

- Colômbia, Villavicencio, 9-V-1947, 2 terminálias masculinas; Villavicencio, Col. Rozeboom, 22-V-1947, 9 pupas, 2 larvas; Villavicencio, Col. Rozeboom, 16-V-1947, 1 pupa; Resistência, Chaco, Col. R.C. Shannon, 25-II-1927, 1 terminália masculina; Resistência, Chaco, Col. R.C. Shannon, 23-II-1927, 1 terminália masculina. NMNH.

- Costa Rica, Barranca, 4 larvas. NMNH.

- Panamá, Juan Mina, 8-VII-1949, 11.21 progênie. 14 larvas; Las Guacas, RP, Col. Rozeboom, 06-VIII-1937, 1 terminália masculina; Las Guacas, RP, Col. Rozeboom, 04-IV-1935, pupa; Panamá, Zona do Canal, Gatun Lake, Col. 
Rozeboom, 30-VII-1934, 1 terminália masculina; Panamá, Col. Rozeboom, 12XI-1935, 2 terminálias masculinas. NMNH.

An. trinkae

- Equador, Província de Pastaza, Puyo, 05-V-1977, Col. Y.M. Huang, 3 terminálias maculinas; Província de Pastaza, 39 Km N de Puyo, 06-V-1977, Col. Y.M. Huang, 1 terminálias masculina; Província de Pastaza, $20 \mathrm{Km}$ N de Puyo, 06-V1977, Col. Y.M. Huang, 1 terminálias masculina; Província de Pastaza, (?) Km NE de Puyo, 07-V-1977, Col. Y.M. Huang, 1 terminálias masculina; Província de Pastaza, 4 Km NE de Puyo, 07-V-1977, Col. Y.M. Huang, 1 pupa, 3 larvas; Província de Pastaza, 16 Km N de Puyo, 07-V-1977, Col. Y.M. Huang, 2 pupas, 2 larvas; Província de Pastaza, Puyo, 08-V-1977, Col. Y.M. Huang, 4 pupas, 2 larvas; Província de Pastaza, Puyo, 05-V-1977, Col. Y.M. Huang, 3 pupas, 3 larvas; 1 terminálias masculina. NMNH.

- Peru, 1985, 7 machos e 27 fềmeas adultas. NMNH.

Grupo-externo

An. cruzii

- Brasil, Cols. Wilkerson e Peyton, 1989, 10 pupas; Cols. Wilkerson e Peyton, 1989, 2 terminálias masculinas; Cols. Wilkerson e Peyton, 1989, 8 larvas. NMNH.

An. laneanus

- Brasil, São Paulo, Col. John Lane, XI-1936, 1 larva; São Paulo, Campos do Jordão, 1400m, Col. Duret, III-1945, 1 larva; Col. Wilkerson e Peyton, 1989, 5 machos e 18 fêmas adultos NMNH.

An. neivai

- Colômbia, 1 terminália masculina; 4 larvas; 6 pupas; Cols. Hogue e Powder, 2 terminálias masculinas. $\mathrm{NMNH}$.

- Costa Rica, Cols. Hogue e Powder, 07-XI a 11-XII-1962, 1 terminálias masculina, 4 pupas; 2 larvas, NMNH.

- Equador, Pichilingue, Santo Domingo, Hacienda Ila, 3-XI-68 e 12-XI-68, 10 fềmeas adultas; Esmeralda, San Lorenzo, Col. Duret, 8-X-68, 5 fêmeas; 
Pichincha, Pto. Libertat, Col. Duret, 11-X-1968, 1 fêmea adulta; Pastaza, Pto. Santa Ana, Col. Duret, 17-X-1968, 2 fêmeas.

- Nicarágua, Zelaya, Rama, Col. Duret, 1-XI-1992, 1 Fêmea adulta.NMNH. 


\section{Glossário}

Apomorfia- estado derivado de um caráter numa série de transformaçåo; caráter descendente.

Autapomorfia- caráter apomórfico restrito um único táxon terminal em um cladograma.

Caráter- diferenças entre estruturas homólogas de organismos diferentes, pode ser morfológico, molecular, fisiológico ou biológico.

Cladograma- dendograma que expressa relações filogenéticas entre táxons terminais baseadas em sinapomorfias.

Comprimento do cladograma- número de passos requerido no cladograma.

Consenso- cladograma que condensa a informação filogenética de cladogramas topologicamente discordantes para um mesmo grupo, gerados por interpretações distintas dos caracteres disponiveis.

Grupo interno- grupo sob investigação em uma análise filogenética.

Grupo-irmão- táxon genealogicamente mais relacionado com o grupo-interno.

Grupo-externo- qualquer táxon usado para comparação em uma análise filogenética, usado para determinar a polaridade do caráter.

Grupo monofilético- grupo taxonômico que inclui uma espécie ancestral e todas suas descendentes, sendo estabelecido por sinapomorfias (homologias).

Grupo polifilético- grupo onde o ancestral comum de todos os membros é colocado em outro táxon.

Grupo parafilético-grupo que exclui um ou mais componentes de um grupo monofilético.

Homologia- relação entre estruturas idênticas ou diferentes entre si em indivíduos ou espécies diferentes presentes em cada um deles devido à herança à partir de um ancestral comum, transmitida ininterruptamente ao longo das gerações ou espécies descendentes intermediárias.

Homoplasia- caráter similar que é compartilhado por dois táxons, mas não satizfaz as condiçð̃es de homologia.

Índice de consistência (CI)- cálculo numérico que expressa a relação entre o número mínimo de passos que um caráter ou um conjunto de caracteres pode exibir 
em um cladograma e o número efetivo de passos ocorridos (s), podendo variar de 0 a 1,0 .

Índide de consistência rescalonado ( $\mathrm{RC}$ )- cálculo numérico do produto do índice de consistência pelo índice de retenção, podendo variar de 0 a 1,0.

Índice de retenção- cálculo numérico que expressa a relação entre a diferença do número efetivo de passos e número de máximo de passos possíveis e a diferença entre o número de caracteres e o número de passos possíveis, podendo variar de $0 \mathrm{a}$ 1,0 .

Lista de Caracteres- texto que apresenta uma descrição de como são as estruturas estudadas nos táxons terminais.

Matriz de caracteres- base de dados sobre a qual os cladogramas são diretamente construídos.

Parcimônia- (1) critério metodológico de decisão usado em análise filogenética, quando existe incongruência entre os caracteres da matriz de dados, procurando escolher entre todos os cladogramas possíveis a reconstrução mais provável da filogenia do grupo; (2) critério científico para escolha entre diferentes hipóteses aquela que explica os dados com mais eficiência e maior simplicidade.

Passo- uma única aquisição ou perda de um caráter ou uma transformação de um caráter multiestado em um cladograma.

Plesiomorfia- estado antigo, pré-existente, de um caráter; caráter ancestral.

Polarização- determinação da direção suposta para a evolução de uma série de transformação entre duas ou mais condições homólogas e diferentes entre si de uma estrutura, determinando qual é plesiomórfica e qual é apomórfica.

Politomia- condição de um nível particular em um dendograma em que três ou mais ramos estão conectados.

Reversão- caso particular de apomorfia em que a condição apomórfica final é semelhante à plesiomórfica anterior numa série de transformação.

Série de transformação- transposição de dois ou mais estados de caracteressupostamente homólogos mas diferentes entre si encontrados em um mesmo horizonte temporal para uma seqüência temporal, em que a condição mais antiga é plesiomórfica e a mais nova é apomórifica. 
Simplesiomorfia e sinapomorfia- compartilhamento dos estados de caráter. 